\title{
1 Development of inhaled formulation of modified clofazimine as an 2 alternative to treatment of tuberculosis
}

3 Renata Ribeiro de Castro $^{\mathrm{a}, \mathrm{b}}$, Valério Todaro ${ }^{\mathrm{c}}$, Luiz Claudio Rodrigues

4 Pereira da Silva ${ }^{a}$, Alice Simon ${ }^{a}$, Flavia Almada do Carmo ${ }^{a}$, Valeria Pereira

5 de Sousa ${ }^{\mathrm{a}}$, Carlos Rangel Rodrigues ${ }^{\mathrm{a}}$, Bruno Sarmento ${ }^{\mathrm{d}}$, Anne Marie 6 Healy ${ }^{\mathrm{c}}$, Lucio Mendes Cabral ${ }^{\mathrm{a}, *}$.

7 a Department of Drugs and Pharmaceutics, Faculty of Pharmacy, Universidade Federal 8 do Rio de Janeiro, Rio de Janeiro, Brazil

9 bundação Oswaldo Cruz, Farmanguinhos, Instituto de Tecnologia em Fármacos, Av.

10 Comandante Guaranys, Rio de Janeiro, Brazil

11 c School of Pharmacy and Pharmaceutical Sciences, Trinity College Dublin, Dublin 2, 12 Ireland

13 di3S - Instituto de Investigação e Inovação em Saúde, Universidade do Porto, Porto, 14 Portugal

* Corresponding author at: Department of Drugs and Pharmaceutics, Faculty of 16 Pharmacy, Universidade Federal do Rio de Janeiro, UFRJ, 21941-902 Rio de Janeiro, 17 RJ, Brazil, +55 2139386605

18 E-mail address: 1mcabral@pharma.ufrj.br (L.M. Cabral) 
Inhalation drug delivery provides a possible useful alternative to oral drug delivery in the treatment of tuberculosis (TB). This work evaluated inclusion complexes of clofazimine (CFZ), an anti-TB drug with low aqueous solubility and potential gastric degradation, in $\beta$-cyclodextrin $(\beta C D), \gamma$-cyclodextrin, $(2-$ hydroxypropyl)- $\beta$-cyclodextrin and sulfobutyl-ether- $\beta$-cyclodextrin. A phase solubility study indicated that $\beta C D$ showed the best inclusion capacity for CFZ, so a CFZ:ßCD complex (1:7) was selected for further studies. Particle engineering was performed using spray drying to obtain powders with suitable characteristics for pulmonary delivery and L-leucine was added to enhance powder dispersibility. Thermal and spectroscopic analyses indicated the CFZ:ßCD integrity after spray drying, and the presence of L-leucine resulted in less hygroscopic and rougher particles, and a less agglomerated powder. All formulations, and especially those containing L-leucine, showed suitable in vitro deposition performance in the Next Generation Impactor and presented higher aqueous solubility compared to the free drug. In vitro studies showed low toxicity against Calu-3 and CFZ retention in the cell monolayer and apical compartment. These results suggest that the inhalation formulation composed of CFZ: $\beta C D$ plus L-leucine should improve CFZ pulmonary bioavailability and provide an alternative treatment for $\mathrm{TB}$, acting on the main infection site of the disease.

Keywords: pulmonary delivery; tuberculosis; clofazimine; cyclodextrin; Lleucine

\section{Introduction}

Tuberculosis (TB) is an infectious disease caused by a unique pathogen, Mycobacterium tuberculosis (M. tuberculosis). TB is the ninth leading cause of death worldwide, ranking above HIV/AIDS. In 2017, the World Health Organization (WHO) estimated that 10.0 million people fell ill with TB (90\% adults) and there were 1.3 million deaths [1-3]. Although controlled in certain developing countries and industrialized areas, the current and continuous migratory movement from Asia and Africa (where there is a high incidence) is a potential risk to the spread of TB to Europe and North America [4]. The disease mainly affects the lungs (within alveolar 
macrophages and granulomas structures) but can also affect other sites [2]. Erratic and discontinuous treatments, associated with $M$. tuberculosis adapting mechanisms (efflux pump mechanisms) and population heterogeneity, have triggered multi-drug-resistant (MDR) strains of this mycobacteria and also extremely drug-resistant (XDR) strains [5,6]. Drug-resistant TB is a continuing threat since the first recorded case more than 12 years ago, and the development of new drugs or therapeutic strategies is necessary [4]. Inhalation is a non-invasive administration route used to deliver a drug substance into the lungs and treat local (asthma, cystic fibrosis) or systemic (diabetes, schizophrenia) diseases [7-9]. In recent years pulmonary drug delivery has received attention for TB treatment because it provides high drug concentrations at the main site of the disease, prevents hepatic-first pass metabolism and gastric intolerance and overcomes poor and erratic oral bioavailability of some drugs that are used in clinical practice $[10,11]$. The United States Pharmacopeia categorizes the dosage forms for pulmonary drug delivery into: (i) inhalation spray, (ii) inhalation solution, (iii) inhalation suspension, (iv) inhalation aerosols or metered-dose inhaler (MDI) and (v) inhalation powder or dry powder inhaler (DPI) [8]. DPIs are commonly employed in therapy for several reasons, including the fact that the formulation is propellant-free, while they also often offer better chemical stability, with a portable device which is easy to use [12].

The efficacy of formulations delivered by means of a DPI depends on the device delivery performance, breathing pattern of the patient, powder deposition pattern in the respiratory tract, the fine particle fraction (FPF) and the disease that is being treated [13]. The deposition site is determined in accordance with the aerosol aerodynamic properties, namely mass median aerodynamic diameter (MMAD) and geometric standard deviation (GSD); these parameters are derived from the aerodynamic particle size distribution (APSD) [7]. MMAD is the aerodynamic diameter $\left(\mathrm{d}_{\mathrm{a}}\right)$ for which $50 \%$ of the aerosol mass is above and below that diameter. GSD shows the level of dispersity of the aerosol particles. To avoid particle deposition in the upper respiratory tract (oropharyngeal and tracheo-bronchial region) and exhalation before deposition, it is desirable to obtain an MMAD of between 1 and $5 \mu \mathrm{m}$ and a GSD $<2$. Powder physicochemical properties and morphological characteristics of the particles also determine the deposition profile and drug bioavailability [7]. Additionally, the literature describes the use of different L-leucine concentrations (10-30\% w/w) in DPI 
91 formulations, as a dispersion aid, to obtain aerosol particles with the desired in vitro 92 deposition profile [14-18].

93 Once deposition occurs in the respiratory tract, the interaction between the particles and the biological environment also determines the therapeutic efficacy of the formulation. The interaction with mucus (aqueous mixture of glycoproteins), which is secreted in the upper airways, and pulmonary surfactant (90\% phospholipids and $10 \%$ proteins), which is secreted in the alveolar region of the lungs, is determined by the physicochemical characteristics of the particles, whereby hydrophilicity favors dissolution in the mucus. The mucus is a biological barrier that blocks the entrance of foreign microorganisms and substances, including drugs. The mucociliary clearance removes insoluble particles deposited in the trachea-bronchial region, within $24 \mathrm{~h}$, resulting in a short retention time in the lung [9]. Drug solubility in the mucus minimizes the mucociliary clearance effect, favoring the desired drug effect [19]. Lipophilic drugs tends to be insoluble in mucus and thereby exhibit reduced cell permeability $[19,20]$. On the other hand, insoluble particles $(1-2 \mu \mathrm{m})$ that reach the alveolar spaces tend to be internalized by macrophages (alveolar clearance), that are surrounded by a thin surfactant layer, and are able to reside for a long time inside them.

108 Thus macrophage uptake represents a strategy to combat microorganisms that infect this cellular type, such as in TB $[11,21]$.

The World Health Organization (WHO) recommends the use of oral

111 clofazimine (CFZ) in combination with other drugs for drug-resistant TB treatment, 112 although its efficacy and long-term safety have not yet been established [2,22]. CFZ's

113 poor clinical efficacy is strongly attributed to low aqueous solubility and gastric

114 degradation, resulting in suboptimal delivery to the target organ. On the other hand, in

115 vitro studies demonstrated good inhibitory activity against MDR strains (minimal

116 inhibitory concentration $0.5-2 \mathrm{mg} / \mathrm{L}$ ) [22]. In vivo studies showed that administration

117 of CFZ together with first or second-line anti-TB drugs promoted a 100 times reduction 118 of bacteria colony count in the lung, suggesting its potential to shorten the duration of 119 TB treatment $[23,24]$. These characteristics point towards CFZ as a potential drug for 120 pulmonary delivery.

121 The use of cyclodextrins (CD) in formulations has allowed many products 122 containing poorly soluble drugs to reach the market, and eventually help to treat many 123 life-threatening disease conditions [25]. The efficacy of CFZ inclusion complexes based 124 on sulfated CD has already been described in the literature, and they showed activity 
against Mycobacterium avium and Mycobacterium intracellulare [26]. The literature has also described the successful inclusion of CFZ into negatively charged sulfobutyl ether $\beta$-cyclodextrin (SBE $\beta C D)$ / epichoridrine oligomer to increase its water solubility and bioavailability [27]. Although the improved solubility results of the sulfated CDs are promising, the cost of these carriers are higher than the traditional (non-sulfated) CDs. Furthermore, in the previously reported studies powder products were not adjusted in terms of aerodynamic properties in order to optimize pulmonary drug delivery, since it was not the objective of these studies.

For these reasons, the aim of the present study was to prepare and undertake the physicochemical characterization of novel CFZ-CD and L-leucine-CFZ-CD complexes, developed to enhance CFZ aqueous solubility with a view to improving dissolution in lung mucus. Particle engineering via spray drying was performed to develop a dry powder formulation for the local delivery of CFZ to the lung.

\section{Materials and Methods}

\subsection{Materials}

Clofazimine (CFZ), (2-hydroxypropyl)- $\beta$-cyclodextrin (2-HPßCD), L-leucine and L-isoleucine were purchased from Sigma Aldrich (St Louis, USA). $\beta$-cyclodextrin $(\beta C D)$ and $\gamma$-cyclodextrin $(\gamma C D)$ were purchased from Wacker Chemie AG (Munich, Germany). Sulfobutyl ether $\beta$-cyclodextrin (SBEßCD) (Captisol ${ }^{\circledR}$ ) was kindly supplied by CyDex Pharmaceuticals (Kansas, USA). The organic solvents (Analytical Degree, A.D.), ethanol, dimethylsulfoxide and acetonitrile, were purchased from TEDIA BRAZIL (Rio de Janeiro, Brazil). Purified water for preparing solutions and performing HPLC studies was obtained by water distillation treatment (Quimis, Diadema, Brazil).

\subsection{Methods}

\subsubsection{Inclusion complex preparation}

154 Complexation efficacy studies were performed by adding an excess amount of

$155 \mathrm{CFZ}$ to water or ethanol:water mixtures (from 7:3 to 0:1, ethanol:water) containing 156 increasing concentrations of a $\mathrm{CD}(\beta C D, \gamma C D$, 2-HP $\beta C D$ or SBE $\beta C D)$, ranging from 1 157 to $10 \mathrm{mM}$ (Table 1). Each system was stirred at $30^{\circ} \mathrm{C}$ for $72 \mathrm{~h}, 40^{\circ} \mathrm{C}$ for $72 \mathrm{~h}, 50^{\circ} \mathrm{C}$ for $15872 \mathrm{~h}$ or $30^{\circ} \mathrm{C}$ for $144 \mathrm{~h}$, and subsequently filtered through a $0.45 \mu \mathrm{m}$ pore size filter 
membrane (ChromPure syringe filter, PVDF, $25 \mathrm{~mm}$ diameter). CFZ concentration in

160 solution was determined by HPLC with UV detection at $495 \mathrm{~nm}$, using the methodology

161 described below. Calculation of complexation efficacy (CE) was according to the

162 following equation [28]:

$$
\mathrm{CE}=\text { Slope / (1 - slope })
$$

164 Where "slope" was the slope of the complexation profile (concentration of CFZ on the $\mathrm{y}$-axis versus concentration of CD on the $\mathrm{x}$-axis).

The molar proportion of CFZ:CD was determined using the following equation [28]:

$$
\mathrm{CFZ}: \mathrm{CD}=1 \mathrm{CFZ}:(\mathrm{CE}+1) / \mathrm{CE}
$$

170 Where CE was the complexation efficacy according to the complexation profile.

The CD inclusion process was then performed by mixing CFZ and the CDs ( $\beta C D, \gamma C D, 2 H P \beta C D$ or SBE $\beta C D$ ) by the solution method, in purified water and ethanol:water (7:3) mixture, under agitation using the previously established ideal conditions/proportions. After cooling the mixture, it was filtered through a $0.45 \mu \mathrm{m}$ pore size filter membrane (ChromPure syringe filter, PVDF, $25 \mathrm{~mm}$ diameter), then ethanol was removed in a rotary evaporator Gehaka RD - 180 (Gehaka, São Paulo, Brazil) at 45 ${ }^{\circ} \mathrm{C}$ for $6 \mathrm{~h}$ and the sample was frozen using liquid nitrogen. The frozen sample was immediately submitted to lyophilization (as described below). The powder obtained was stored under a nitrogen atmosphere in a closed glass vial in a desiccator with silica gel.

Physical mixtures were prepared by pulverization and mixing CFZ and the CD (1:7 molar ratio) in a glass mortar.

\subsubsection{Determination of CFZ content}

The CFZ content in inclusion complex and permeation studies was determined by HPLC (Shimadzu, pump LC- 30AD, autosampler SIL-30AC, detector SPD-M 20A). A Perkin Elmer C18 column ( $150 \times 4.6 \mathrm{~mm}$, particle size $3 \mu \mathrm{m})$ was used at $35{ }^{\circ} \mathrm{C}$. The mobile phase was a mixture of methanol and phosphate buffer $(80: 20, \mathrm{v} / \mathrm{v})$, and the flow rate was $1.0 \mathrm{ml} / \mathrm{min}$. The elution was carried out isocratically and the injection volume was $20 \mu 1$. The eluant was monitored at $284 \mathrm{~nm}$. Retention time was 4 minutes. 
Freeze drying was carried out using a laboratory scale freeze dryer Liotop L101

195 (Liobras, São Carlos, Brazil). Each sample was frozen using liquid nitrogen and then

196 freeze-dried for $72 \mathrm{~h}$ to allow the complete removal of water. The resulting powders

197 were characterized by differential scanning calorimetry (DSC), X-ray powder

198 diffraction (XRPD) and 13C-CP/MAS NMR spectroscopy. The freeze drying process

199 was used only during preliminary drying evaluation studies; spray drying was used

200 thereafter.

\subsubsection{Spray drying process}

203 Production of CFZ-CD inclusion complex or CFZ-CD inclusion complex/Lleucine or L-isoleucine complex spray dried powders was carried out using a laboratory scale spray dryer LabMaq MSD 1.0 (Labmaq do Brasil, Ribeirão Preto, Brazil) with a $0.7 \mathrm{~mm}$ nozzle tip. An ethanol-water solution (1:1) was prepared containing the CFZCD complex (1:7 molar ratio) and a total solute concentration of $0.70-0.85 \%(\mathrm{w} / \mathrm{v})$, depending on the L-leucine/isoleucine concentration. The amino acids, L-leucine or Lisoleucine, and the organic solvent dichloromethane were added after the preparation of the CFZ-CD inclusion complex in ethanol-water. Amino acid concentration ranged

211 from $10 \%$ to $15 \%(\mathrm{w} / \mathrm{w})$ in relation to the total solid amount, and the dichloromethane

212 concentration was $2 \%(\mathrm{v} / \mathrm{v})$. Spray drying parameters are presented in Table 3 . The

213 dichloromethane was used as a co-solvent (and potential "blowing/pore-forming agent")

214 due to its low boiling point $\left(39.8^{\circ} \mathrm{C}\right)$ and fast evaporation rate, allowing particle size

215 reduction and porosity increase [29-31]. Spray drying was used both to obtain the dry

216 complexes and to adjust the properties of these complexes in order to prepare

217 formulations that were suitable for pulmonary delivery. The resulting powders were

218 characterized by DSC, XRPD, Fourier-transform infra-red spectroscopy (FTIR),

219 dynamic vapour sorption (DVS), specific surface area analysis (SSA), particle sizing, 220 morphology, 13C-CP/MA NMR spectroscopy and aerodynamic assessment using a

221 Next Generation Impactor (NGI).

\subsubsection{Powder characterization}

A differential scanning calorimeter DSC-60 (Shimadzu, Kyoto, Japan) was used at a heating rate of $5{ }^{\circ} \mathrm{C} / \mathrm{min}$. Accurately weighed samples $(1-2 \mathrm{mg})$ were placed into sealed aluminum pans and heated from 30 to $300{ }^{\circ} \mathrm{C}$. 
XRPD patterns of raw materials, physical mixtures and inclusion complexes were obtained using a Lab X XRD-6100 X-ray (Shimadzu, Kyoto, Japan) with a Cu Ko line as the source of radiation. Measurements were carried out using a voltage of $40 \mathrm{kV}$, a current of $30 \mathrm{~mA}$ and a scanning rate of $2^{\circ} / \mathrm{min}$ over a range of $2^{\circ}-80^{\circ}$, on the two theta scale at a step size of $0.02^{\circ}$.

The infrared spectra of raw materials, physical mixtures and inclusion complexes were obtained from KBr pellets using a Prestige-21 spectrometer (Shimadzu, Kyoto, Japan). Spectra were recorded between 4000 and $600 \mathrm{~cm}^{-1}$ with a resolution of 4 $\mathrm{cm}^{-1}$

${ }^{13} \mathrm{C}$ solid-state NMR spectra were recorded on a Bruker Avance III 400 (9.4 T) spectrometer (Bruker, Massachusetts, USA), operating at 100.64 MHz. A CPMAS 3.2 $\mathrm{mm}$ probe head and $\mathrm{ZrO}_{2}$ rotors spinning at $9.3 \mathrm{KHz}$ were employed. Cross polarization magic angle spinning with ramp in the ${ }^{1} \mathrm{H}$ channel (CPMAS) combined with high power proton decoupling (HPDEC) were used as the pulse sequence. The contact time varied from $100 \mu \mathrm{s}$ to $10,000 \mu \mathrm{s}$. The recycle delay was $4 \mathrm{~s}$, and the $\pi / 2$ pulse length was $4 \mu \mathrm{s}$. The spectra were transformed after accumulation of 512 scans. The line broadening used to process the data was $20 \mathrm{~Hz}$. Adamantane ( $\mathrm{CH}$ at $29.46 \mathrm{ppm})$ was used as an external chemical shift reference.

Particle size distributions of prepared formulations for inhalation were determined using a Coulter Counter, Multisizer 4 (Beckman Coulter, California, USA). Each formulation was dispersed in an electrolyte solution (Isoton $\left.{ }^{\circledR}\right)$ and measurement was performed using an aperture tube size of $0.4-16 \mu \mathrm{m}$ and current of $600 \mu \mathrm{A}$.

Bulk density (b $\rho$ ) was calculated by determining the weight of powder required to occupy a $1 \mathrm{ml}$ volume in a graduated glass syringe, by pouring under gravity. The tapped density ( $\mathrm{t} \rho)$ was determined by vertically tapping this sample onto a level benchtop surface, from a height of $5 \mathrm{~cm}$, until there was no observed volume change (100 times) [29]. The tapped density was calculated as the ratio of the mass to the tapped volume of the sample. Each measurement was performed in triplicate. The theoretical aerodynamic diameter $\left(d_{a}\right)$ was calculated based on the following definition $d_{a}=$ $\sqrt{\mathrm{t} \rho} / \rho 1 . \mathrm{d}$; where $\rho 1=1 \mathrm{~g} / \mathrm{cm}^{3}$ and " $\mathrm{d}$ " is the geometric diameter of the particle [32].

The surface morphology of CFZ:CD complexes was observed using a scanning electron microscope (SEM), TM 3030 Plus (Hitachi, Tokyo, Japan). The SEM was operated under high vacuum, at $15 \mathrm{kV}$, small spot size, while images were acquired in 
260 the backscattered electrons mode (BSE) with an acceleration voltage of $15 \mathrm{kV}$ and a

261 secondary detector. The powder was deposited on double-sided adhesive tape, vacuum-

262 coated with gold and directly analyzed under SEM with magnifications of $x 500, x 1000$,

$263 \times 3000$ and $\times 5000$.

264 The water vapour sorption-desorption isotherms of CFZ inclusion complexes

265 were obtained by means of an automated gravimetric vapour sorption analyser, DVS

266 Advantage-1 (Surface Measurements Systems). Samples were equilibrated at 0\%

267 relative humidity $(\mathrm{RH})$ until a steady dry reference mass was recorded. The samples

268 were exposed to the following RH profile: $0-90 \%$ in 10\% steps and the reverse for

269 desorption at $25.0 \pm 0.1^{\circ} \mathrm{C}$. At each stage, the sample mass was allowed to reach

270 equilibrium (i.e. weight change over $10 \mathrm{~min}(\mathrm{dm} / \mathrm{dt}) \leq 0.002 \mathrm{mg} / \mathrm{min})$.

271 The specific surface area was determined by the Brunauer, Emmett, Teller

272 (BET) isotherm method using a Micromeritics Gemini VI (Micromeritics, Norcross,

273 USA) surface area analyser. The amount of nitrogen adsorbed at 6 relative pressure

274 points in the relative pressure $(\mathrm{P} / \mathrm{Po})$ range of 0.05 to 0.3 , with an equilibration time of

$27510 \mathrm{~s}$, was used for the BET analysis. Each average result was calculated on the basis of

276 three measurements.

277

278 2.2.6. In vitro aerosol deposition studies using the Next Generation Impactor (NGI)

279 The aerodynamic properties of the powders were assessed using an NGI (Copley

280 Scientific Limited, Nottingham, UK), apparatus 5, operated under pharmacopeial

281 conditions [8]. The flow rate was adjusted to achieve a pressure drop of $4 \mathrm{kPa}$ in the

282 powder inhaler, (Handihaler ${ }^{2}$, Boehringher Ingelheim, Ingelheim, Germany) and the

283 time of aspiration was adjusted to obtain $4 \mathrm{~L}$ air flow. The pre-separator was used to

284 remove coarse particles. The dry powder inhaler was loaded with a number 3 hard

285 gelatin capsule loaded with $20 \pm 2 \mathrm{mg}$ of powder for each test. NGI stages (stages 1-7

286 and filter) were coated with $1 \mathrm{~mL}$ of HPLC mobile phase to wet the collection surfaces.

287 The deposition profile of each formulation was determined in triplicate and the results

288 presented are the average results of the replicated analyses. After dissolution in an

289 appropriate volume of HPLC mobile phase, particle deposition in the device, the throat

290 and all the stages and the filter was determined by the HPLC method described above.

291 Each test was repeated three times. The emitted recovered dose (ED) was determined as

292 the percent of total powder mass exiting the capsule and device. The total amount of

293 particles with aerodynamic diameters smaller than 5 and $3 \mu \mathrm{m}$ was calculated by 
294 interpolation from the inverse of the standard normal cumulative mass distribution less

295 than stated size cut-off against the natural logarithm of the cut-off diameter of the

296 respective stages. This amount was considered as the fine particle fraction (FPF\%)

297 below $5 \mu \mathrm{m}$ and $3 \mu \mathrm{m}$, and expressed as a percentage of the ED. The mass median

298 aerodynamic diameter (MMAD) of the particles was determined from the same plot as

299 the particle size corresponding to the $50 \%$ point of the cumulative distribution, and the

300 geometric standard deviation (GSD) as GSD $=\sqrt{ }($ Size $X /$ Size $Y)$, where Size $X$ is the

301 particle size corresponding to the $84 \%$ point and size $\mathrm{Y}$ is the particle size

302 corresponding to the $16 \%$ point of the cumulative distribution.

\subsubsection{Solubility studies}

The solubility studies were determined using a shaker Innova 44 (New

Brunswick Scientific, New Jersey, USA). It was performed by the $24 \mathrm{~h}$ shake flask method at $100 \mathrm{rpm}$ and $37^{\circ} \mathrm{C}$ (Wermuth, 2008; The Practice of Medicinal Chemistry,

308 3rd ed. Elsevier Ltd, p. 750). Therefore, an excess of pure CFZ, and formulations were

309 individually added to $10 \mathrm{ml}$ of pure water in glass tubes. After the appropriate time, the

310 tubes were opened, and the supernatant withdrawn and filtered through $0.45 \mu \mathrm{m}$

311 membrane filters (ChromPure syringe filter, PVDF, $25 \mathrm{~mm}$ diameter). CFZ

312 concentrations in the supernatant were determined by HPLC as previously described.

\section{$314 \quad$ 2.2.8. Cytotoxicity studies}

315 Exponentially growing human lung adenocarcinoma cells (Calu-3) were seeded

316 at an initial density of $5 \times 10^{4}$ cells $/ \mathrm{mL}$ in 96 -well plates in DMEM medium,

317 supplemented with $10 \%$ fetal bovine serum, $2 \mathrm{mM} \mathrm{L-glutamine,} 1 \mathrm{mM}$ sodium pyruvate

318 and $1 \%$ penicillin/streptomycin. Cell cultures were then incubated at $37{ }^{\circ} \mathrm{C}$ in a

319 humidified, $5 \% \mathrm{CO}_{2}$ atmosphere, for $24 \mathrm{~h}$. After this time, the medium was removed

320 and replaced with fresh medium containing either pure $\beta C D(25-200 \mu \mathrm{M})$, pure CFZ,

321 the physical mixture or the inclusion complex. All samples that contained CFZ ranged

322 from 3.125 to $25 \mu \mathrm{M}$, in relation to CFZ concentration. The plate was incubated at 37

$323{ }^{\circ} \mathrm{C}$ in a humidified, $5 \% \mathrm{CO}_{2}$ atmosphere. The highest concentration tested when CFZ

324 was present was limited to the equivalent of pure CFZ solubility $(25 \mu \mathrm{M})$. Cell viability

325 was determined after $24 \mathrm{~h}$ by the 3-(4,5-dimethylthiazol-2-yl)-2,5- diphenyl-tetrazolium

326 bromide method (MTT) [33]. 
The absorbance was measured at $570 \mathrm{~nm}$ in a microplate reader, Perkin Elmer

328 Victor X5 (Perkin Elmer, Massachusetts, USA).

A second approach to cytotoxicity testing was used to evaluate the effect of

330 higher CFZ equivalent concentrations (50 and $100 \mu \mathrm{M})$ for a shorter incubation time

331 (4h). Results from this study were needed to support the permeability study conditions

332 (detailed below), where initial low drug concentration $(25 \mu \mathrm{M})$ were found to result in

333 levels falling outside the detection limit of the analytical method employed (HPLC)

334 after permeation. This issue has previously been reported for poorly water soluble

335 molecules in permeability testing [34].

336

\subsubsection{Permeability studies}

338 Calu-3 cells were cultured in DMEM medium, supplemented with $10 \%$ fetal bovine serum, $2 \mathrm{mM}$ L-glutamine, $1 \mathrm{mM}$ sodium pyruvate and $1 \%$ penicillin/streptomycin. Cell monolayers were obtained by seeding $5.5 \times 10^{5} \mathrm{cells} / \mathrm{cm}^{2}$ onto tissue culture inserts (Costar polyester filters, with a $1.12 \mathrm{~cm}^{2}$ growth surface area and $0.4 \mu \mathrm{m}$ pore size) placed in twelve-well plates and maintained at $37{ }^{\circ} \mathrm{C}$ in a humidified, $5 \% \mathrm{CO}_{2}$ atmosphere. During the first seven days, cells were cultured under

344 liquid-liquid interface and growth medium $(0.5 \mathrm{ml}$ on the apical side and $1.5 \mathrm{ml}$ on the 345 basal side) was replaced with fresh medium every 2-3 days. From the eighth to twelfth day, cells were cultured in an air-liquid interface $(0.6 \mathrm{ml}$ on the basal side)

The epithelial monolayer confluence was estimated by visual inspection under an optical microscope. The monolayer integrity was evaluated by transepithelial electrical resistance (TEER) measurements, using a Millicell® ERS-2 (Merck Millipore, Massachusetts, USA). TEER was calculated by subtracting the resistance of a cell-free culture insert and correcting for the surface area of the Transwell cell culture support. The increase in the values of TEER accompanied the growth of cells in each filter to reach a constant value of $>700 \Omega \mathrm{cm}^{2}$, indicating suitable cellular maturity for the test [35]. TEER was measured at the beginning, during and after the experiment, to check cell layer integrity. Transport experiments were evaluated in the apical to basolateral direction and were carried out in Hank's Balanced Salt Solution (HBSS). The apical side was filled with $0.5 \mathrm{ml}$ of sample suspension $(100 \mu \mathrm{M}$, in relation to CFZ) and the basolateral side with $1.0 \mathrm{ml}$ of HBSS. After $0.5 \mathrm{~h}, 1 \mathrm{~h}, 2 \mathrm{~h}, 3 \mathrm{~h}$ and $4 \mathrm{~h}$ all the basolateral side volume was collected and immediately replaced with fresh HBSS.

360 At the last time point, the apical content was also collected. The cell monolayer was 
361 washed with HBSS and disrupted using DMSO (200 $\mu \mathrm{l})$, after which this volume was

362 collected. CFZ concentration in all collected samples was determined by HPLC as

363 previously described.

364

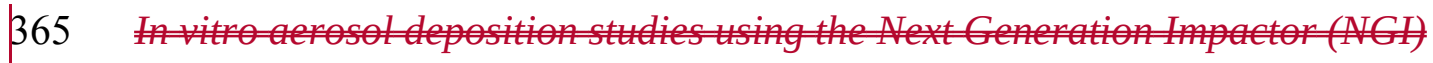

366 The dynamic propertie the por

367 Seientifie Limite

368 do The flow

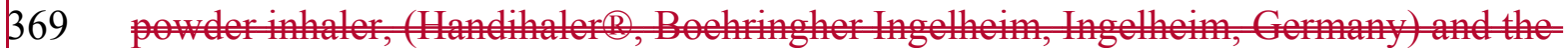

370 tim o

371 partes. The dry 3 hard

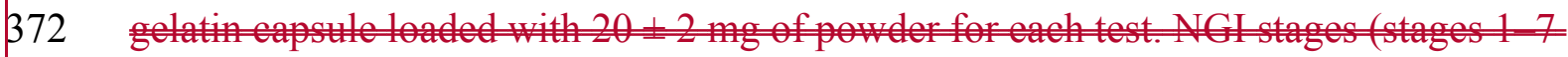

373 and filter) $1 \mathrm{~mL}$ of 1 HPLC mobile pha

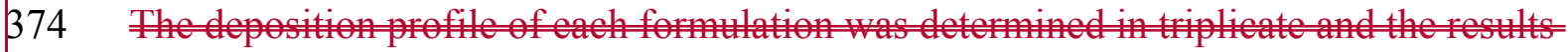

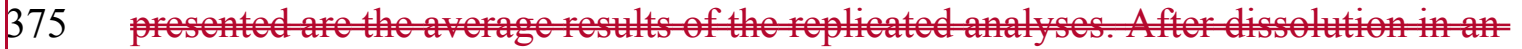

376 IPI

377 and a thes a

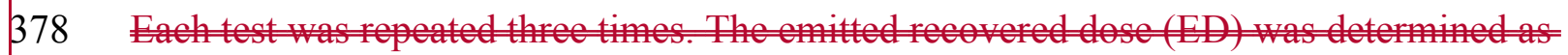

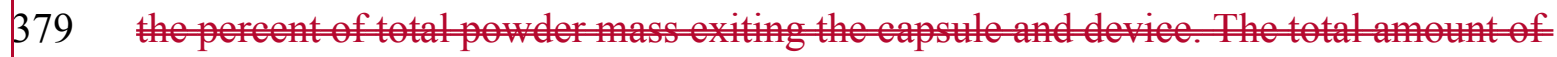

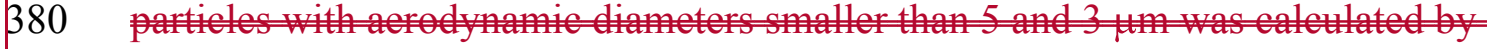

381 in the

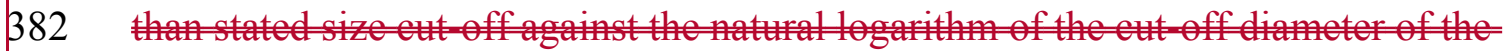

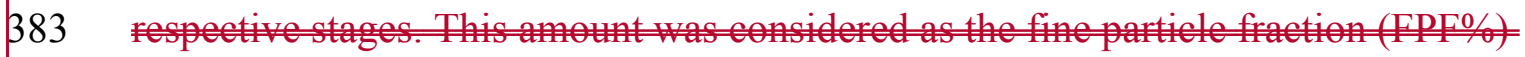

384 below 5 and 3 and axpestan a

385 dymic diameter (MMAD) of the particles determined from the same plotas

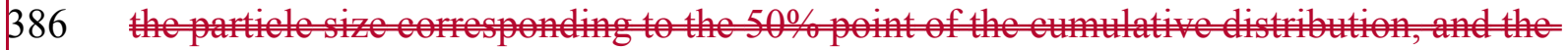

387 (GSO)aSGD-V(SizX/Size Y), whe Size X is

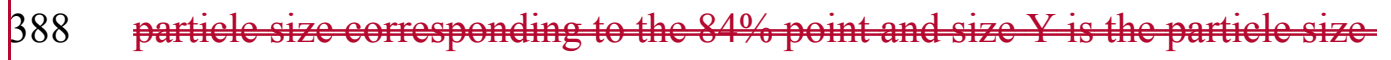

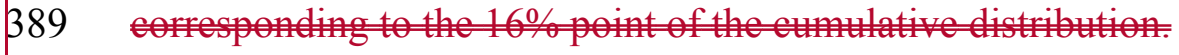

$390 \quad$ 2.2.10. Statistical analysis

$391 \quad$ Results are presented as mean \pm standard deviation. Significant differences were

392 evaluated using analysis of variance (ANOVA) with post-hoc test. All statistical 
analyses were performed with the software GraphPad Prism 5 (GraphPad Software Inc.,

394 San Diego, CA, USA).

\section{Results and Discussion}

\subsection{Inclusion complex preparation}

The efficacy of CFZ inclusion complexes based on sulfated CD has previously been described, showing these complexes' activity against two different TB strains ( $M$. avium/M. intracellulare) [26]. Thus, the use of CD to formulate a CFZ pulmonary delivery system was considered the first-choice option. This approach was reinforced by the reported successful inclusion of CFZ in negatively charged SBE $\beta C D$ / epichoridrine oligomer to increase its water solubility and bioavailability [27].

The inclusion complexes between CFZ and the CDs $(\beta C D, \gamma C D, 2-H P \beta C D$ and SBE $\beta C D)$ were obtained using different conditions, described in Table 1.

The association efficiency between $\mathrm{CFZ}$ and each $\mathrm{CD}$ was verified after the inclusion process (Figure 1). It can be observed that $\beta C D$ (ethanol:water, $\beta C D \_b$ condition) provided the highest percentage of drug inclusion (included drug mass*100/total drug mass). The highest affinity of CFZ for $\beta C D$ compared to other CDs was an unexpected result, since other water insoluble drugs, such as curcumin, adreg struetrally related to CFZ, -have shown higher affinities for more hydrophobic CDs, like RM $\beta \mathrm{CD}$ (randomly methylated $\beta$-cyclodextrin) and HP $\gamma \mathrm{CD}$ (hydroxypropyl- $\gamma$ cyclodextrin). Another interesting result was the low affinity observed for the negatively charged SBE $\beta C D$, when the least affinity observed for curcumin was for the cationic HTA $\beta C D$ (hydroxytrimethyla-moniumpropyl- $\beta$-cyclodextrin) [36].

\subsection{Cyclodextrin Complexation studies}

The complexation efficacy (CE) determined for the condition ethanol: water

420 (named $\beta C D \_b$, described in Table 1), which provided a higher percentage of recovered 421 CFZ, was 0.1738, with the ideal CFZ: $\beta$ CD molar ratio being 1:7. For comparative 422 purposes, the CE and the molar ratio were also determined for the $\beta C D \_a$ (water, in

423 Table 1) condition. Compared to the $\beta C D \_a$, the $\beta C D \_b$ condition, as expected, showed 424 greater $\mathrm{CE}$ and a molar ratio comprising 12-fold lower $\beta \mathrm{CD}$, compared to condition $425 \beta C D \_$a. Figure 2 shows the complexing profiles between CFZ and $\beta C D$ under conditions a and b. Phase solubility curves are represented as dissolved drug 
concentration against the concentration of $\beta C D$ used. The binding constant $(K)$ for complexes formed under conditions $\beta C D \_a$ and $\beta C D \_b$ were calculated from the slope of the straight-line portion of the curve, according to the following equation:

$$
\mathrm{K}=\text { slope } / \mathrm{S}_{0}(1-\text { slope })
$$

432

\subsection{Characterization studies}

The characterization studies of the complexes were performed on the dry powder obtained by lyophilization and spray drying, resulting from the complexation obtained under condition $\beta C D \_b(1 C F Z: 7 \beta C D)$. The inclusion of a molecule in the CD cavity generally promotes a change in the melting point, with a reduction in signal intensity or the disappearance of the fusion event signal in the DSC [37]. The thermograms of the raw materials ( $\mathrm{CFZ}$ and $\beta \mathrm{CD}$ ), physical mixture and the 1CFZ:7 $\beta \mathrm{CD}$ complex powders (dried by lyophilization and spray drying) are shown in Figure 3. The CFZ has a typical DSC curve of a crystalline substance, i.e. with a sharp and narrow melting event with a peak at approximately $223{ }^{\circ} \mathrm{C}$. $\beta \mathrm{CD}$ exhibits a large endothermic signal related to loss of water, peaking at $81.5^{\circ} \mathrm{C}$. The physical mixture presents the signal corresponding to the loss of water from $\beta C D$, followed by the melting peak of $\mathrm{CFZ}$ with a reduced signal intensity. The thermograms of the products obtained by lyophilization and spray drying maintained the thermal event related to the loss of water from the $\mathrm{CD}$, and show the disappearance of the drug melting peak, suggesting the formation of the inclusion complex in both cases (Figure 3). Thus, the use of the spray drying technique can be proposed for the formation of the complex, while optimizing the powder properties to obtain the desired pulmonary formulation. 
At the same time, complexation of CFZ tends to promote changes in its diffractogram, seen as a signal shift or change in signal intensity when compared to isolated molecules or the physical mixture [37-39]. XRPD analysis of CFZ and $\beta C D$ demonstrates typical crystalline substance diffraction patterns, corresponding to those deposited in the Cambridge Structural Database (CSD). The diffraction pattern of the CFZ raw material was typical of polymorphic form I of the drug $(9.2,13.4,19.8$ and $21.7^{\circ} 2 \theta$ ), according to CSD reference (DAKUI01), Figure 4. amorphization after processing, with broad peaks (at $6.6^{\circ}, 11.6^{\circ}$ and $18.3^{\circ} 2 \theta$ ) evident. In a previous study, Amaro et. al (2015) $[40]$, observed a similar diffraction pattern for spray-dried 2-HPßCD, with diffuse peaks in a similar position [40]. The diffraction pattern was reported to be associated with the molecular arrangement of the $\mathrm{CD}$ as a cup that can form small domains with some degree of short-range order. Despite this, the resulting powder was classified as amorphous [40]. The diffractogram of the physical mixture was similar to that of combined diffraction patterns of the individual raw materials (Figure 5). The physical mixture peak pattern (Table 2) indicated a simple mixture (lack of chemical interaction) as it was the sum of the diffraction peaks of the raw materials. On the other hand, for the inclusion complex a new peak (7.7 29), peak displacements $\left(12-13.4^{\circ}\right.$ and $\left.18.3-19.8^{\circ} 2 \theta\right)$ and peak absences $\left(4.5^{\circ}, 8.9-9.2^{\circ}, 10.8^{\circ}\right.$, $15.4^{\circ}$ and $22.0^{\circ} 2 \theta$ ) were observed (Table 2 ), indicating complex formation by means of CFZ- $\beta C D$ interaction. The DSC result presented in the previous section, corroborates with the XRPD result pointing to inclusion complex formation. The diffractogram of the 1CFZ:7 $\beta C D$ complex obtained by freeze drying exhibited broad peaks while spray drying appeared to promote a higher degree of amorphization, based on the XRPD patterns (Figure 5). The formation of completely or partially amorphous material can represent complex formation, but it can also be a characteristic resulting from lyophilization and spray drying processes $[15,41]$. Therefore, XRPD results should be considered in association with results from thermal (DSC - described above) and spectroscopy analyses (discussed below) for the appropriate characterization of the inclusion complex [37].

The FTIR spectra of the dried complexes compared to the physical mixture and the raw materials, did not show any relevant alterations of the characteristic absorption peaks of CFZ, indicating only the presence of the drug, as shown in Figure 6. 

information of the analyzed material than the techniques used above, where the occurrence of a chemical shift $(\delta)$ in the carbon (13C) signals reveals the formation of an inclusion complex [37]. From the 13C-CP/MAS solid phase NMR spectra (Figure 7), the main signals $(60.77,72.89$ and $102.89 \mathrm{ppm})$ of the $\beta C D$ present in the physical mixture and the CFZ: $\beta C D$ complex (1:7) were analyzed. The CFZ: $\beta C D(1: 7)$ complex shows, in relation to $\beta C D$, chemical shift variations of $0.37 \mathrm{ppm}, 0.61 \mathrm{ppm}$ and 1.22 ppm, whereas in the physical mixture the same displacements were lower and correspond to $0.35 \mathrm{ppm}, 0.06 \mathrm{ppm}$ and $0.21 \mathrm{ppm}$. The change in multiplicity plus the greater variation in chemical displacement were indicative of inclusion complex formation. The CFZ signals were not exploited due to its low concentration in the complex.

\subsection{Spray drying for pulmonary delivery formulations}

508 Spray dryer settings and formulation constituents are known to influence the 509 final particle properties, such as size, density, morphology and moisture content, which

510 in turn determine powder aerosolisation characteristics and site of lung deposition

$511 \quad[1,42-44]$. Different formulations and spray drying conditions were evaluated, as

512 presented in Table 3. The geometric mean diameter (GD) and the polydispersity index 513 obtained for the different formulations are shown in Figure 8. The polydispersity index

514 (span value) was calculated from the equation: $\left(\mathrm{d}_{90}-\mathrm{d}_{10}\right) / \mathrm{d}_{50}$, where $\mathrm{d}_{90}, \mathrm{~d}_{50}$ and $\mathrm{d}_{10}$

515 correspond respectively to the geometric diameter of $90 \%, 50 \%$ and $10 \%$ of the

516 distribution fraction (data not shown) [15,40,42].

517 Initial spray dryer settings were shown to be sub-optimal due to a high GD

$518(11.59 \mu \mathrm{m}$, Figure 8$)$. The high inlet temperature $\left(95^{\circ} \mathrm{C}\right)$ and pump flow $(0.55 \mathrm{~L} / \mathrm{h})$

519 used to generate the SP1 formulation (Table 3) probably caused this behavior, as

520 previously observed by Wang and Wang [45]. These authors indicated that the high

521 temperature and flow caused, respectively, fast solvent evaporation and larger droplet

522 size formation, and consequently a larger particle GD [45]. The inlet temperature was

523 reduced to $65^{\circ} \mathrm{C}$, as previously described in a study to determine the influence of spray

524 dryer conditions on the preparation of a beclomethasone: $\gamma C D$ inclusion complex using

525 the same co-solvent system as used in this work [44]. The lower inlet temperature and

526 flow resulted in small but statistically insignificant decrease in GD for SP2 compared to 527 SP1 (Figure 8). 
Formulations SP3-9 tested the inclusion of L-leucine or L-isoleucine to evaluate the influence of these excipients on particle size. These formulations were also finetuned with respect to amino acid concentration, pump flow and co-solvent used (Table 3). A pump feed increase to $0.35 \mathrm{~L} / \mathrm{h}$ for SP6, SP7 and SP8 formulations led to the lowest values of GD, corresponding to $5.73 \pm 1.20 \mu \mathrm{m}, 5.45 \pm 1.62 \mu \mathrm{m}$ and $2.18 \pm 0.110$ $\mu \mathrm{m}$, respectively, and narrowest size distribution, observed for SP8 ( $\operatorname{span}=0.03$ ). These GD values were promising with respect to the production of powder with appropriate aerodynamic characteristics for pulmonary delivery [7]. L-leucine addition led to a particle size reduction, while L-isoleucine (in SP5) did not. Likewise, the addition of $2 \%$ dichloromethane (SP9) did not result in a significant reduction in GD.

\subsection{Particle morphology}

The morphological evaluation of formulations SP6 to SP9 (Figure 9) revealed a near-spherical shape. Among the formulations spray dried from ethanol:water $(1: 1)$ and with the same spray drying conditions (SP6 - SP8), L-leucine incorporation led to the production of powders comprised of fewer agglomerates, with a more homogeneous size distribution and particle surfaces that were slightly corrugated, consistent with previous reports $[14,15]$. The lesser agglomeration and increased particle corrugation may favor powder dispersibility and the effective fraction of breathable powder $(<5 \mu \mathrm{m})$ [46]. The SP9 formulation (CFZ: $\beta C D+$ L-leucine 15\%, dispersed in dichloromethane $2 \%$, in addition to ethanol:water), differs considerably in its appearance from the other powders, since the particles appear to be cohesive, forming rod structures with smooth surfaces, i.e., without pores (unlike what may have been expected when using a blowing agent). A more heterogeneous particle size distribution (larger span) was measured for this system (Table 3).

\subsection{Bulk density (bo), Tapped density (to), Specific Surface Area (SSA) and}

\section{Aerodynamic Characteristics}

The $b \rho, t \rho$, SSA and the aerodynamic characteristics were measured for formulations with greatest potential for pulmonary delivery (SP6, SP7 and SP8), given their GD and morphology (Table 4). The b $\rho$ and t $\rho$ ranged between 0.113 and 0.265 $\mathrm{g} / \mathrm{cm}^{3}$ and were considered suitable for pulmonary delivery, as previously reported by some authors $\left(<0.3 \mathrm{~g} / \mathrm{cm}^{3}\right)[15,43,47]$. The theoretical $\mathrm{d}_{\mathrm{a}}$ calculated from $\mathrm{t} \rho$ and GD for SP6, SP7 and SP8 were $2.36 \mu \mathrm{m}, 2.28 \mu \mathrm{m}$ and $1.12 \mu \mathrm{m}$ respectively, further indicating 
562 suitability for pulmonary delivery $(1-5 \mu \mathrm{m})$ [9]. The L-leucine promoted an increase in $563 \mathrm{~b} \rho$ and $\mathrm{t} \rho$, related to the higher solid content and formation of dense particles, in 564 agreement with previously reported data [15]. As expected, when compared to the other 565 formulations, the presence of $15 \%$ L-leucine significantly increased the SSA $(\mathrm{P}<0.001)$

566 due to the formation of rougher/corrugated/more textured particles (Figure 9-D) [1].

567 The roughness tends to reduce the interparticle contact, thus favoring powder 568 dispersibility. The aerodynamic behavior of the formulation is influenced by the 569 interrelationship of factors related to the particle (geometric diameter, morphology, 570 surface area) and to the powder (b $\rho, \mathrm{t} \rho$, hygroscopicity). The emitted recovered dose 571 (ED) (i.e. total dose less the amount remaining in the capsule and device) for all evaluated formulations was similar, and high (94.13 to 95.19\%). This result indicated adequate release from the capsule and the inhalation device and at the same time demonstrated good powder flow properties. The addition of L-leucine did not change the $\% \mathrm{ED}$ (probably due to the fact that the \%ED for the equivalent formulation without leucine was already high). Previous studies have commonly indicated an increased ED corresponding to the presence and increasing concentration of this amino acid $[17,48]$. However, here the fine particle fraction (FPF) of the selected formulations ranged from 46.20 to $51.56 \%$, with no significant difference between different formulations S6, S7, S8. A comparison between MMADs (Table 4) and theoretical aerodynamic diameter values for SP6 - SP8 (given above) showed that MMAD $>d_{a}$ in all cases, suggesting that during aerosolisation, the powder remains aggregated rather than behaving as individual particles. Other researchers had already noted the same MMAD $>d_{a}$ relation, with an even larger difference between values $[32,49]$. However, despite the aggregates, approximately fifty percent of ED corresponded to FPF in all tested formulations. The MMAD of all formulations was less than $5 \mu \mathrm{m}$ and the geometric standard deviation (GSD) was less than 2. These were considered adequate values for pulmonary formulations and delivery, since the combination of these parameters indicates a narrow particle size distribution in the FPF region $[11,43]$.

\subsection{Dynamic vapour sorption (DVS)}

DVS analysis was performed to evaluate the behavior of SP6, SP7 and SP8

593 formulations when exposed to different moisture conditions (Figure 10). The adsorption

594 isotherms of the formulations evaluated were similar and showed considerable

595 incorporation of vapor (water) even at low relative humidities (RH). As expected, due to 
the amorphous characteristics of these powders, the three formulations exhibited

597 considerable and continuous mass gain with increasing relative humidity (RH). Li et. al.

598 (2016) demonstrated that water uptake by spray dried L-leucine alone was very low

$599(<1 \%)$ at $90 \% \mathrm{RH}$, being classified as non-hygroscopic. Thus, the L-leucine

600 contribution to water uptake when incorporated in a powder should be insignificant

601 [50]. However, the presence of L-leucine made the water sorption both slower and

602 overall lower and provided some protection to the powder against increasing relative

603 humidity. When comparing the formulations containing L-leucine (SP7 and SP8) to that

604 without (SP6), it was observed that, up to $80 \% \mathrm{RH}$, the weight gain due to water

605 sorption was much lower for the L-leucine-containing formulations, but from $90 \% \mathrm{RH}$

606 the difference in the sorption profiles was negligible. At the end of the sorption process,

607 the mass increase was $23.22 \%, 22.03 \%$ and $19.78 \%$ for the formulations SP6, SP7 and

608 SP8 respectively, demonstrating the anti-hygroscopic effect of L-leucine $[48,50]$. The

609 absence of inflection in the adsorption isotherms indicated the absence of

610 recrystallization for all formulations. The diffractograms obtained after the DVS runs

611 (Figure 11) still demonstrated high degrees of amorphization. The broad peaks in the

612 XRPDs can be attributed to the spray-dried $\beta C D$ which was present in a large

613 proportion in all formulations. The peak position displacements for the complexes

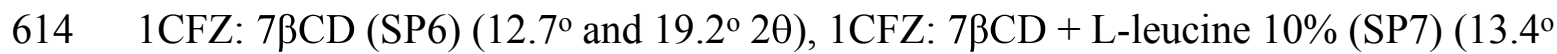

615 and $\left.19.3^{\circ} 2 \theta\right)$ and 1CFZ: $7 \beta C D+$ L-leucine $15 \%$ (SP8) $\left(6.2^{\circ}, 13.6^{\circ}\right.$ and $\left.19.1^{\circ} 2 \theta\right)$ when

616 compared to spray-dried $\beta C D\left(6.6^{\circ}, 11.6^{\circ}\right.$ and $18.3^{\circ} 2 \theta$ - Figure $\left.5 C\right)$ can be explained by

617 differences in powder composition, leading to slight variations in molecular

618 interactions. In addition, the diffractogram of spray-dried L-leucine after the DVS

619 analysis exhibited peaks at $2 \theta$ of $6.2^{\circ}$ and $19.1^{\circ}$, as previously reported [15]. The

620 intensity of the peak ranging in position from $19.1^{\circ}$ to $19.3^{\circ} 2 \theta$ reflected the L-leucine

621 content variation in formulations SP6-8 (Figure 11). For the desorption in the range of

$62280-10 \%$, the presence of L-leucine slowed down the water loss. However, after the

623 desorption process, all formulations returned to the initial mass levels, indicating a

624 reversible water sorption process.

625

626

3.8. In vitro aerosol deposition studies using the Next Generation Impactor (NGI)

627 The deposition profiles of SP6, SP7 and SP8 formulations show that $58-62 \%$ of

628 emitted dose (ED) was able to cross the mouthpiece adapter/induction port (MA/IC), 
which in vivo would correspond to the oro-pharyngeal region and indicates suitability

630 for deposition in the respiratory tract (Figure 12). Particle deposition on MA/IC can be

631 explained by agglomerate formation as a consequence of powder hygroscopicity, due to

632 its amorphous state. Regarding the NGI stages, the particle deposition of the evaluated

633 formulations at a $100 \mathrm{~L} / \mathrm{min}$ flow rate was concentrated in stages 2, 3 and 4, which have

634 cut-off diameters of $3.42 \mu \mathrm{m}, 2.18 \mu \mathrm{m}$ and $1.31 \mu \mathrm{m}$ respectively [8]. Stage 2 was the only

635 one that exhibited significant deposition differences $(\mathrm{P}<0.001)$ between formulations

636 SP6 (without L-leucine) and SP8 (L-leucine 15\%). The higher SP6 deposition was in

637 line with its larger MMAD (3.38 $\pm 0.19 \mu \mathrm{m}$ for SP6 compared to $2.98 \pm 0.08 \mu \mathrm{m}$ for

638 SP8) and the stage cut-off diameter $(3.42 \mu \mathrm{m})$. The SP8 formulation presented lower

639 deposition at this stage, which is an advantage and can enable better pulmonary

640 retention. The percentage of particle deposition in the stages corresponding to the lower

641 respiratory tract (stages $3-7$ ) was $30-40 \%$, with, perhaps surprisingly, no significant

642 difference between formulations with or without L-leucine, in spite of significant

643 difference in SSA ( $<<0.001)$ and MMAD ( $<0.05)$ for SP8 (with $15 \% L$-leucine)

644 compared to other formulations.

645 When considering exclusively the aerodynamic powder characteristics, the

646 formulations SP6 - SP8 all showed appropriate parameters for use in a DPI. Efficacy

647 tests should be performed in the future to confirm this hypothesis.

649 3.9. Solubility studies

650 The aqueous solubility of SP6, SP7 and SP8 formulations were evaluated

651 (Figure 13). When compared to the free drug, formation of the CFZ: $\beta C D$ complex (1:7)

652 increased the aqueous solubility of CFZ by sixteen-fold $(\mathrm{P}<0.001)$ and incorporation of

$65310 \%$ L-leucine, promoted an even greater increase (almost twenty seven-fold). A further

654 increase in L-leucine content from $10 \%$ to $15 \%$ did not modify the water solubility of

655 the complex $(\mathrm{P}>0.05)$. The $\mathrm{CFZ}$ solubility improvement when complexed with $\beta C D$

656 may be explained not only by their association, but also by the formation of amorphous

657 particles during the spray drying process [1,25]. On the other hand the L-leucine effect

658 on solubility is likely to be due to its surfactant-like properties [17], which has already

659 been observed for azithromycin co-spray-dried particles [51]. The higher solubility for

660 L-leucine containing formulations improves their therapeutic potential, since they may

661 be better able to overcome the mucus barrier, present prolonged lung retention time and

662 higher CFZ bioavailability. 


\subsection{Cytotoxicity studies}

The in vitro cytotoxicity of free $\mathrm{CFZ}$ and $\beta \mathrm{CD}$, and the CFZ: $\beta \mathrm{CD}$ complex,

666 Figure 14, was evaluated after 24 h exposure in a Calu-3 cell line, due to its

667 representativeness of the constituents of the respiratory tract [52]. The cytotoxicity

668 assay was performed not only to identify the cytotoxicity of the raw material itself, but

669 also to identify if the complexation could reduce this. The $\beta C D$ complex revealed $>90 \%$

670 cell viability even when exposed to the highest equivalent CFZ concentration $(25 \mu \mathrm{M})$.

671 This value was not significantly different from that observed for CFZ or a CFZ-CD

672 physical mixture. The $\beta C D$ toxicity at Calu-3 cells (Figure 14B) revealed that it was

673 dependent on $\beta C D$ concentration. Cell viability for a $\beta C D$ concentration $\leq 50 \mu \mathrm{M}$ was

674 higher than $90 \%$, while it was higher than $70 \%$ for a concentration of $200 \mu \mathrm{M}$. These

675 results indicated a high tolerability of Calu-3 cells for the CFZ:ßCD complex, enabling

676 its lung administration. The international guide ISO 10993-5, states that cell viabilility $>$

$67770 \%$ is not considered a cytotoxic effect [53]. The cytotoxicity test based on the cell

678 viability assay condition to inform the permeability study used CFZ equivalent

679 concentrations of $50-100 \mu \mathrm{M}$ incubated for $4 \mathrm{~h}$. Cell viability results were: (i) for the

680 free CFZ: $78.2 \pm 9.9 \%(50 \mu \mathrm{M})$ and $77.0 \pm 6.1 \%(100 \mu \mathrm{M})$; and (ii) for SP8 formulation

681 (selected for permeability study, as justified in the next section): $75.1 \pm 11.34 \%$ (50

$682 \mu \mathrm{M})$ and $72.5 \pm 3.9 \%(100 \mu \mathrm{M})$. Then, in terms of cytotoxicity, these results

683 demonstrated the suitability of both concentrations for permeability studies and $100 \mu \mathrm{M}$

684 was the concentration selected for this study.

685

\subsection{Permeability studies}

687 As described in the literature, the in vitro permeability study is a good indicator 688 for drug delivery in the respiratory tract [54]. Because of its lower MMAD $(2.98 \mu \mathrm{m})$, 689 higher FPF (51.6\%), promising deposition profile, improved water solubility and 690 specially low hygroscopicity compared to other tested formulations, SP8 was selected 691 for this evaluation._-The formulation was added as a suspension to the surface of the 692 Calu-3 monolayer, as reported in other studies [55]. The maintenance of the integrity of 693 the monolayer was confirmed by the stability of TEER values, which was verified 694 during and after the experiment (Figure S1 15 ). After $4 \mathrm{~h}$, there was no CFZ detected in 695 the basolateral compartment for wells containing the free drug or for SP8. This result 
696 points to the possibility of obtaining a high drug concentration directly at the site of

697 pulmonary infection, while minimizing systemic CFZ biodistribution and toxicity. The

698 quantification of intracellular CFZ was similar for the free drug $(44.4 \pm 14.0 \%)$ and for

699 SP8 $(43.7 \pm 4.6 \%)$, indicating that both exhibit the same penetrating capacity in the

700 monolayer and availability for local action in the lungs. This result points to the

701 possibility of obtaining a high drug concentration directly at the site of pulmonary

702 infection and thus a more effective therapy, while minimizing systemic CFZ

703 biodistribution and toxicity. Hence, reducing systemic side effects like reddish-brown

704 discoloration of the skin and conjunctiva [22], a relevant issue at TB prolonged

705 treatment regime (minimum 6 months) $[2,10]$. At the same time, pulmonary delivery of

706 CFZ microparticles can be an interesting strategy to improve mycobacteria death by

707 favoring two inherent mechanisms: (i) CFZ distribution to the mononuclear phagocyte

708 system, and (ii) the macrophages uptake of microparticles [10,56]. In addition, the CFZ

709 inside macrophages also can act as a drug reservoir, prolonging the residence time at the

710 lungs, reaching granulomas and supporting the TB latent cases treatment [10].

711 Cellular internalization can act as a drug reservoir and thus prolong the residence time-

712 of the drug in the lungs and favor treatment for latent cases of TB.

713

$714 \quad$ 3.12. Pulmonary dose calculation

715 The CFZ WHO treatment regimen for TB has established a daily oral dose of $716100 \mathrm{mg}$ [57], this drug also has an oral bioavailability of 45-62\% [22]. The calculation

717 of the inhaled estimated dose $(4.5 \mathrm{mg} / \mathrm{day})$ considered that the pulmonary delivery drug 718 amount usually is about ten-times lower compared to oral one $[43,58,59]$. Considering 719 that the best formulation (SP8) exhibited a drug:powder ratio of about 1:20 (w/w), the 720 total powder mass amount was of $89.3 \mathrm{mg} /$ day. This mass is smaller than those of the 721 marketed tobramycin and colistimethate dry powder inhaled formulation, and like the 722 examples can be used in multiple doses or inhalations [60-62].

\section{Conclusions}

In the present study, CFZ:CD complexes were studied with a view to developing

727 CFZ:CD by spray drying to facilitate the particle formation process, with water soluble

728 CD complex formation, able to overcome the mucus barrier and prolong the lung 
retention time. The $1 \mathrm{CFZ}$ :7CD complex improved the CFZ water solubility and L-

730 leucine incorporation promoted an even greater solubility. Inhalable microparticles were produced under optimized spray drying conditions of: $65^{\circ} \mathrm{C}$ inlet temperature, $0.35 \mathrm{~L} / \mathrm{h}$ pump rate, and $35 \mathrm{~L} / \mathrm{min}$ gas flow rate. DPI formulations with or without L-leucine were developed, comprising suitable aerodynamic properties and improved CFZ water solubility. The addition of $15 \%$ L-leucine had the advantage of reducing powder hygroscopicity while also enhancing in vitro powder deposition in the lower airways. In vitro studies showed a viability of at least $70 \%$ for Calu-3 cells after 24 hours of exposure to $\mathrm{CFZ}$ and $\beta \mathrm{CD}$ (high concentrations) and permeability testing indicated that the drug was retained at the apical compartment and achieved cellular internalization. The inhaled estimated dose was $4.5 \mathrm{mg}$ in a powder mass of $89.3 \mathrm{mg} /$ day, allowing dry powder device use. inhalation of cyclodextrin complex representing a potential new local treatment for lung

Data availability: The dataset analyzed during the current study is available from the corresponding author on reasonable request. Data generated during this study are included in this published article.

\section{Declaration of interest: None.}

Acknowledgements: This work was supported by Fundação de Amparo à Pesquisa do Estado do Rio de Janeiro (FAPERJ); Conselho Nacional de Desenvolvimento Científico e Tecnológico (CNPq) and Coordenação de Aperfeiçoamento de Pessoal de Nível Superior (CAPES). A.M. Healy acknowledges Science Foundation Ireland grants cofunded under the European Regional Development Fund (SFI/12/RC/2275 and SFI/12/RC/2275_P2).

\section{References}

759 [1] R. Vehring, Pharmaceutical particle engineering via spray drying, Pharm. Res. 25 (2008) 999-1022. https://doi.org/10.1007/s11095-007-9475-1.

761 [2] WHO, Global Tuberculosis Report, 2017.

762 [3] I. Smith, Mycobacterium tuberculosis pathogenesis and molecular determinants 
of virulence, Clin. Microbiol. Rev. 16 (2003) 463-496. https://doi.org/10.1128/CMR.16.3.463.

S. Giovagnoli, A. Schoubben, M. Ricci, The Long And Winding Road To Inhaled TB therapy: not only the bug's fault, Drug Dev. Ind. Pharm. 43 (2017) 347-363. https://doi.org/10.1080/03639045.2016.1272119.

[5] D. Evangelopoulos, J. Diniz, S.J. Waddell, Understanding anti-tuberculosis drug efficacy : rethinking bacterial populations and how we model them, Int. J. Infect. Dis. 32 (2015) 76-80. https://doi.org/10.1016/j.ijid.2014.11.028.

[6] C.M. Pule, S.L. Sampson, R.M. Warren, P.A. Black, P.D. van Helden, T.C. Victor, G.E. Louw, Efflux pump inhibitors: Targeting mycobacterial efflux systems to enhance TB therapy, J. Antimicrob. Chemother. 71 (2016) 17-26. https://doi.org/10.1093/jac/dkv316.

[7] M. Ibrahim, R. Verma, L. Garcia-Contreras, Inhalation drug delivery devices: technology update., Med. Devices (Auckl). 8 (2015) 131-9. https://doi.org/10.2147/MDER.S48888.

8] US Pharmacopeial Convention, Inhalation and nasal drug products: aerosols, sprays and powders - performance quality tests, in: United States Pharmacop., 2017: pp. 472-498.

] H.G. Lee, D.W. Kim, C.W. Park, Dry powder inhaler for pulmonary drug delivery: human respiratory system, approved products and therapeutic equivalence guideline, J. Pharm. Investig. 48 (2018) 603-616. https://doi.org/10.1007/s40005-017-0359-z.

[10] P. Muttil, C. Wang, A.J. Hickey, Inhaled drug delivery for tuberculosis therapy, Pharm. Res. 26 (2009) 2401-2416. https://doi.org/10.1007/s11095-009-9957-4.

[11] J.S. Patton, P.R. Byron, Inhaling medicines: Delivering drugs to the body through the lungs, Nat. Rev. Drug Discov. 6 (2007) 67-74. https://doi.org/10.1038/nrd2153.

[12] M.Y. Yang, J.G.Y. Chan, H.K. Chan, Pulmonary drug delivery by powder aerosols, J. Control. Release. 193 (2014) 228-240. https://doi.org/10.1016/j.jconrel.2014.04.055.

[13] N.R. Labiris, M.B. Dolovich, Pulmonary drug delivery . Part I : Physiological factors affecting therapeutic effectiveness of aerosolized medications, J Clin Pharmacol. 56 (2003) 588-599. https://doi.org/10.1046/j.13652125.2003.01892.x. 
[14] A. Barazesh, K. Gilani, M. Rouini, M. Ali, Effect of $\mathrm{pH}$ and leucine concentration on aerosolization properties of carrier-free formulations of levofloxacin, Eur. J. Pharm. Sci. 118 (2018) 13-23. https://doi.org/10.1016/j.ejps.2018.03.002.

[15] A. Simon, M.I. Amaro, L.M. Cabral, A.M. Healy, V.P. De Sousa, Development of a novel dry powder inhalation formulation for the delivery of rivastigmine hydrogen tartrate, Int. J. Pharm. 501 (2016) 124-138. https://doi.org/10.1016/j.jpharm.2016.01.066.

[16] S. Arora, M. Haghi, P.M. Young, M. Kappl, D. Traini, S. Jain, Highly respirable dry powder inhalable formulation of voriconazole with enhanced pulmonary bioavailability, Expert Opin. Drug Deliv. 13 (2016) 183-193. https://doi.org/10.1517/17425247.2016.1114603.

[17] N.Y.K. Chew, B.Y. Shekunov, H.H.Y. Tong, A.H.L. Chow, C. Savage, J. Wu, H.K. Chan, Effect of amino acids on the dispersion of disodium cromoglycate powders, J. Pharm. Sci. 94 (2005) 2289-2300. https://doi.org/10.1002/jps.20426.

[18] B. Lamy, D.R. Serrano, P. O'Connell, W. Couet, S. Marchand, A.M. Healy, F. Tewes, Use of leucine to improve aerodynamic properties of ciprofloxacinloaded maltose microparticles for inhalation, Eur. J. Pharm. Res. 1 (2019) 02-11. https://doi.org/10.34154/2019-ejpr.01(01).pp-02-11/euraass.

[19] A. Hidalgo, A. Cruz, J. Pérez-Gil, Barrier or carrier? Pulmonary surfactant and drug delivery, Eur. J. Pharm. Biopharm. 95 (2015) 117-127. https://doi.org/10.1016/j.ejpb.2015.02.014.

[20] H.H. Sigurdsson, J. Kirch, C. Lehr, Mucus as a barrier to lipophilic drugs, Int. J. Pharm. 453 (2013) 56-64. https://doi.org/10.1016/j.ijpharm.2013.05.040.

[21] J.B. Torrelles, L.S. Schlesinger, Integrating Lung Physiology, Immunology, and Tuberculosis, Trends Microbiol. 25 (2017) 688-697. https://doi.org/10.1016/j.tim.2017.03.007.

[22] M.C. Cholo, H.C. Steel, P.B. Fourie, W.A. Germishuizen, R. Anderson, Clofazimine: Current status and future prospects, J. Antimicrob. Chemother. 67 (2012) 290-298. https://doi.org/10.1093/jac/dkr444.

[23] S. Tyagi, N.C. Ammerman, S.Y. Li, J. Adamson, P.J. Converse, R. V. Swanson, D. V. Almeida, J.H. Grosset, Clofazimine shortens the duration of the first-line treatment regimen for experimental chemotherapy of tuberculosis, Proc. Natl. Acad. Sci. U. S. A. 112 (2015) 869-874. 
https://doi.org/10.1073/pnas.1416951112.

[24] N.C. Ammerman, R. V Swanson, A. Tapley, C. Moodley, B. Ngcobo, J. Adamson, A. Dorasamy, S. Moodley, Z. Mgaga, L.A. Bester, S.D. Singh, D. V Almeida, J.H. Grosset, Clofazimine has delayed antimicrobial activity against Mycobacterium tuberculosis both in vitro and in vivo, J. Antimicrob. Chemother. 72 (2016) 455-461. https://doi.org/10.1093/jac/dkw417.

[25] T. Loftsson, M.E. Brewster, Pharmaceutical applications of cyclodextrins: Basic

[26] I.I. Salem, G. Steffan, N. Düzgünes, Efficacy of clofazimine-modified cyclodextrin against Mycobacterium avium complex in human macrophages, Int. J. Pharm. 260 (2003) 105-114. https://doi.org/10.1016/S0378-5173(03)00236-9.

[27] J. Wankar, F. Bonvicini, G. Benkovics, V. Marassi, M. Malanga, E. Fenyvesi, G.A. Gentilomi, P. Reschiglian, B. Roda, I. Manet, Widening the Therapeutic Perspectives of Clofazimine by Its Loading in Sulfobutylether $\beta$-Cyclodextrin Nanocarriers: Nanomolar IC50 Values against MDR S. epidermidis, Mol. Pharm. 15 (2018) 3823-3836. https://doi.org/10.1021/acs.molpharmaceut.8b00321.

[30] O. NíÓgáin, L. Tajber, O.I. Corrigan, A.M. Healy, Spray drying from organic

[28] T. Loftsson, M.E. Brewster, Cyclodextrins as Functional Excipients : Methods to Enhance Complexation Efficiency, J. Pharm. Sci. 101 (2012) 3019-3032. https://doi.org/10.1002/jps.23077.

[29] A.M. Healy, B.F. McDonald, L. Tajber, O.I. Corrigan, Characterisation of excipient-free nanoporous microparticles (NPMPs) of bendroflumethiazide, Eur. J. Pharm. Biopharm. 69 (2008) 1182-1186. https://doi.org/10.1016/j.ejpb.2008.04.020. solvents to prepare nanoporous/nanoparticulate microparticles of protein: Excipient composites designed for oral inhalation, J. Pharm. Pharmacol. 64 (2012) 1275-1290. https://doi.org/10.1111/j.2042-7158.2012.01488.x.

[31] Y. Wei, Y. Wang, H. Zhang, W. Zhou, G. Ma, A novel strategy for the preparation of porous microspheres and its application in peptide drug loading, J. Colloid Interface Sci. 478 (2016) 46-53. https://doi.org/10.1016/j.jcis.2016.05.045.

[32] N.R. Rabbani, P.C. Seville, The influence of formulation components on the aerosolisation properties of spray-dried powders, J. Control. Release. 110 (2005) 
130-140. https://doi.org/10.1016/j.jconrel.2005.09.004.

[33] T. Mosmann, Rapid colorimetric assay for cellular growth and survival: Application to proliferation and cytotoxicity assays, J. Immunol. Methods. 65 (1983) 55-63. https://doi.org/10.1016/0022-1759(83)90303-4.

[34] S.T. Buckley, S.M. Fischer, G. Fricker, M. Brandl, In vitro models to evaluate the permeability of poorly soluble drug entities: Challenges and perspectives, Eur. J. Pharm. Sci. 45 (2012) 235-250. https://doi.org/10.1016/j.ejps.2011.12.007.

[35] B. Srinivasan, A.R. Kolli, M.B. Esch, H.E. Abaci, M.L. Shuler, J.J. Hickman, TEER Measurement Techniques for In Vitro Barrier Model Systems, J. Lab. Autom. 20 (2015) 107-126. https://doi.org/10.1177/2211068214561025.

[36] H. Hjorth, Studies of curcumin and curcuminoids . XXVII . Cyclodextrin complexation : solubility, chemical and photochemical stability, Int. J. Pharm. 244 (2002) 127-135.

[37] P. Mura, Analytical techniques for characterization of cyclodextrin complexes in the solid state: A review, J. Pharm. Biomed. Anal. 113 (2015) 226-238. https://doi.org/10.1016/j.jpba.2015.01.058.

[38] X.S. Le, F.T. Chuan, Y. Yang, Preparation and characterization of the solid inclusion compounds of alfa-, beta-cyclodextrin with phenylalanine (D-, L- and DL-Phe) and tryptophan (D-, L- and DL-Trp), J. Incl. Phenom. 54 (2006) 221232. https://doi.org/10.1007/s10847-005-7970-8.

[39] M.E. Cortes, R.D. Sinisterra, M.J. Avila-Campos, N. Tortamano, R.G. Rocha, The chlorhexidine: beta-cyclodextrin inclusion compound: Preparation, characterization and microbiological evaluation, J. Incl. Phenom. Macrocycl. Chem. 40 (2001) 297-302. https://doi.org/10.1023/A:1012788432106.

[40] M.I. Amaro, L. Tajber, O.I. Corrigan, A.M. Healy, Co-Spray dried carbohydrate microparticles: Crystallisation delay/inhibition and improved aerosolization characteristics through the incorporation of hydroxypropyl- $\beta$-cyclodextrin with amorphous raffinose or trehalose, Pharm. Res. 32 (2015) 180-195. https://doi.org/10.1007/s11095-014-1454-8.

[41] M.M. Doile, K.A. Fortunato, I.C. Schmücker, S.K. Schucko, M.A.S. Silva, P.O. Rodrigues, Physicochemical properties and dissolution studies of dexamethasone acetate-beta-cyclodextrin inclusion complexes produced by different methods., AAPS PharmSciTech. 9 (2008) 314-21. https://doi.org/10.1208/s12249-008- 
899

900

901

902

903

904

905

906

907

908

909

910

911

912

913

914

915

916

917

918

919

920

921

922

923

924

925

926

927

928

929

930

931

932

9042-z.

[42] M.I. Amaro, L. Tajber, O.I. Corrigan, A.M. Healy, Optimisation of spray drying process conditions for sugar nanoporous microparticles (NPMPs) intended for inhalation, Int. J. Pharm. 421 (2011) 99-109. https://doi.org/10.1016/j.ijpharm.2011.09.021.

[43] É.Y. Suzuki, M.I. Amaro, G.S. de Almeida, L.M. Cabral, A.M. Healy, V.P. de Sousa, Development of a new formulation of roflumilast for pulmonary drug delivery to treat inflammatory lung conditions, Int. J. Pharm. 550 (2018) 89-99. https://doi.org/10.1016/j.ijpharm.2018.08.035.

[44] H. Cabral-Marques, R. Almeida, Optimisation of spray-drying process variables for dry powder inhalation (DPI) formulations of corticosteroid/cyclodextrin inclusion complexes, Eur. J. Pharm. Biopharm. 73 (2009) 121-129. https://doi.org/10.1016/j.ejpb.2009.05.002.

[45] F.J. Wang, C. Wang, Effects of fabrication conditions on the characteristics of etanidazole spray-dried microspheres, J. Microencapsul. 19 (2002) 495-510. https://doi.org/10.1080/02652040210140483.

[46] R. Vanbever, C. Bosquillon, C. Lombry, Influence of formulation excipients and physical characteristics of inhalation dry powders on their aerosolization performance, J Control Release. 70 (2001) 329-339. https://doi.org/10.1016/s0168-3659(00)00362-x.

[47] A.M. Healy, M.I. Amaro, K.J. Paluch, L. Tajber, Dry powders for oral inhalation free of lactose carrier particles, Adv. Drug Deliv. Rev. 75 (2014) 32-52. https://doi.org/10.1016/j.addr.2014.04.005.

[48] M.A.M. Momin, S. Sinha, I.G. Tucker, C. Doyle, S.C. Das, Dry powder formulation of kanamycin with enhanced aerosolization efficiency for drugresistant tuberculosis, Int. J. Pharm. 528 (2017) 107-117. https://doi.org/10.1016/j.ijpharm.2017.06.004.

[49] C. Bosquillon, V. Préat, R. Vanbever, Pulmonary delivery of growth hormone using dry powders and visualization of its local fate in rats, J. Control. Release. 96 (2004) 233-244. https://doi.org/10.1016/j.jconrel.2004.01.027.

[50] L. Li, S. Sun, T. Parumasivam, J.A. Denman, T. Gengenbach, P. Tang, S. Mao, H. Chan, L-Leucine as an excipient against moisture on in vitro aerosolization performances of highly hygroscopic spray-dried powders, Eur. J. Pharm. Biopharm. 102 (2016) 132-141. https://doi.org/10.1016/j.ejpb.2016.02.010. 
[51] S. Mangal, R. Xu, R. Guo, Q. (Tony) Zhou, H. Nie, A. Cavallaro, D. Zemlyanov, Physico-Chemical Properties, Aerosolization and Dissolution of Co-Spray Dried Azithromycin Particles with L-Leucine for Inhalation, Pharm. Res. 35 (2018). https://doi.org/10.1007/s11095-017-2334-9.

[52] K.A. Min, G.R. Rosania, C.-K. Kim, M.C. Shin, Functional and cytometric examination of different human lung epithelial cell types as drug transport barriers., Arch. Pharm. Res. 39 (2016) 359-69. https://doi.org/10.1007/s12272015-0704-6.

[53] International Organization for Standardization, ISO 10993 - Biological Evaluation of Medical Devices, 3rd ed., International Organization for Standardization, Switzerland, 2009.

[54] K.A. Foster, M.L. Avery, M. Yazdanian, K.L. Audus, Characterization of the Calu-3 cell line as a tool to screen pulmonary drug delivery, Int. J. Pharm. 208 (2000) 1-11. https://doi.org/10.1016/S0378-5173(00)00452-X.

[55] V. Vartiainen, L.M. Bimbo, J. Hirvonen, E.I. Kauppinen, J. Raula, Drug permeation and cellular interaction of amino acid-coated drug combination powders for pulmonary delivery, Int. J. Pharm. 504 (2016) 89-97. https://doi.org/10.1016/j.ijpharm.2016.03.052.

[56] W.-H. Lee, C.-Y. Loo, D. Traini, P.M. Young, Nano- and micro-based inhaled drug delivery systems for targeting alveolar macrophages, Expert Opin. Drug Deliv. 12 (2015) 1009-1026. https://doi.org/10.1517/17425247.2015.1039509.

[57] The World Health Organization, WHO consolidated guidelines on drug-resistant tuberculosis treatment, Geneva, 2019.

[58] C. Loira-Pastoriza, J. Todoroff, R. Vanbever, Delivery strategies for sustained drug release in the lungs, Adv. Drug Deliv. Rev. 75 (2014) 81-91. https://doi.org/10.1016/j.addr.2014.05.017.

[59] S. Katiyar, S. Bihari, S. Prakash, Low-dose inhaled versus standard dose oral form of anti-tubercular drugs: Concentrations in bronchial epithelial lining fluid, alveolar macrophage and serum, J. Postgrad. Med. 54 (2008) 245-246. https://doi.org/10.4103/0022-3859.41823.

[60] FDA, TOBI® PODHALER ${ }^{\mathrm{TM}},(2015)$. https://www.accessdata.fda.gov/drugsatfda_docs/label/2015/201688s006lbl.pdf (accessed April 29, 2020).

[61] K. McKeage, Tobramycin Inhalation Powder: A Review of Its Use in the 
973

974

975

976

977

978

979

980

981

982

983

984

985

986

987

988

989

990

991

992

993

994

995

996

997

998

999

1000
Treatment of Chronic Pseudomonas aeruginosa Infection in Patients with Cystic Fibrosis, Drugs. 73 (2013) 1815-1827. https://doi.org/10.1007/s40265-013-01410.

[62] R. Scherließ, C. Etschmann, DPI formulations for high dose applications Challenges and opportunities, Int. J. Pharm. 548 (2018) 49-53. https://doi.org/https://doi.org/10.1016/j.ijpharm.2018.06.038. 
1002

\begin{tabular}{|c|c|c|c|c|}
\hline $\begin{array}{l}\text { Cyclodextrin } \\
\text { condition }\end{array}$ & Solvent & $\begin{array}{l}\text { Molar proportion } \\
\text { CFZ:CD }(\mathrm{mM})\end{array}$ & $\begin{array}{c}\text { Temperature } \\
\left({ }^{\circ} \mathrm{C}\right)\end{array}$ & $\begin{array}{l}\text { Time } \\
\text { (h) }\end{array}$ \\
\hline$\beta C D \_a$ & Water & $1: 1 / 1: 2 / 1: 4 / 1: 6 / 1: 8 / 1: 10$ & 40 & 72 \\
\hline$\beta C D b$ & Ethanol:Water $(1: 1)$ & $1: 1 / 1: 2 / 1: 4 / 1: 6 / 1: 8 / 1: 10$ & 40 & 72 \\
\hline$\gamma \mathrm{CD} \_\mathrm{a}$ & Ethanol:Water (1:1) & $1: 1 / 1: 2 / 1: 4 / 1: 6 / 1: 8 / 1: 10$ & 40 & 72 \\
\hline 2-HPßCD_a & Ethanol:Water (1:1) & $1: 1 / 1: 2 / 1: 4 / 1: 6 / 1: 8 / 1: 10$ & 40 & 72 \\
\hline 2-HPßCD_b & Ethanol:Water (1:1) & $1: 1 / 1: 2 / 1: 4 / 1: 6 / 1: 8 / 1: 10$ & 40 & 72 \\
\hline 2-HPßCD_c & Ethanol:Water $(7: 3)$ & $1: 1 / 1: 5 / 1: 10$ & 50 & 72 \\
\hline 2-HPßCD_d & Ethanol:Water (4:6) & $1: 1 / 1: 5 / 1: 10$ & 40 & 72 \\
\hline 2-HP $\beta C D \_$e & Ethanol:Water (2:8) & $1: 1 / 1: 5 / 1: 10$ & 40 & 72 \\
\hline 2-HP $\beta \mathrm{CD}^{-} \mathrm{f}$ & Ethanol:Water (1:9) & $1: 1 / 1: 5 / 1: 10$ & 40 & 72 \\
\hline SBE $\beta C D \_a$ & Ethanol:Water (1:1) & $1: 1 / 1: 2 / 1: 4 / 1: 6 / 1: 8 / 1: 10$ & 30 & 144 \\
\hline $\mathrm{SBE} \beta C \mathrm{D}_{-}^{-} \mathrm{b}$ & Water & $1: 1 / 1: 2 / 1: 4 / 1: 6 / 1: 8 / 1: 10$ & 30 & 72 \\
\hline
\end{tabular}


1027 Table 2. The characteristic peaks of CFZ, CDs, physical mixture and their complexes in 1028 the XRPD diffractograms.

1029

Main peaks $2 \theta$ (degrees)

\begin{tabular}{lcccccccc}
\hline $\begin{array}{l}\text { 1CFZ:7 } \beta C D \\
\text { Spray dried }\end{array}$ & --- & --- & --- & --- & 13.1 & --- & 18.8 & --- \\
\hline $\begin{array}{l}\text { 1CFZ:7 } \beta C D \\
\text { Freeze dried }\end{array}$ & --- & 7.7 & --- & --- & 12.3 & --- & 18.3 & --- \\
\hline $\begin{array}{l}\text { Physical } \\
\text { mixture }\end{array}$ & 4.4 & --- & 8.9 & 10.5 & 12.4 & 15.3 & 19.5 & 22.7 \\
\hline$\beta C D$ & 4.5 & --- & 8.9 & 10.8 & 12.5 & 15.4 & 19.6 & --- \\
\hline Clofazimine & --- & --- & 9.2 & --- & 13.4 & --- & 19.8 & 22.0 \\
\hline
\end{tabular}

1030

1031

1032

1033

1034

1035

1036

1037

1038

1039

1040

1041

1042

1043

1044

1045

1046

1047

1048

1049

1050

1051

1052

1053

1054 
1055 Table 3. Clofazimine powder formulations and spray dryer settings.

1056

\begin{tabular}{|c|c|c|c|c|c|c|}
\hline \multirow[b]{2}{*}{ Formulation } & \multirow[b]{2}{*}{$\begin{array}{c}\text { Solid } \\
\text { constituents }\end{array}$} & \multirow[b]{2}{*}{$\begin{array}{c}\text { Liquid } \\
\text { constituents }\end{array}$} & \multicolumn{4}{|c|}{ Spray dryer settings } \\
\hline & & & $\begin{array}{c}\text { Inlet } \\
\text { temperature } \\
\left({ }^{\circ} \mathrm{C}\right)\end{array}$ & $\begin{array}{c}\text { Outlet } \\
\text { temperature } \\
\left({ }^{\circ} \mathrm{C}\right)\end{array}$ & $\begin{array}{l}\text { Pump } \\
\text { flow } \\
(\mathrm{L} / \mathrm{h})\end{array}$ & $\begin{array}{c}\text { Gas } \\
\text { flow } \\
(\mathrm{L} / \mathrm{min})\end{array}$ \\
\hline SP1 & $\begin{array}{c}\text { CFZ: } \beta C D \\
(1: 7)\end{array}$ & Ethanol:Water $(1: 1)$ & 95 & $45-48$ & 0.55 & 35 \\
\hline SP2 & $\begin{array}{c}\text { CFZ: } \beta C D \\
(1: 7)\end{array}$ & Ethanol:Water $(1: 1)$ & 65 & $41-43$ & 0.30 & 35 \\
\hline SP3 & $\begin{array}{c}\text { CFZ: } \beta C D \\
(1: 7) \\
\text { L-leucine } 10 \% \\
\end{array}$ & Ethanol:Water $(1: 1)$ & 65 & $41-43$ & 0.30 & 35 \\
\hline SP4 & $\begin{array}{c}\text { CFZ: } \beta C D \\
(1: 7) \\
\text { L-leucine } 15 \% \\
\end{array}$ & Ethanol:Water $(1: 1)$ & 65 & $37-42$ & 0.30 & 35 \\
\hline SP5 & $\begin{array}{c}\text { CFZ: } \beta C D \\
(1: 7) \\
\text { Isoleucine } 15 \% \\
\end{array}$ & Ethanol:Water $(1: 1)$ & 65 & $38-41$ & 0.30 & 35 \\
\hline SP6 & $\begin{array}{c}\text { CFZ: } \beta C D \\
(1: 7)\end{array}$ & Ethanol:Water (1:1) & 65 & $44-47$ & 0.35 & 35 \\
\hline SP7 & $\begin{array}{c}\text { CFZ: } \beta C D \\
(1: 7) \\
\text { L-leucine } 10 \%\end{array}$ & Ethanol:Water $(1: 1)$ & 65 & $44-47$ & 0.35 & 35 \\
\hline SP8 & $\begin{array}{c}\text { CFZ: } \beta C D \\
(1: 7) \\
\text { L-leucine } 15 \%\end{array}$ & Ethanol:Water $(1: 1)$ & 65 & $44-47$ & 0.35 & 35 \\
\hline SP9 & $\begin{array}{c}\text { CFZ: } \beta C D \\
(1: 7) \\
\text { L-leucine } 15 \% \\
\end{array}$ & $\begin{array}{c}\text { Ethanol:Water }(1: 1) \\
\text { Dichloromethane } \\
2 \% \\
\end{array}$ & 65 & $34-46$ & 0.35 & 35 \\
\hline
\end{tabular}

1057

1058

1059

1060

1061

1062

1063

1064

1065

1066

1067

1068

1069 
1070 Table 4. Bulk (b $\rho)$ and tapped density ( $\mathrm{t} \rho$ ), specific surface area (SSA) and aerodynamic

1071 characteristics of L-leucine free (SP6) and L-leucine spray dried formulations (SP7 -

1072 SP8).

1073

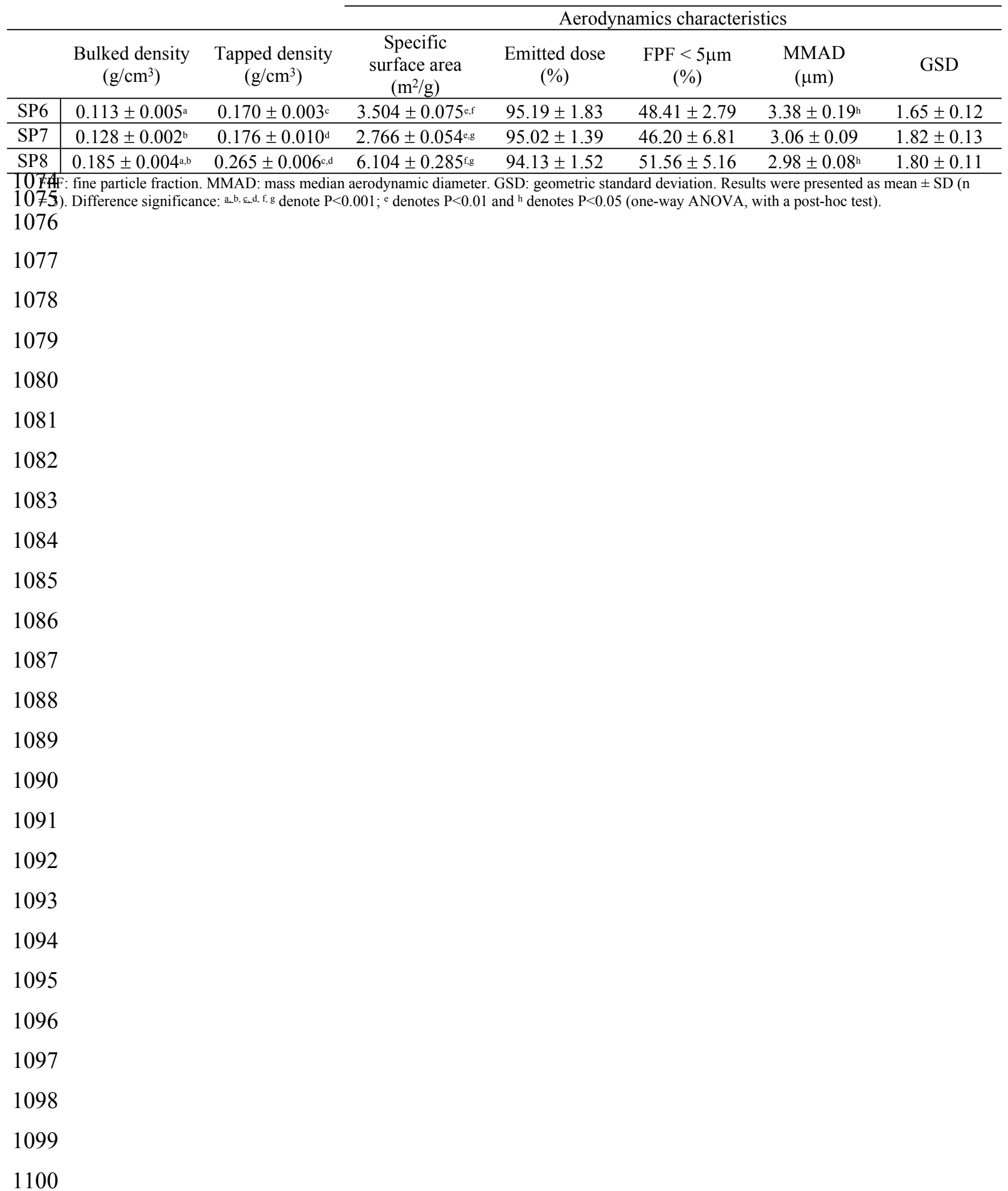


1103 Figure 1. Percentage of total mass of clofazimine recovered after complexation process.

1104 Each condition is described in Table 1. Results are presented as mean $\pm \operatorname{SD}(n=3)$.

1106 Figure 2. Clofazimine's phase solubility profile determined under different conditions

1107 (A) Condition $\beta C D \_a$ in Table 1: excess amount of CFZ was added to aqueous

1108 solutions containing increasing concentrations of $\beta C D(1-10 \mathrm{mM})$ and were stirred at 40

$1109{ }^{\circ} \mathrm{C}$ for $72 \mathrm{~h}$, and subsequently filtered through a $0.45 \mu \mathrm{m}$ membrane. (B) Condition

$1110 \quad \beta C D \_b$ in Table 1: excess amount of CFZ was added to ethanol:water (1:1) solutions

1111 containing increasing concentrations of $\beta C D(1-10 \mathrm{mM})$ and were stirred at $40{ }^{\circ} \mathrm{C}$ for 72

$1112 \mathrm{~h}$, and subsequently filtered through a $0.45 \mu \mathrm{m}$ membrane. "CE" was the complexation

1113 efficacy. Results are presented as mean $\pm \operatorname{SD}(n=3)$.

1115 Figure 3. DSC curves of CFZ systems and $\beta C D$ : (A) CFZ raw material; (B) $\beta C D$ raw 1116 material; (C) physical mixture of CFZ and $\beta C D$ raw materials; (D) inclusion complex, 1117 freeze-dried; (E) inclusion complex, spray-dried.

1119 Figure 4. XRPD diffractograms of CFZ from CSD (polymorph form I, DAKUI01) and

1120 CFZ raw material.

Figure 5. XRPD diffractograms of CFZ and $\beta C D$ systems: (A) CFZ raw material; (B) $\beta C D$ raw material; (C) spray-dried $\beta C D$; (D) physical mixture of $C F Z$ and $\beta C D$ raw materials; (E) inclusion complex, freeze-dried; (F) inclusion complex, spray-dried.

1126 Figure 6. FTIR spectra of CFZ and $\beta C D$ systems: (A) CFZ raw material; (B) $\beta C D$ raw 1127 material; (C) physical mixture of CFZ and $\beta C D$ raw materials; (D) inclusion complex, 1128 spray-dried. The dotted lines (---) and the circle indicates the main vibrational bands of 1129 CFZ (aromatic C-H stretching and $\mathrm{C}=\mathrm{N}$ stretching).

1131 Figure 7. 13C-CP/MAS NMR spectra of CFZ systems and $\beta C D$ : (A) CFZ raw material;

1132 (B) $\beta C D$ raw material; (C) physical mixture of CFZ and $\beta C D$ raw materials; (D)

1133 inclusion complex, freeze-dried. 
1135 Figure 8. Geometric mean diameter and polydispersity index (span) of raw material

1136 (CFZ and $\beta C D$ ) and spray dried formulations (SP). The SP formulation constituents and

1137 spray dryer settings are provided in Table 3 . Results are presented as mean \pm SD ( $\mathrm{n}=$

1138 3). Difference significance: * $\mathrm{P}<0.05$ and $* * * \mathrm{P}<0.001$ (one-way ANOVA, with a post-

1139 hoc test).

1140

1141 Figure 9. Scanning electron micrographs of physical mixture of CFZ and $\beta C D$ and

1142 spray dried formulations. (A) physical mixture of CFZ and $\beta C D$ raw materials; (B) SP6;

1143 (C) SP7; (D) SP8 and (E) SP9.

1144

1145 Figure 10. Water vapour isotherms (sorption and desorption). (a) SP6 - CFZ:ßCD (1:7);

1146 (b) SP7 - CFZ:ßCD (1:7) + L-leucine 10\% and (c) SP8 - CFZ:ßCD (1:7) + L-leucine

$1147 \quad 15 \%$

1148

1149 Figure 11. XRPD profile after DVS analyses. (A) SP6 - CFZ:ßCD (1:7); (B) SP7 -

1150 CFZ:ßCD (1:7) + L-leucine 10\% and (C) SP8 - CFZ:ßCD (1:7) + L-leucine 15\%.

1151

1152 Figure 12. In vitro aerosol deposition profile by use of NGI for spray dried formulations

1153 as calculated \% of recovered emitted dose vs. NGI stages. (A) SP6 - CFZ:ßCD (1:7);

1154 (B) SP7 - CFZ:ßCD (1:7) + L-leucine 10\% and (C) SP8 - CFZ:ßCD (1:7) + L-leucine

1155 15\%. MA: mouthpiece adapter / IP: induction port. MOC: micro-orifice collector.

1156 Results are presented as mean $\pm \mathrm{SD}(\mathrm{n}=3)$. Difference significance: $* * * \mathrm{P}<0.001$ (two-

1157 way ANOVA, with a post-hoc test).

1158

1159 Figure 13. Water solubility of clofazimine as free drug and formulations SP6 -

1160 CFZ:ßCD (1:7); SP7 - CFZ:ßCD (1:7) + L-leucine 10\% and SP8 - CFZ:ßCD (1:7) + L-

1161 leucine $15 \%$. The water $\mathrm{pH}=6.5$. n.d: not detected. Results are presented as mean $\pm \mathrm{SD}$

$1162(\mathrm{n}=3)$. Difference significance: $* * \mathrm{P}<0.01$ and $* * * \mathrm{P}<0.001$ (two-way ANOVA, with a

1163 post-hoc test).

1164

1165 Figure 14. (A) Viability of Calu-3 grown as cell layer after 24h exposure to 3.125 -

$116625 \mu \mathrm{M}$ of equivalent clofazimine. CFZ: Clofazimine raw material. CFZ: $\beta C D(1: 7)$

1167 complex . PM: physical mixture of CFZ and $\beta C D$ raw materials. (B) Viability of Calu-3

1168 grown as cell layer after $24 \mathrm{~h}$ exposure to $25-200 \mu \mathrm{M} \beta \mathrm{CD}$. Both experiments were 
1169 measured by MTT test (mean \pm SD, $\mathrm{n}=3$ ). The dotted lines mark $70 \%$ and $90 \%$

1170 viability. Difference significance: ** $\mathrm{P}<0.01$ and $* * * \mathrm{P}<0.001$ (two-way ANOVA, with

1171 a post-hoc test).

$1 \mid 172$

1173

Supplementary material:

1174

1175 Figure $\underline{S 1} 15$. TEER values of Calu-3 culture during the permeability study. Control: no 1176 treatment; CFZ: Clofazimine raw material; SP8: CFZ: $\beta C D(1: 7)+$ L-leucine 15\%. The 1177 measurements were at the sampling time points. 
1. Clofazimine: $\beta$-cyclodextrin (1:7) with L-leucine were submitted to spray drying.

2. Dry powder formulations showed suitable performance in Next Generation Impactor.

3. This inhalable formulation should improve clofazimine pulmonary bioavailability.

4. This study presented a potential local treatment for lung tuberculosis infection. 

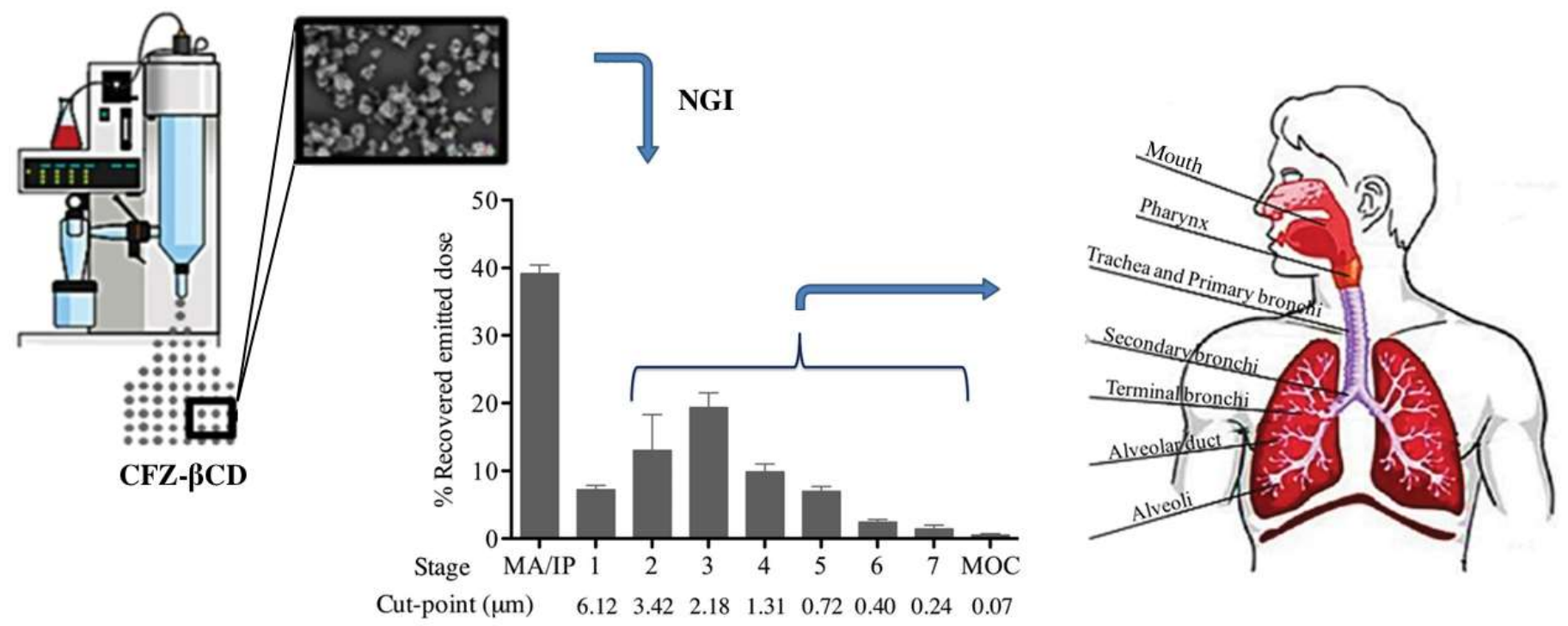


\section{Development of inhaled formulation of modified clofazimine as an 2 alternative to treatment of tuberculosis}

3 Renata Ribeiro de Castro $^{\mathrm{a}, \mathrm{b}}$, Valério Todaro ${ }^{\mathrm{c}}$, Luiz Claudio Rodrigues

4 Pereira da Silva ${ }^{a}$, Alice Simon ${ }^{a}$, Flavia Almada do Carmo ${ }^{a}$, Valeria Pereira

5 de Sousa ${ }^{\mathrm{a}}$, Carlos Rangel Rodrigues ${ }^{\mathrm{a}}$, Bruno Sarmento ${ }^{\mathrm{d}}$, Anne Marie 6 Healy ${ }^{\mathrm{c}}$, Lucio Mendes Cabral ${ }^{\mathrm{a}, *}$.

7 a Department of Drugs and Pharmaceutics, Faculty of Pharmacy, Universidade Federal 8 do Rio de Janeiro, Rio de Janeiro, Brazil

9 bundação Oswaldo Cruz, Farmanguinhos, Instituto de Tecnologia em Fármacos, Av.

10 Comandante Guaranys, Rio de Janeiro, Brazil

11 c School of Pharmacy and Pharmaceutical Sciences, Trinity College Dublin, Dublin 2, 12 Ireland

13 di3S - Instituto de Investigação e Inovação em Saúde, Universidade do Porto, Porto, 14 Portugal

* Corresponding author at: Department of Drugs and Pharmaceutics, Faculty of 16 Pharmacy, Universidade Federal do Rio de Janeiro, UFRJ, 21941-902 Rio de Janeiro, 17 RJ, Brazil, +55 2139386605

18 E-mail address: 1mcabral@pharma.ufrj.br (L.M. Cabral) 
Inhalation drug delivery provides a possible useful alternative to oral drug delivery in the treatment of tuberculosis (TB). This work evaluated inclusion complexes of clofazimine (CFZ), an anti-TB drug with low aqueous solubility and potential gastric degradation, in $\beta$-cyclodextrin $(\beta C D)$, $\gamma$-cyclodextrin, (2hydroxypropyl)- $\beta$-cyclodextrin and sulfobutyl-ether- $\beta$-cyclodextrin. A phase solubility study indicated that $\beta C D$ showed the best inclusion capacity for CFZ, so a CFZ:ßCD complex (1:7) was selected for further studies. Particle engineering was performed using spray drying to obtain powders with suitable characteristics for pulmonary delivery and L-leucine was added to enhance powder dispersibility. Thermal and spectroscopic analyses indicated the CFZ: $\beta C D$ integrity after spray drying, and the presence of L-leucine resulted in less hygroscopic and rougher particles, and a less agglomerated powder. All formulations, and especially those containing L-leucine, showed suitable in vitro deposition performance in the Next

40 Generation Impactor and presented higher aqueous solubility compared to the free 41 drug. In vitro studies showed low toxicity against Calu-3 and CFZ retention in the 42 cell monolayer and apical compartment. These results suggest that the inhalation 43 formulation composed of CFZ: $\beta C D$ plus L-leucine should improve CFZ 44 pulmonary bioavailability and provide an alternative treatment for $\mathrm{TB}$, acting on the main infection site of the disease.

Keywords: pulmonary delivery; tuberculosis; clofazimine; cyclodextrin; Lleucine

\section{Introduction}

Tuberculosis (TB) is an infectious disease caused by a unique pathogen, Mycobacterium tuberculosis (M. tuberculosis). TB is the ninth leading cause of death worldwide, ranking above HIV/AIDS. In 2017, the World Health Organization (WHO) estimated that 10.0 million people fell ill with TB (90\% adults) and there were 1.3 million deaths [1-3]. Although controlled in certain developing countries and industrialized areas, the current and continuous migratory movement from Asia and Africa (where there is a high incidence) is a potential risk to the spread of TB to Europe and North America [4]. The disease mainly affects the lungs (within alveolar 
macrophages and granulomas structures) but can also affect other sites [2]. Erratic and discontinuous treatments, associated with $M$. tuberculosis adapting mechanisms (efflux pump mechanisms) and population heterogeneity, have triggered multi-drug-resistant (MDR) strains of this mycobacteria and also extremely drug-resistant (XDR) strains [5,6]. Drug-resistant TB is a continuing threat since the first recorded case more than 12 years ago, and the development of new drugs or therapeutic strategies is necessary [4]. Inhalation is a non-invasive administration route used to deliver a drug substance into the lungs and treat local (asthma, cystic fibrosis) or systemic (diabetes, schizophrenia) diseases [7-9]. In recent years pulmonary drug delivery has received attention for TB treatment because it provides high drug concentrations at the main site of the disease, prevents hepatic-first pass metabolism and gastric intolerance and overcomes poor and erratic oral bioavailability of some drugs that are used in clinical practice $[10,11]$. The United States Pharmacopeia categorizes the dosage forms for pulmonary drug delivery into: (i) inhalation spray, (ii) inhalation solution, (iii) inhalation suspension, (iv) inhalation aerosols or metered-dose inhaler (MDI) and (v) inhalation powder or dry powder inhaler (DPI) [8]. DPIs are commonly employed in therapy for several reasons, including the fact that the formulation is propellant-free, while they also often offer better chemical stability, with a portable device which is easy to use [12].

The efficacy of formulations delivered by means of a DPI depends on the device delivery performance, breathing pattern of the patient, powder deposition pattern in the respiratory tract, the fine particle fraction (FPF) and the disease that is being treated [13]. The deposition site is determined in accordance with the aerosol aerodynamic properties, namely mass median aerodynamic diameter (MMAD) and geometric standard deviation (GSD); these parameters are derived from the aerodynamic particle size distribution (APSD) [7]. MMAD is the aerodynamic diameter $\left(\mathrm{d}_{\mathrm{a}}\right)$ for which $50 \%$ of the aerosol mass is above and below that diameter. GSD shows the level of dispersity of the aerosol particles. To avoid particle deposition in the upper respiratory tract (oropharyngeal and tracheo-bronchial region) and exhalation before deposition, it is desirable to obtain an MMAD of between 1 and $5 \mu \mathrm{m}$ and a GSD $<2$. Powder physicochemical properties and morphological characteristics of the particles also determine the deposition profile and drug bioavailability [7]. Additionally, the literature describes the use of different L-leucine concentrations (10-30\% w/w) in DPI 
91 formulations, as a dispersion aid, to obtain aerosol particles with the desired in vitro 92 deposition profile [14-18].

93 Once deposition occurs in the respiratory tract, the interaction between the particles and the biological environment also determines the therapeutic efficacy of the formulation. The interaction with mucus (aqueous mixture of glycoproteins), which is secreted in the upper airways, and pulmonary surfactant (90\% phospholipids and $10 \%$ proteins), which is secreted in the alveolar region of the lungs, is determined by the physicochemical characteristics of the particles, whereby hydrophilicity favors dissolution in the mucus. The mucus is a biological barrier that blocks the entrance of foreign microorganisms and substances, including drugs. The mucociliary clearance removes insoluble particles deposited in the trachea-bronchial region, within $24 \mathrm{~h}$, resulting in a short retention time in the lung [9]. Drug solubility in the mucus minimizes the mucociliary clearance effect, favoring the desired drug effect [19]. Lipophilic drugs tends to be insoluble in mucus and thereby exhibit reduced cell permeability $[19,20]$. On the other hand, insoluble particles $(1-2 \mu \mathrm{m})$ that reach the alveolar spaces tend to be internalized by macrophages (alveolar clearance), that are surrounded by a thin surfactant layer, and are able to reside for a long time inside them.

108 Thus macrophage uptake represents a strategy to combat microorganisms that infect this cellular type, such as in TB $[11,21]$.

The World Health Organization (WHO) recommends the use of oral

111 clofazimine (CFZ) in combination with other drugs for drug-resistant TB treatment, 112 although its efficacy and long-term safety have not yet been established [2,22]. CFZ's

113 poor clinical efficacy is strongly attributed to low aqueous solubility and gastric

114 degradation, resulting in suboptimal delivery to the target organ. On the other hand, in

115 vitro studies demonstrated good inhibitory activity against MDR strains (minimal

116 inhibitory concentration $0.5-2 \mathrm{mg} / \mathrm{L}$ ) [22]. In vivo studies showed that administration

117 of CFZ together with first or second-line anti-TB drugs promoted a 100 times reduction 118 of bacteria colony count in the lung, suggesting its potential to shorten the duration of 119 TB treatment $[23,24]$. These characteristics point towards CFZ as a potential drug for 120 pulmonary delivery.

121 The use of cyclodextrins (CD) in formulations has allowed many products 122 containing poorly soluble drugs to reach the market, and eventually help to treat many 123 life-threatening disease conditions [25]. The efficacy of CFZ inclusion complexes based 124 on sulfated CD has already been described in the literature, and they showed activity 
against Mycobacterium avium and Mycobacterium intracellulare [26]. The literature has also described the successful inclusion of CFZ into negatively charged sulfobutyl ether $\beta$-cyclodextrin (SBE $\beta C D)$ / epichoridrine oligomer to increase its water solubility and bioavailability [27]. Although the improved solubility results of the sulfated CDs are promising, the cost of these carriers are higher than the traditional (non-sulfated) CDs. Furthermore, in the previously reported studies powder products were not adjusted in terms of aerodynamic properties in order to optimize pulmonary drug delivery, since it was not the objective of these studies.

For these reasons, the aim of the present study was to prepare and undertake the physicochemical characterization of novel CFZ-CD and L-leucine-CFZ-CD complexes, developed to enhance CFZ aqueous solubility with a view to improving dissolution in lung mucus. Particle engineering via spray drying was performed to develop a dry powder formulation for the local delivery of CFZ to the lung.

\section{Materials and Methods}

\subsection{Materials}

Clofazimine (CFZ), (2-hydroxypropyl)- $\beta$-cyclodextrin (2-HPßCD), L-leucine and L-isoleucine were purchased from Sigma Aldrich (St Louis, USA). $\beta$-cyclodextrin $(\beta C D)$ and $\gamma$-cyclodextrin $(\gamma C D)$ were purchased from Wacker Chemie AG (Munich, Germany). Sulfobutyl ether $\beta$-cyclodextrin (SBEßCD) (Captisol ${ }^{\circledR}$ ) was kindly supplied by CyDex Pharmaceuticals (Kansas, USA). The organic solvents (Analytical Degree, A.D.), ethanol, dimethylsulfoxide and acetonitrile, were purchased from TEDIA BRAZIL (Rio de Janeiro, Brazil). Purified water for preparing solutions and performing HPLC studies was obtained by water distillation treatment (Quimis, Diadema, Brazil).

\subsection{Methods}

\subsubsection{Inclusion complex preparation}

154 Complexation efficacy studies were performed by adding an excess amount of CFZ to water or ethanol:water mixtures (from 7:3 to 0:1, ethanol:water) containing

156 increasing concentrations of a $C D(\beta C D, \gamma C D$, 2-HP $\beta C D$ or SBE $\beta C D)$, ranging from 1

157 to $10 \mathrm{mM}$ (Table 1). Each system was stirred at $30^{\circ} \mathrm{C}$ for $72 \mathrm{~h}, 40^{\circ} \mathrm{C}$ for $72 \mathrm{~h}, 50^{\circ} \mathrm{C}$ for $15872 \mathrm{~h}$ or $30^{\circ} \mathrm{C}$ for $144 \mathrm{~h}$, and subsequently filtered through a $0.45 \mu \mathrm{m}$ pore size filter 
membrane (ChromPure syringe filter, PVDF, $25 \mathrm{~mm}$ diameter). CFZ concentration in

160 solution was determined by HPLC with UV detection at $495 \mathrm{~nm}$, using the methodology

161 described below. Calculation of complexation efficacy (CE) was according to the

162 following equation [28]:

$$
\mathrm{CE}=\text { Slope / (1 - slope })
$$

164 Where "slope" was the slope of the complexation profile (concentration of CFZ on the $\mathrm{y}$-axis versus concentration of CD on the $\mathrm{x}$-axis).

The molar proportion of CFZ:CD was determined using the following equation [28]:

$$
\mathrm{CFZ}: \mathrm{CD}=1 \mathrm{CFZ}:(\mathrm{CE}+1) / \mathrm{CE}
$$

170 Where CE was the complexation efficacy according to the complexation profile.

The CD inclusion process was then performed by mixing CFZ and the CDs ( $\beta C D, \gamma C D, 2 H P \beta C D$ or SBE $\beta C D$ ) by the solution method, in purified water and ethanol:water (7:3) mixture, under agitation using the previously established ideal conditions/proportions. After cooling the mixture, it was filtered through a $0.45 \mu \mathrm{m}$ pore size filter membrane (ChromPure syringe filter, PVDF, $25 \mathrm{~mm}$ diameter), then ethanol was removed in a rotary evaporator Gehaka RD - 180 (Gehaka, São Paulo, Brazil) at 45 ${ }^{\circ} \mathrm{C}$ for $6 \mathrm{~h}$ and the sample was frozen using liquid nitrogen. The frozen sample was immediately submitted to lyophilization (as described below). The powder obtained was stored under a nitrogen atmosphere in a closed glass vial in a desiccator with silica gel.

Physical mixtures were prepared by pulverization and mixing CFZ and the CD (1:7 molar ratio) in a glass mortar.

\subsubsection{Determination of CFZ content}

The CFZ content in inclusion complex and permeation studies was determined by HPLC (Shimadzu, pump LC- 30AD, autosampler SIL-30AC, detector SPD-M 20A). A Perkin Elmer C18 column ( $150 \times 4.6 \mathrm{~mm}$, particle size $3 \mu \mathrm{m})$ was used at $35{ }^{\circ} \mathrm{C}$. The mobile phase was a mixture of methanol and phosphate buffer $(80: 20, \mathrm{v} / \mathrm{v})$, and the flow rate was $1.0 \mathrm{ml} / \mathrm{min}$. The elution was carried out isocratically and the injection volume was $20 \mu 1$. The eluant was monitored at $284 \mathrm{~nm}$. Retention time was 4 minutes. 
Freeze drying was carried out using a laboratory scale freeze dryer Liotop L101 (Liobras, São Carlos, Brazil). Each sample was frozen using liquid nitrogen and then freeze-dried for $72 \mathrm{~h}$ to allow the complete removal of water. The resulting powders were characterized by differential scanning calorimetry (DSC), X-ray powder diffraction (XRPD) and 13C-CP/MAS NMR spectroscopy. The freeze drying process was used only during preliminary drying evaluation studies; spray drying was used thereafter.

\subsubsection{Spray drying process}

Production of CFZ-CD inclusion complex or CFZ-CD inclusion complex/Lleucine or L-isoleucine complex spray dried powders was carried out using a laboratory scale spray dryer LabMaq MSD 1.0 (Labmaq do Brasil, Ribeirão Preto, Brazil) with a $0.7 \mathrm{~mm}$ nozzle tip. An ethanol-water solution (1:1) was prepared containing the CFZCD complex (1:7 molar ratio) and a total solute concentration of $0.70-0.85 \%(\mathrm{w} / \mathrm{v})$, depending on the L-leucine/isoleucine concentration. The amino acids, L-leucine or Lisoleucine, and the organic solvent dichloromethane were added after the preparation of the CFZ-CD inclusion complex in ethanol-water. Amino acid concentration ranged

211 from $10 \%$ to $15 \%(\mathrm{w} / \mathrm{w})$ in relation to the total solid amount, and the dichloromethane

212 concentration was $2 \%(\mathrm{v} / \mathrm{v})$. Spray drying parameters are presented in Table 3 . The

213 dichloromethane was used as a co-solvent (and potential "blowing/pore-forming agent")

214 due to its low boiling point $\left(39.8^{\circ} \mathrm{C}\right)$ and fast evaporation rate, allowing particle size

215 reduction and porosity increase [29-31]. Spray drying was used both to obtain the dry

216 complexes and to adjust the properties of these complexes in order to prepare

217 formulations that were suitable for pulmonary delivery. The resulting powders were

218 characterized by DSC, XRPD, Fourier-transform infra-red spectroscopy (FTIR),

219 dynamic vapour sorption (DVS), specific surface area analysis (SSA), particle sizing, 220 morphology, 13C-CP/MA NMR spectroscopy and aerodynamic assessment using a

221 Next Generation Impactor (NGI).

\subsubsection{Powder characterization}

A differential scanning calorimeter DSC-60 (Shimadzu, Kyoto, Japan) was used at a heating rate of $5{ }^{\circ} \mathrm{C} / \mathrm{min}$. Accurately weighed samples $(1-2 \mathrm{mg})$ were placed into sealed aluminum pans and heated from 30 to $300{ }^{\circ} \mathrm{C}$. 
XRPD patterns of raw materials, physical mixtures and inclusion complexes were obtained using a Lab X XRD-6100 X-ray (Shimadzu, Kyoto, Japan) with a Cu Ko line as the source of radiation. Measurements were carried out using a voltage of $40 \mathrm{kV}$, a current of $30 \mathrm{~mA}$ and a scanning rate of $2^{\circ} / \mathrm{min}$ over a range of $2^{\circ}-80^{\circ}$, on the two theta scale at a step size of $0.02^{\circ}$.

The infrared spectra of raw materials, physical mixtures and inclusion complexes were obtained from KBr pellets using a Prestige-21 spectrometer (Shimadzu, Kyoto, Japan). Spectra were recorded between 4000 and $600 \mathrm{~cm}^{-1}$ with a resolution of 4 $\mathrm{cm}^{-1}$

${ }^{13} \mathrm{C}$ solid-state NMR spectra were recorded on a Bruker Avance III 400 (9.4 T) spectrometer (Bruker, Massachusetts, USA), operating at 100.64 MHz. A CPMAS 3.2 $\mathrm{mm}$ probe head and $\mathrm{ZrO}_{2}$ rotors spinning at $9.3 \mathrm{KHz}$ were employed. Cross polarization magic angle spinning with ramp in the ${ }^{1} \mathrm{H}$ channel (CPMAS) combined with high power proton decoupling (HPDEC) were used as the pulse sequence. The contact time varied from $100 \mu \mathrm{s}$ to $10,000 \mu \mathrm{s}$. The recycle delay was $4 \mathrm{~s}$, and the $\pi / 2$ pulse length was $4 \mu \mathrm{s}$. The spectra were transformed after accumulation of 512 scans. The line broadening used to process the data was $20 \mathrm{~Hz}$. Adamantane ( $\mathrm{CH}$ at $29.46 \mathrm{ppm})$ was used as an external chemical shift reference.

Particle size distributions of prepared formulations for inhalation were determined using a Coulter Counter, Multisizer 4 (Beckman Coulter, California, USA). Each formulation was dispersed in an electrolyte solution (Isoton $\left.{ }^{\circledR}\right)$ and measurement was performed using an aperture tube size of $0.4-16 \mu \mathrm{m}$ and current of $600 \mu \mathrm{A}$.

Bulk density (b $\rho$ ) was calculated by determining the weight of powder required to occupy a $1 \mathrm{ml}$ volume in a graduated glass syringe, by pouring under gravity. The tapped density ( $\mathrm{t} \rho)$ was determined by vertically tapping this sample onto a level benchtop surface, from a height of $5 \mathrm{~cm}$, until there was no observed volume change (100 times) [29]. The tapped density was calculated as the ratio of the mass to the tapped volume of the sample. Each measurement was performed in triplicate. The theoretical aerodynamic diameter $\left(d_{a}\right)$ was calculated based on the following definition $d_{a}=$ $\sqrt{\mathrm{t} \rho} / \rho 1 . \mathrm{d}$; where $\rho 1=1 \mathrm{~g} / \mathrm{cm}^{3}$ and " $\mathrm{d}$ " is the geometric diameter of the particle [32].

The surface morphology of CFZ:CD complexes was observed using a scanning electron microscope (SEM), TM 3030 Plus (Hitachi, Tokyo, Japan). The SEM was operated under high vacuum, at $15 \mathrm{kV}$, small spot size, while images were acquired in 
the backscattered electrons mode (BSE) with an acceleration voltage of $15 \mathrm{kV}$ and a secondary detector. The powder was deposited on double-sided adhesive tape, vacuumcoated with gold and directly analyzed under SEM with magnifications of x500, x1000, x3000 and x5000.

The water vapour sorption-desorption isotherms of CFZ inclusion complexes were obtained by means of an automated gravimetric vapour sorption analyser, DVS Advantage-1 (Surface Measurements Systems). Samples were equilibrated at 0\% relative humidity $(\mathrm{RH})$ until a steady dry reference mass was recorded. The samples were exposed to the following RH profile: 0 - $90 \%$ in $10 \%$ steps and the reverse for desorption at $25.0 \pm 0.1^{\circ} \mathrm{C}$. At each stage, the sample mass was allowed to reach equilibrium (i.e. weight change over $10 \mathrm{~min}(\mathrm{dm} / \mathrm{dt}) \leq 0.002 \mathrm{mg} / \mathrm{min})$.

The specific surface area was determined by the Brunauer, Emmett, Teller (BET) isotherm method using a Micromeritics Gemini VI (Micromeritics, Norcross, USA) surface area analyser. The amount of nitrogen adsorbed at 6 relative pressure points in the relative pressure $(\mathrm{P} / \mathrm{Po})$ range of 0.05 to 0.3 , with an equilibration time of $10 \mathrm{~s}$, was used for the BET analysis. Each average result was calculated on the basis of three measurements.

\subsubsection{In vitro aerosol deposition studies using the Next Generation Impactor (NGI)}

The aerodynamic properties of the powders were assessed using an NGI (Copley Scientific Limited, Nottingham, UK), apparatus 5, operated under pharmacopeial conditions [8]. The flow rate was adjusted to achieve a pressure drop of $4 \mathrm{kPa}$ in the powder inhaler, (Handihaler ${ }^{\circledR}$, Boehringher Ingelheim, Ingelheim, Germany) and the time of aspiration was adjusted to obtain $4 \mathrm{~L}$ air flow. The pre-separator was used to remove coarse particles. The dry powder inhaler was loaded with a number 3 hard gelatin capsule loaded with $20 \pm 2 \mathrm{mg}$ of powder for each test. NGI stages (stages 1-7 and filter) were coated with $1 \mathrm{~mL}$ of HPLC mobile phase to wet the collection surfaces. The deposition profile of each formulation was determined in triplicate and the results presented are the average results of the replicated analyses. After dissolution in an appropriate volume of HPLC mobile phase, particle deposition in the device, the throat and all the stages and the filter was determined by the HPLC method described above.

291 Each test was repeated three times. The emitted recovered dose (ED) was determined as

292 the percent of total powder mass exiting the capsule and device. The total amount of 293 particles with aerodynamic diameters smaller than 5 and $3 \mu \mathrm{m}$ was calculated by 
interpolation from the inverse of the standard normal cumulative mass distribution less

295 than stated size cut-off against the natural logarithm of the cut-off diameter of the respective stages. This amount was considered as the fine particle fraction (FPF\%) below $5 \mu \mathrm{m}$ and $3 \mu \mathrm{m}$, and expressed as a percentage of the ED. The mass median aerodynamic diameter (MMAD) of the particles was determined from the same plot as the particle size corresponding to the $50 \%$ point of the cumulative distribution, and the geometric standard deviation (GSD) as GSD $=\sqrt{ }($ Size $X /$ Size $Y)$, where Size $X$ is the particle size corresponding to the $84 \%$ point and size $\mathrm{Y}$ is the particle size corresponding to the $16 \%$ point of the cumulative distribution.

\subsubsection{Solubility studies}

The solubility studies were determined using a shaker Innova 44 (New Brunswick Scientific, New Jersey, USA). It was performed by the $24 \mathrm{~h}$ shake flask method at $100 \mathrm{rpm}$ and $37^{\circ} \mathrm{C}$ (Wermuth, 2008; The Practice of Medicinal Chemistry, 3rd ed. Elsevier Ltd, p. 750). Therefore, an excess of pure CFZ, and formulations were individually added to $10 \mathrm{ml}$ of pure water in glass tubes. After the appropriate time, the tubes were opened, and the supernatant withdrawn and filtered through $0.45 \mu \mathrm{m}$ membrane filters (ChromPure syringe filter, PVDF, $25 \mathrm{~mm}$ diameter). CFZ concentrations in the supernatant were determined by HPLC as previously described.

\subsubsection{Cytotoxicity studies}

315 Exponentially growing human lung adenocarcinoma cells (Calu-3) were seeded

316 at an initial density of $5 \times 10^{4}$ cells $/ \mathrm{mL}$ in 96 -well plates in DMEM medium,

317 supplemented with $10 \%$ fetal bovine serum, $2 \mathrm{mM}$ L-glutamine, $1 \mathrm{mM}$ sodium pyruvate

318 and $1 \%$ penicillin/streptomycin. Cell cultures were then incubated at $37{ }^{\circ} \mathrm{C}$ in a

319 humidified, $5 \% \mathrm{CO}_{2}$ atmosphere, for $24 \mathrm{~h}$. After this time, the medium was removed

320 and replaced with fresh medium containing either pure $\beta C D(25-200 \mu \mathrm{M})$, pure $\mathrm{CFZ}$,

321 the physical mixture or the inclusion complex. All samples that contained CFZ ranged

322 from 3.125 to $25 \mu \mathrm{M}$, in relation to CFZ concentration. The plate was incubated at 37

$323{ }^{\circ} \mathrm{C}$ in a humidified, $5 \% \mathrm{CO}_{2}$ atmosphere. The highest concentration tested when $\mathrm{CFZ}$

324 was present was limited to the equivalent of pure CFZ solubility $(25 \mu \mathrm{M})$. Cell viability

325 was determined after $24 \mathrm{~h}$ by the 3-(4,5-dimethylthiazol-2-yl)-2,5- diphenyl-tetrazolium 326 bromide method (MTT) [33]. 
The absorbance was measured at $570 \mathrm{~nm}$ in a microplate reader, Perkin Elmer

328 Victor X5 (Perkin Elmer, Massachusetts, USA).

A second approach to cytotoxicity testing was used to evaluate the effect of

330 higher CFZ equivalent concentrations (50 and $100 \mu \mathrm{M})$ for a shorter incubation time

331 (4h). Results from this study were needed to support the permeability study conditions

332 (detailed below), where initial low drug concentration $(25 \mu \mathrm{M})$ were found to result in

333 levels falling outside the detection limit of the analytical method employed (HPLC)

334 after permeation. This issue has previously been reported for poorly water soluble

335 molecules in permeability testing [34].

336

\subsubsection{Permeability studies}

338 Calu-3 cells were cultured in DMEM medium, supplemented with $10 \%$ fetal bovine serum, $2 \mathrm{mM}$ L-glutamine, $1 \mathrm{mM}$ sodium pyruvate and $1 \%$ penicillin/streptomycin. Cell monolayers were obtained by seeding $5.5 \times 10^{5} \mathrm{cells} / \mathrm{cm}^{2}$ onto tissue culture inserts (Costar polyester filters, with a $1.12 \mathrm{~cm}^{2}$ growth surface area and $0.4 \mu \mathrm{m}$ pore size) placed in twelve-well plates and maintained at $37^{\circ} \mathrm{C}$ in a humidified, $5 \% \mathrm{CO}_{2}$ atmosphere. During the first seven days, cells were cultured under

344 liquid-liquid interface and growth medium $(0.5 \mathrm{ml}$ on the apical side and $1.5 \mathrm{ml}$ on the 345 basal side) was replaced with fresh medium every 2-3 days. From the eighth to twelfth day, cells were cultured in an air-liquid interface $(0.6 \mathrm{ml}$ on the basal side)

The epithelial monolayer confluence was estimated by visual inspection under an optical microscope. The monolayer integrity was evaluated by transepithelial electrical resistance (TEER) measurements, using a Millicell® ERS-2 (Merck Millipore, Massachusetts, USA). TEER was calculated by subtracting the resistance of a cell-free culture insert and correcting for the surface area of the Transwell cell culture support. The increase in the values of TEER accompanied the growth of cells in each filter to reach a constant value of $>700 \Omega \mathrm{cm}^{2}$, indicating suitable cellular maturity for the test [35]. TEER was measured at the beginning, during and after the experiment, to check cell layer integrity. Transport experiments were evaluated in the apical to basolateral direction and were carried out in Hank's Balanced Salt Solution (HBSS). The apical side was filled with $0.5 \mathrm{ml}$ of sample suspension $(100 \mu \mathrm{M}$, in relation to CFZ) and the basolateral side with $1.0 \mathrm{ml}$ of HBSS. After $0.5 \mathrm{~h}, 1 \mathrm{~h}, 2 \mathrm{~h}, 3 \mathrm{~h}$ and $4 \mathrm{~h}$ all the basolateral side volume was collected and immediately replaced with fresh HBSS.

360 At the last time point, the apical content was also collected. The cell monolayer was 
washed with HBSS and disrupted using DMSO (200 $\mu \mathrm{l})$, after which this volume was collected. CFZ concentration in all collected samples was determined by HPLC as previously described.

\subsubsection{Statistical analysis}

Results are presented as mean \pm standard deviation. Significant differences were evaluated using analysis of variance (ANOVA) with post-hoc test. All statistical analyses were performed with the software GraphPad Prism 5 (GraphPad Software Inc., San Diego, CA, USA).

\section{Results and Discussion}

\subsection{Inclusion complex preparation}

The efficacy of CFZ inclusion complexes based on sulfated CD has previously been described, showing these complexes' activity against two different TB strains ( $M$. avium/M. intracellulare) [26]. Thus, the use of CD to formulate a CFZ pulmonary delivery system was considered the first-choice option. This approach was reinforced by the reported successful inclusion of CFZ in negatively charged SBE $3 C D$ / epichoridrine oligomer to increase its water solubility and bioavailability [27].

The inclusion complexes between CFZ and the CDs $(\beta C D, \gamma C D, 2-H P \beta C D$ and SBE $\beta C D)$ were obtained using different conditions, described in Table 1.

The association efficiency between CFZ and each CD was verified after the inclusion process (Figure 1). It can be observed that $\beta C D$ (ethanol:water, $\beta C D \_b$ condition) provided the highest percentage of drug inclusion (included drug mass*100/total drug mass). The highest affinity of CFZ for $\beta C D$ compared to other CDs was an unexpected result, since other water insoluble drugs, such as curcumin, have shown higher affinities for more hydrophobic CDs, like RM $\beta C D$ (randomly methylated $\beta$-cyclodextrin) and $\mathrm{HP} \gamma \mathrm{CD}$ (hydroxypropyl- $\gamma$-cyclodextrin). Another interesting result was the low affinity observed for the negatively charged SBE $\beta C D$, when the least affinity observed for curcumin was for the cationic HTA $\beta C D$ (hydroxytrimethylamoniumpropyl- $\beta$-cyclodextrin) [36].

\subsection{Cyclodextrin Complexation studies}


395 (named $\beta C D \_b$, described in Table 1), which provided a higher percentage of recovered 396 CFZ, was 0.1738, with the ideal CFZ: $\beta$ CD molar ratio being 1:7. For comparative 397 purposes, the CE and the molar ratio were also determined for the $\beta C D \_a$ (water, in 398 Table 1) condition. Compared to the $\beta C D \_a$, the $\beta C D \_b$ condition, as expected, showed 399 greater $\mathrm{CE}$ and a molar ratio comprising 12-fold lower $\beta \mathrm{CD}$, compared to condition $400 \quad \beta C D \_a$. Figure 2 shows the complexing profiles between CFZ and $\beta C D$ under

401

402

403

404 405

406

407

408

409

410

411

412

413

414

415

416

417

418

419

420

421

422

423

424

425

426

427

conditions a and b. Phase solubility curves are represented as dissolved drug concentration against the concentration of $\beta C D$ used. The binding constant $(K)$ for complexes formed under conditions $\beta C D \_a$ and $\beta C D \_b$ were calculated from the slope of the straight-line portion of the curve, according to the following equation:

$$
\mathrm{K}=\text { slope } / \mathrm{S}_{0}(1-\text { slope })
$$

Where $S_{0}$ was the solubility of the drug in the absence of $\beta C D$. The obtained K value for the complex formed under condition $\beta C D \_b\left(5.03 \mathrm{M}^{-1}\right)$ was higher than that of the complex obtained under condition $\beta C D \_a\left(2.61 \mathrm{M}^{-1}\right)$, therefore, indicating a more stable complex for condition $\beta C D \_b$, using ethanol as co-solvent.

Despite the increased powder volume associated with a system comprised of drug and $C D$ in a 1:7 ratio, (i.e. $1 C F Z: 7 \beta C D$ ), the bulk of the formulation to be delivered is not of concern, since a reduction in the therapeutic concentration of the drug to be delivered (and the powder volume used, less than 100mg) is expected, due to an improvement in its bioavailability by means of pulmonary administration $[13,22]$

\subsection{Characterization studies}

The characterization studies of the complexes were performed on the dry powder obtained by lyophilization and spray drying, resulting from the complexation obtained under condition $\beta C D \_b(1 C F Z: 7 \beta C D)$. The inclusion of a molecule in the CD cavity generally promotes a change in the melting point, with a reduction in signal intensity or the disappearance of the fusion event signal in the DSC [37]. The thermograms of the raw materials (CFZ and $\beta C D$ ), physical mixture and the $1 \mathrm{CFZ}$ :7 $\beta C D$ complex powders (dried by lyophilization and spray drying) are shown in Figure 3. The CFZ has a typical DSC curve of a crystalline substance, i.e. with a sharp and narrow melting event with a peak at approximately $223^{\circ} \mathrm{C} . \beta \mathrm{CD}$ exhibits a large endothermic signal related to loss of 
water, peaking at $81.5^{\circ} \mathrm{C}$. The physical mixture presents the signal corresponding to the loss of water from $\beta C D$, followed by the melting peak of CFZ with a reduced signal intensity. The thermograms of the products obtained by lyophilization and spray drying maintained the thermal event related to the loss of water from the $\mathrm{CD}$, and show the disappearance of the drug melting peak, suggesting the formation of the inclusion complex in both cases (Figure 3). Thus, the use of the spray drying technique can be proposed for the formation of the complex, while optimizing the powder properties to obtain the desired pulmonary formulation.

At the same time, complexation of CFZ tends to promote changes in its diffractogram, seen as a signal shift or change in signal intensity when compared to isolated molecules or the physical mixture [37-39]. XRPD analysis of CFZ and $\beta C D$ demonstrates typical crystalline substance diffraction patterns, corresponding to those deposited in the Cambridge Structural Database (CSD). The diffraction pattern of the CFZ raw material was typical of polymorphic form I of the drug $(9.2,13.4,19.8$ and 21. $7^{\circ} 2 \theta$ ), according to CSD reference (DAKUI01), Figure 4. amorphization after processing, with broad peaks (at $6.6^{\circ}, 11.6^{\circ}$ and $18.3^{\circ} 2 \theta$ ) evident. In a previous study, Amaro et. al (2015), observed a similar diffraction pattern for spray-dried 2-HPßCD, with diffuse peaks in a similar position [40]. The diffraction pattern was reported to be associated with the molecular arrangement of the $\mathrm{CD}$ as a cup that can form small domains with some degree of short-range order. Despite this, the resulting powder was classified as amorphous [40]. The diffractogram of the physical mixture was similar to that of combined diffraction patterns of the individual raw materials (Figure 5). The physical mixture peak pattern (Table 2) indicated a simple mixture (lack of chemical interaction) as it was the sum of the diffraction peaks of the raw materials. On the other hand, for the inclusion complex a new peak (7.7 29), peak displacements $\left(12-13.4^{\circ}\right.$ and $\left.18.3-19.8^{\circ} 2 \theta\right)$ and peak absences $\left(4.5^{\circ}, 8.9-9.2^{\circ}, 10.8^{\circ}\right.$, $15.4^{\circ}$ and $22.0^{\circ} 2 \theta$ ) were observed (Table 2), indicating complex formation by means of CFZ- $\beta C D$ interaction. The DSC result presented in the previous section, corroborates with the XRPD result pointing to inclusion complex formation. The diffractogram of the 1CFZ:7 $\beta C D$ complex obtained by freeze drying exhibited broad peaks while spray drying appeared to promote a higher degree of amorphization, based on the XRPD patterns (Figure 5). The formation of completely or partially amorphous material can 
represent complex formation, but it can also be a characteristic resulting from

462 lyophilization and spray drying processes [15,41]. Therefore, XRPD results should be considered in association with results from thermal (DSC - described above) and spectroscopy analyses (discussed below) for the appropriate characterization of the inclusion complex [37].

The FTIR spectra of the dried complexes compared to the physical mixture and the raw materials, did not show any relevant alterations of the characteristic absorption peaks of CFZ, indicating only the presence of the drug, as shown in Figure 6.

Nuclear magnetic resonance (NMR) spectra can reveal more structural information of the analyzed material than the techniques used above, where the occurrence of a chemical shift $(\delta)$ in the carbon (13C) signals reveals the formation of an inclusion complex [37]. From the 13C-CP/MAS solid phase NMR spectra (Figure 7), the main signals $(60.77,72.89$ and $102.89 \mathrm{ppm})$ of the $\beta C D$ present in the physical mixture and the CFZ: $\beta C D$ complex (1:7) were analyzed. The CFZ: $\beta C D(1: 7)$ complex shows, in relation to $\beta C D$, chemical shift variations of $0.37 \mathrm{ppm}, 0.61 \mathrm{ppm}$ and 1.22 ppm, whereas in the physical mixture the same displacements were lower and correspond to $0.35 \mathrm{ppm}, 0.06 \mathrm{ppm}$ and $0.21 \mathrm{ppm}$. The change in multiplicity plus the greater variation in chemical displacement were indicative of inclusion complex formation. The CFZ signals were not exploited due to its low concentration in the complex.

\subsection{Spray drying for pulmonary delivery formulations}

Spray dryer settings and formulation constituents are known to influence the final particle properties, such as size, density, morphology and moisture content, which in turn determine powder aerosolisation characteristics and site of lung deposition [1,42-44]. Different formulations and spray drying conditions were evaluated, as presented in Table 3. The geometric mean diameter (GD) and the polydispersity index obtained for the different formulations are shown in Figure 8. The polydispersity index (span value) was calculated from the equation: $\left(d_{90}-d_{10}\right) / d_{50}$, where $d_{90}, d_{50}$ and $d_{10}$ correspond respectively to the geometric diameter of $90 \%, 50 \%$ and $10 \%$ of the distribution fraction (data not shown) $[15,40,42]$.

$493\left(11.59 \mu \mathrm{m}\right.$, Figure 8). The high inlet temperature $\left(95^{\circ} \mathrm{C}\right)$ and pump flow $(0.55 \mathrm{~L} / \mathrm{h})$ 
previously observed by Wang and Wang [45]. These authors indicated that the high temperature and flow caused, respectively, fast solvent evaporation and larger droplet size formation, and consequently a larger particle GD [45]. The inlet temperature was reduced to $65{ }^{\circ} \mathrm{C}$, as previously described in a study to determine the influence of spray dryer conditions on the preparation of a beclomethasone: $\gamma C D$ inclusion complex using

500 the same co-solvent system as used in this work [44]. The lower inlet temperature and

501 flow resulted in small but statistically insignificant decrease in GD for SP2 compared to 502 SP1 (Figure 8).

Formulations SP3-9 tested the inclusion of L-leucine or L-isoleucine to evaluate the influence of these excipients on particle size. These formulations were also finetuned with respect to amino acid concentration, pump flow and co-solvent used (Table 3). A pump feed increase to $0.35 \mathrm{~L} / \mathrm{h}$ for SP6, SP7 and SP8 formulations led to the lowest values of GD, corresponding to $5.73 \pm 1.20 \mu \mathrm{m}, 5.45 \pm 1.62 \mu \mathrm{m}$ and $2.18 \pm 0.110$ $\mu \mathrm{m}$, respectively, and narrowest size distribution, observed for SP8 (span=0.03). These GD values were promising with respect to the production of powder with appropriate aerodynamic characteristics for pulmonary delivery [7]. L-leucine addition led to a particle size reduction, while L-isoleucine (in SP5) did not. Likewise, the addition of $2 \%$ dichloromethane (SP9) did not result in a significant reduction in GD.

\subsection{Particle morphology}

The morphological evaluation of formulations SP6 to SP9 (Figure 9) revealed a near-spherical shape. Among the formulations spray dried from ethanol:water (1:1) and with the same spray drying conditions (SP6 - SP8), L-leucine incorporation led to the production of powders comprised of fewer agglomerates, with a more homogeneous size distribution and particle surfaces that were slightly corrugated, consistent with previous reports $[14,15]$. The lesser agglomeration and increased particle corrugation may favor powder dispersibility and the effective fraction of breathable powder $(<5 \mu \mathrm{m})$ [46]. The SP9 formulation (CFZ: $\beta C D+$ L-leucine 15\%, dispersed in dichloromethane $2 \%$, in addition to ethanol:water), differs considerably in its appearance from the other powders, since the particles appear to be cohesive, forming rod structures with smooth surfaces, i.e., without pores (unlike what may have been expected when using a blowing agent). A more heterogeneous particle size distribution (larger span) was measured for this system (Table 3 ). 


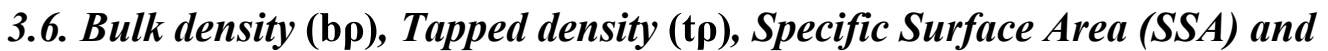

530

531

532

533

534

535

536

537

538

539

540

541

542

543

544

545

546

547

548

549

550

551

552

553

554

555

556

557

558

559

560

561

562

\section{Aerodynamic Characteristics}

The $b \rho, t \rho$, SSA and the aerodynamic characteristics were measured for formulations with greatest potential for pulmonary delivery (SP6, SP7 and SP8), given their GD and morphology (Table 4). The b $\rho$ and t $\rho$ ranged between 0.113 and 0.265 $\mathrm{g} / \mathrm{cm}^{3}$ and were considered suitable for pulmonary delivery, as previously reported by some authors $\left(<0.3 \mathrm{~g} / \mathrm{cm}^{3}\right)[15,43,47]$. The theoretical $d_{a}$ calculated from t $\rho$ and GD for SP6, SP7 and SP8 were $2.36 \mu \mathrm{m}, 2.28 \mu \mathrm{m}$ and $1.12 \mu \mathrm{m}$ respectively, further indicating suitability for pulmonary delivery $(1-5 \mu \mathrm{m})$ [9]. The L-leucine promoted an increase in b $\rho$ and $t \rho$, related to the higher solid content and formation of dense particles, in agreement with previously reported data [15]. As expected, when compared to the other formulations, the presence of $15 \%$ L-leucine significantly increased the SSA $(\mathrm{P}<0.001)$ due to the formation of rougher/corrugated/more textured particles (Figure 9-D) [1]. The roughness tends to reduce the interparticle contact, thus favoring powder dispersibility. The aerodynamic behavior of the formulation is influenced by the interrelationship of factors related to the particle (geometric diameter, morphology, surface area) and to the powder (b $\rho, \mathrm{t} \rho$, hygroscopicity). The emitted recovered dose (ED) (i.e. total dose less the amount remaining in the capsule and device) for all evaluated formulations was similar, and high (94.13 to 95.19\%). This result indicated adequate release from the capsule and the inhalation device and at the same time demonstrated good powder flow properties. The addition of L-leucine did not change the $\% \mathrm{ED}$ (probably due to the fact that the \%ED for the equivalent formulation without leucine was already high). Previous studies have commonly indicated an increased ED corresponding to the presence and increasing concentration of this amino acid $[17,48]$. However, here the fine particle fraction (FPF) of the selected formulations ranged from 46.20 to $51.56 \%$, with no significant difference between different formulations S6, S7, S8. A comparison between MMADs (Table 4) and theoretical aerodynamic diameter values for SP6 - SP8 (given above) showed that MMAD $>d_{a}$ in all cases, suggesting that during aerosolisation, the powder remains aggregated rather than behaving as individual particles. Other researchers had already noted the same MMAD $>d_{a}$ relation, with an even larger difference between values [32,49]. However, despite the aggregates, approximately fifty percent of ED corresponded to FPF in all tested formulations. The MMAD of all formulations was less than $5 \mu \mathrm{m}$ and the geometric standard deviation (GSD) was less than 2. These were considered adequate values for pulmonary 
563 formulations and delivery, since the combination of these parameters indicates a narrow particle size distribution in the FPF region $[11,43]$.

\subsection{Dynamic vapour sorption (DVS)}

DVS analysis was performed to evaluate the behavior of SP6, SP7 and SP8 formulations when exposed to different moisture conditions (Figure 10). The adsorption isotherms of the formulations evaluated were similar and showed considerable incorporation of vapor (water) even at low relative humidities (RH). As expected, due to the amorphous characteristics of these powders, the three formulations exhibited considerable and continuous mass gain with increasing relative humidity (RH). Li et. al. (2016) demonstrated that water uptake by spray dried L-leucine alone was very low $(<1 \%)$ at $90 \% \mathrm{RH}$, being classified as non-hygroscopic. Thus, the L-leucine contribution to water uptake when incorporated in a powder should be insignificant [50]. However, the presence of L-leucine made the water sorption both slower and overall lower and provided some protection to the powder against increasing relative humidity. When comparing the formulations containing L-leucine (SP7 and SP8) to that without (SP6), it was observed that, up to $80 \% \mathrm{RH}$, the weight gain due to water sorption was much lower for the L-leucine-containing formulations, but from $90 \% \mathrm{RH}$ the difference in the sorption profiles was negligible. At the end of the sorption process, the mass increase was $23.22 \%, 22.03 \%$ and $19.78 \%$ for the formulations SP6, SP7 and SP8 respectively, demonstrating the anti-hygroscopic effect of L-leucine $[48,50]$. The absence of inflection in the adsorption isotherms indicated the absence of recrystallization for all formulations. The diffractograms obtained after the DVS runs (Figure 11) still demonstrated high degrees of amorphization. The broad peaks in the XRPDs can be attributed to the spray-dried $\beta C D$ which was present in a large proportion in all formulations. The peak position displacements for the complexes

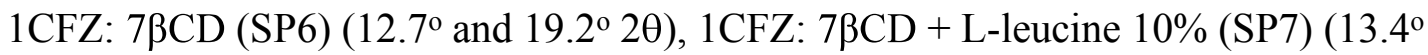
and $\left.19.3^{\circ} 2 \theta\right)$ and 1CFZ: $7 \beta C D+$ L-leucine $15 \%$ (SP8) $\left(6.2^{\circ}, 13.6^{\circ}\right.$ and $\left.19.1^{\circ} 2 \theta\right)$ when compared to spray-dried $\beta \mathrm{CD}\left(6.6^{\circ}, 11.6^{\circ}\right.$ and $18.3^{\circ} 2 \theta$ - Figure $\left.5 \mathrm{C}\right)$ can be explained by differences in powder composition, leading to slight variations in molecular

593 interactions. In addition, the diffractogram of spray-dried L-leucine after the DVS 594 analysis exhibited peaks at $2 \theta$ of $6.2^{\circ}$ and $19.1^{\circ}$, as previously reported [15]. The intensity of the peak ranging in position from $19.1^{\circ}$ to $19.3^{\circ} 2 \theta$ reflected the L-leucine 
content variation in formulations SP6-8 (Figure 11). For the desorption in the range of

$59780-10 \%$, the presence of L-leucine slowed down the water loss. However, after the desorption process, all formulations returned to the initial mass levels, indicating a reversible water sorption process.

600

\subsection{In vitro aerosol deposition studies using the Next Generation Impactor (NGI)}

The deposition profiles of SP6, SP7 and SP8 formulations show that 58-62\% of emitted dose (ED) was able to cross the mouthpiece adapter/induction port (MA/IC), which in vivo would correspond to the oro-pharyngeal region and indicates suitability for deposition in the respiratory tract (Figure 12). Particle deposition on MA/IC can be explained by agglomerate formation as a consequence of powder hygroscopicity, due to its amorphous state. Regarding the NGI stages, the particle deposition of the evaluated formulations at a $100 \mathrm{~L} / \mathrm{min}$ flow rate was concentrated in stages 2, 3 and 4, which have cut-off diameters of $3.42 \mu \mathrm{m}, 2.18 \mu \mathrm{m}$ and $1.31 \mu \mathrm{m}$ respectively [8]. Stage 2 was the only one that exhibited significant deposition differences $(\mathrm{P}<0.001)$ between formulations SP6 (without L-leucine) and SP8 (L-leucine 15\%). The higher SP6 deposition was in line with its larger MMAD $(3.38 \pm 0.19 \mu \mathrm{m}$ for SP6 compared to $2.98 \pm 0.08 \mu \mathrm{m}$ for SP8) and the stage cut-off diameter $(3.42 \mu \mathrm{m})$. The SP8 formulation presented lower deposition at this stage, which is an advantage and can enable better pulmonary retention. The percentage of particle deposition in the stages corresponding to the lower respiratory tract (stages $3-7$ ) was $30-40 \%$, with, perhaps surprisingly, no significant difference between formulations with or without L-leucine, in spite of significant difference in SSA $(\mathrm{P}<0.001)$ and MMAD $(\mathrm{P}<0.05)$ for SP8 (with $15 \%$-leucine) compared to other formulations.

When considering exclusively the aerodynamic powder characteristics, the formulations SP6 - SP8 all showed appropriate parameters for use in a DPI. Efficacy tests should be performed in the future to confirm this hypothesis.

\subsection{Solubility studies}

The aqueous solubility of SP6, SP7 and SP8 formulations were evaluated

626 (Figure 13). When compared to the free drug, formation of the CFZ: $\beta C D$ complex (1:7) 627 increased the aqueous solubility of CFZ by sixteen-fold $(\mathrm{P}<0.001)$ and incorporation of $62810 \%$ L-leucine, promoted an even greater increase (almost twenty seven-fold). A further 629 increase in L-leucine content from $10 \%$ to $15 \%$ did not modify the water solubility of 
630 the complex $(\mathrm{P}>0.05)$. The $\mathrm{CFZ}$ solubility improvement when complexed with $\beta \mathrm{CD}$

631 may be explained not only by their association, but also by the formation of amorphous 632 particles during the spray drying process [1,25]. On the other hand the L-leucine effect 633 on solubility is likely to be due to its surfactant-like properties [17], which has already 634 been observed for azithromycin co-spray-dried particles [51]. The higher solubility for 635 L-leucine containing formulations improves their therapeutic potential, since they may 636 be better able to overcome the mucus barrier, present prolonged lung retention time and 637 higher CFZ bioavailability.

638

\subsection{Cytotoxicity studies}

640 The in vitro cytotoxicity of free CFZ and $\beta C D$, and the CFZ: $\beta C D$ complex,

641 Figure 14, was evaluated after 24 h exposure in a Calu-3 cell line, due to its

642 representativeness of the constituents of the respiratory tract [52]. The cytotoxicity

643 assay was performed not only to identify the cytotoxicity of the raw material itself, but 644 also to identify if the complexation could reduce this. The $\beta C D$ complex revealed $>90 \%$ 645 cell viability even when exposed to the highest equivalent CFZ concentration $(25 \mu \mathrm{M})$.

646 This value was not significantly different from that observed for CFZ or a CFZ-CD 647 physical mixture. The $\beta C D$ toxicity at Calu-3 cells (Figure 14B) revealed that it was 648 dependent on $\beta C D$ concentration. Cell viability for a $\beta C D$ concentration $\leq 50 \mu \mathrm{M}$ was 649 higher than $90 \%$, while it was higher than $70 \%$ for a concentration of $200 \mu \mathrm{M}$. These 650 results indicated a high tolerability of Calu-3 cells for the CFZ: $\beta C D$ complex, enabling 651 its lung administration. The international guide ISO 10993-5, states that cell viabilility $>$ $70 \%$ is not considered a cytotoxic effect [53]. The cytotoxicity test based on the cell viability assay condition to inform the permeability study used CFZ equivalent concentrations of $50-100 \mu \mathrm{M}$ incubated for $4 \mathrm{~h}$. Cell viability results were: (i) for the free CFZ: $78.2 \pm 9.9 \%(50 \mu \mathrm{M})$ and $77.0 \pm 6.1 \%(100 \mu \mathrm{M})$; and (ii) for SP8 formulation

656 (selected for permeability study, as justified in the next section): $75.1 \pm 11.34 \%$ (50 $\mu \mathrm{M})$ and $72.5 \pm 3.9 \%(100 \mu \mathrm{M})$. Then, in terms of cytotoxicity, these results demonstrated the suitability of both concentrations for permeability studies and $100 \mu \mathrm{M}$ was the concentration selected for this study.

660

\subsection{Permeability studies}


663 for drug delivery in the respiratory tract [54]. Because of its lower MMAD $(2.98 \mu \mathrm{m})$,

664 higher FPF (51.6\%), promising deposition profile, improved water solubility and

665 specially low hygroscopicity compared to other tested formulations, SP8 was selected

666 for this evaluation. The formulation was added as a suspension to the surface of the

667 Calu-3 monolayer, as reported in other studies [55]. The maintenance of the integrity of

668 the monolayer was confirmed by the stability of TEER values, which was verified

669 during and after the experiment (Figure S1). After $4 \mathrm{~h}$, there was no CFZ detected in the

670 basolateral compartment for wells containing the free drug or for SP8. The

671 quantification of intracellular CFZ was similar for the free drug $(44.4 \pm 14.0 \%)$ and for

672 SP8 $(43.7 \pm 4.6 \%)$, indicating that both exhibit the same penetrating capacity in the

673 monolayer and availability for local action in the lungs. This result points to the

674 possibility of obtaining a high drug concentration directly at the site of pulmonary

675 infection and thus a more effective therapy, while minimizing systemic CFZ

676 biodistribution and toxicity. Hence, reducing systemic side effects like reddish-brown

677 discoloration of the skin and conjunctiva [22], a relevant issue at TB prolonged

678 treatment regime (minimum 6 months) [2,10]. At the same time, pulmonary delivery of

679 CFZ microparticles can be an interesting strategy to improve mycobacteria death by

680 favoring two inherent mechanisms: (i) CFZ distribution to the mononuclear phagocyte 681 system, and (ii) the macrophages uptake of microparticles [10,56]. In addition, the CFZ 682 inside macrophages also can act as a drug reservoir, prolonging the residence time at the 683 lungs, reaching granulomas and supporting the TB latent cases treatment [10].

684

\subsection{Pulmonary dose calculation}

686 The CFZ WHO treatment regimen for TB has established a daily oral dose of $687100 \mathrm{mg}$ [57], this drug also has an oral bioavailability of 45-62\% [22]. The calculation 688 of the inhaled estimated dose $(4.5 \mathrm{mg} /$ day $)$ considered that the pulmonary delivery drug 689 amount usually is about ten-times lower compared to oral one [43,58,59]. Considering 690 that the best formulation (SP8) exhibited a drug:powder ratio of about 1:20 (w/w), the 691 total powder mass amount was of $89.3 \mathrm{mg} /$ day. This mass is smaller than those of the 692 marketed tobramycin and colistimethate dry powder inhaled formulation, and like the 693 examples can be used in multiple doses or inhalations [60-62].

694

695

\section{Conclusions}


In the present study, CFZ:CD complexes were studied with a view to developing pulmonary delivery systems for TB treatment. We produced inhalable microparticles of 698 CFZ:CD by spray drying to facilitate the particle formation process, with water soluble

699 CD complex formation, able to overcome the mucus barrier and prolong the lung 700 retention time. The 1CFZ:7CD complex improved the CFZ water solubility and L701 leucine incorporation promoted an even greater solubility. Inhalable microparticles were 702 produced under optimized spray drying conditions of: $65^{\circ} \mathrm{C}$ inlet temperature, $0.35 \mathrm{~L} / \mathrm{h}$ pump rate, and $35 \mathrm{~L} / \mathrm{min}$ gas flow rate. DPI formulations with or without L-leucine were developed, comprising suitable aerodynamic properties and improved CFZ water solubility. The addition of $15 \%$ L-leucine had the advantage of reducing powder hygroscopicity while also enhancing in vitro powder deposition in the lower airways. In vitro studies showed a viability of at least $70 \%$ for Calu-3 cells after 24 hours of exposure to $\mathrm{CFZ}$ and $\beta C D$ (high concentrations) and permeability testing indicated that the drug was retained at the apical compartment and achieved cellular internalization. The inhaled estimated dose was $4.5 \mathrm{mg}$ in a powder mass of $89.3 \mathrm{mg} /$ day, allowing dry powder device use.

In conclusion, the current work presented dry powder formulations for inhalation of cyclodextrin complex representing a potential new local treatment for lung tuberculosis infection and should be tested in vivo in the near future.

Data availability: The dataset analyzed during the current study is available from the corresponding author on reasonable request. Data generated during this study are included in this published article.

Declaration of interest: None.

Acknowledgements: This work was supported by Fundação de Amparo à Pesquisa do Estado do Rio de Janeiro (FAPERJ); Conselho Nacional de Desenvolvimento Científico e Tecnológico (CNPq) and Coordenação de Aperfeiçoamento de Pessoal de Nível Superior (CAPES). A.M. Healy acknowledges Science Foundation Ireland grants cofunded under the European Regional Development Fund (SFI/12/RC/2275 and $\left.\mathrm{SFI} / 12 / \mathrm{RC} / 2275 \_\mathrm{P} 2\right)$.

\section{References}


[1] R. Vehring, Pharmaceutical particle engineering via spray drying, Pharm. Res. 25

[2] WHO, Global Tuberculosis Report, 2017.

733 [3] I. Smith, Mycobacterium tuberculosis pathogenesis and molecular determinants of virulence, Clin. Microbiol. Rev. 16 (2003) 463-496. https://doi.org/10.1128/CMR.16.3.463.

[4] S. Giovagnoli, A. Schoubben, M. Ricci, The Long And Winding Road To Inhaled TB therapy: not only the bug's fault, Drug Dev. Ind. Pharm. 43 (2017) 347-363. https://doi.org/10.1080/03639045.2016.1272119.

5] Evangelopoulos, J. Diniz, S.J. Waddell, Understanding anti-tuberculosis drug efficacy : rethinking bacterial populations and how we model them, Int. J. Infect. Dis. 32 (2015) 76-80. https://doi.org/10.1016/j.ijid.2014.11.028.

[6] C.M. Pule, S.L. Sampson, R.M. Warren, P.A. Black, P.D. van Helden, T.C. Victor, G.E. Louw, Efflux pump inhibitors: Targeting mycobacterial efflux systems to enhance TB therapy, J. Antimicrob. Chemother. 71 (2016) 17-26. https://doi.org/10.1093/jac/dkv316.

[7] M. Ibrahim, R. Verma, L. Garcia-Contreras, Inhalation drug delivery devices: technology update., Med. Devices (Auckl). 8 (2015) 131-9. https://doi.org/10.2147/MDER.S48888.

[8] US Pharmacopeial Convention, Inhalation and nasal drug products: aerosols, sprays and powders - performance quality tests, in: United States Pharmacop., 2017: pp. 472-498.

[9] H.G. Lee, D.W. Kim, C.W. Park, Dry powder inhaler for pulmonary drug delivery: human respiratory system, approved products and therapeutic equivalence guideline, J. Pharm. Investig. 48 (2018) 603-616. https://doi.org/10.1007/s40005-017-0359-z.

[10] P. Muttil, C. Wang, A.J. Hickey, Inhaled drug delivery for tuberculosis therapy, Pharm. Res. 26 (2009) 2401-2416. https://doi.org/10.1007/s11095-009-9957-4.

[11] J.S. Patton, P.R. Byron, Inhaling medicines: Delivering drugs to the body through the lungs, Nat. Rev. Drug Discov. 6 (2007) 67-74. https://doi.org/10.1038/nrd2153.

[12] M.Y. Yang, J.G.Y. Chan, H.K. Chan, Pulmonary drug delivery by powder aerosols, J. Control. Release. 193 (2014) 228-240. https://doi.org/10.1016/j.jconrel.2014.04.055. 
[13] N.R. Labiris, M.B. Dolovich, Pulmonary drug delivery . Part I : Physiological factors affecting therapeutic effectiveness of aerosolized medications, J Clin Pharmacol. 56 (2003) 588-599. https://doi.org/10.1046/j.13652125.2003.01892.x.

[14] A. Barazesh, K. Gilani, M. Rouini, M. Ali, Effect of $\mathrm{pH}$ and leucine concentration on aerosolization properties of carrier-free formulations of levofloxacin, Eur. J. Pharm. Sci. 118 (2018) 13-23. https://doi.org/10.1016/j.ejps.2018.03.002.

[15] A. Simon, M.I. Amaro, L.M. Cabral, A.M. Healy, V.P. De Sousa, Development of a novel dry powder inhalation formulation for the delivery of rivastigmine hydrogen tartrate, Int. J. Pharm. 501 (2016) 124-138. https://doi.org/10.1016/j.jpharm.2016.01.066.

[16] S. Arora, M. Haghi, P.M. Young, M. Kappl, D. Traini, S. Jain, Highly respirable dry powder inhalable formulation of voriconazole with enhanced pulmonary bioavailability, Expert Opin. Drug Deliv. 13 (2016) 183-193. https://doi.org/10.1517/17425247.2016.1114603.

[17] N.Y.K. Chew, B.Y. Shekunov, H.H.Y. Tong, A.H.L. Chow, C. Savage, J. Wu, H.K. Chan, Effect of amino acids on the dispersion of disodium cromoglycate powders, J. Pharm. Sci. 94 (2005) 2289-2300. https://doi.org/10.1002/jps.20426.

[18] B. Lamy, D.R. Serrano, P. O'Connell, W. Couet, S. Marchand, A.M. Healy, F. Tewes, Use of leucine to improve aerodynamic properties of ciprofloxacinloaded maltose microparticles for inhalation, Eur. J. Pharm. Res. 1 (2019) 02-11. https://doi.org/10.34154/2019-ejpr.01(01).pp-02-11/euraass.

[19] A. Hidalgo, A. Cruz, J. Pérez-Gil, Barrier or carrier? Pulmonary surfactant and drug delivery, Eur. J. Pharm. Biopharm. 95 (2015) 117-127. https://doi.org/10.1016/j.ejpb.2015.02.014.

[20] H.H. Sigurdsson, J. Kirch, C. Lehr, Mucus as a barrier to lipophilic drugs, Int. J. Pharm. 453 (2013) 56-64. https://doi.org/10.1016/j.jpharm.2013.05.040.

[21] J.B. Torrelles, L.S. Schlesinger, Integrating Lung Physiology, Immunology, and Tuberculosis, Trends Microbiol. 25 (2017) 688-697. https://doi.org/10.1016/j.tim.2017.03.007.

[22] M.C. Cholo, H.C. Steel, P.B. Fourie, W.A. Germishuizen, R. Anderson, Clofazimine: Current status and future prospects, J. Antimicrob. Chemother. 67 (2012) 290-298. https://doi.org/10.1093/jac/dkr444. 
[23] S. Tyagi, N.C. Ammerman, S.Y. Li, J. Adamson, P.J. Converse, R. V. Swanson, D. V. Almeida, J.H. Grosset, Clofazimine shortens the duration of the first-line treatment regimen for experimental chemotherapy of tuberculosis, Proc. Natl. Acad. Sci. U. S. A. 112 (2015) 869-874. https://doi.org/10.1073/pnas.1416951112.

[24] N.C. Ammerman, R. V Swanson, A. Tapley, C. Moodley, B. Ngcobo, J. Adamson, A. Dorasamy, S. Moodley, Z. Mgaga, L.A. Bester, S.D. Singh, D. V Almeida, J.H. Grosset, Clofazimine has delayed antimicrobial activity against Mycobacterium tuberculosis both in vitro and in vivo, J. Antimicrob. Chemother. 72 (2016) 455-461. https://doi.org/10.1093/jac/dkw417.

[25] T. Loftsson, M.E. Brewster, Pharmaceutical applications of cyclodextrins: Basic science and product development, J. Pharm. Pharmacol. 62 (2010) 1607-1621. https://doi.org/10.1111/j.2042-7158.2010.01030.x.

[26] I.I. Salem, G. Steffan, N. Düzgünes, Efficacy of clofazimine-modified cyclodextrin against Mycobacterium avium complex in human macrophages, Int. J. Pharm. 260 (2003) 105-114. https://doi.org/10.1016/S0378-5173(03)00236-9.

[27] J. Wankar, F. Bonvicini, G. Benkovics, V. Marassi, M. Malanga, E. Fenyvesi, G.A. Gentilomi, P. Reschiglian, B. Roda, I. Manet, Widening the Therapeutic Perspectives of Clofazimine by Its Loading in Sulfobutylether $\beta$-Cyclodextrin Nanocarriers: Nanomolar IC50 Values against MDR S. epidermidis, Mol. Pharm. 15 (2018) 3823-3836. https://doi.org/10.1021/acs.molpharmaceut.8b00321.

[28] T. Loftsson, M.E. Brewster, Cyclodextrins as Functional Excipients : Methods to Enhance Complexation Efficiency, J. Pharm. Sci. 101 (2012) 3019-3032. https://doi.org/10.1002/jps.23077.

[29] A.M. Healy, B.F. McDonald, L. Tajber, O.I. Corrigan, Characterisation of excipient-free nanoporous microparticles (NPMPs) of bendroflumethiazide, Eur. J. Pharm. Biopharm. 69 (2008) 1182-1186. https://doi.org/10.1016/j.ejpb.2008.04.020.

[30] O. Nígáin, L. Tajber, O.I. Corrigan, A.M. Healy, Spray drying from organic solvents to prepare nanoporous/nanoparticulate microparticles of protein: Excipient composites designed for oral inhalation, J. Pharm. Pharmacol. 64 (2012) 1275-1290. https://doi.org/10.1111/j.2042-7158.2012.01488.x.

[31] Y. Wei, Y. Wang, H. Zhang, W. Zhou, G. Ma, A novel strategy for the preparation of porous microspheres and its application in peptide drug loading, J. 
Colloid Interface Sci. 478 (2016) 46-53.

https://doi.org/10.1016/j.jcis.2016.05.045.

[32] N.R. Rabbani, P.C. Seville, The influence of formulation components on the aerosolisation properties of spray-dried powders, J. Control. Release. 110 (2005) 130-140. https://doi.org/10.1016/j.jconrel.2005.09.004.

[33] T. Mosmann, Rapid colorimetric assay for cellular growth and survival: Application to proliferation and cytotoxicity assays, J. Immunol. Methods. 65 (1983) 55-63. https://doi.org/10.1016/0022-1759(83)90303-4.

[34] S.T. Buckley, S.M. Fischer, G. Fricker, M. Brandl, In vitro models to evaluate the permeability of poorly soluble drug entities: Challenges and perspectives, Eur. J. Pharm. Sci. 45 (2012) 235-250. https://doi.org/10.1016/j.ejps.2011.12.007.

[35] B. Srinivasan, A.R. Kolli, M.B. Esch, H.E. Abaci, M.L. Shuler, J.J. Hickman, TEER Measurement Techniques for In Vitro Barrier Model Systems, J. Lab. Autom. 20 (2015) 107-126. https://doi.org/10.1177/2211068214561025.

[36] H. Hjorth, Studies of curcumin and curcuminoids . XXVII . Cyclodextrin complexation : solubility, chemical and photochemical stability, Int. J. Pharm. 244 (2002) 127-135.

[37] P. Mura, Analytical techniques for characterization of cyclodextrin complexes in the solid state: A review, J. Pharm. Biomed. Anal. 113 (2015) 226-238. https://doi.org/10.1016/j.jpba.2015.01.058.

[38] X.S. Le, F.T. Chuan, Y. Yang, Preparation and characterization of the solid inclusion compounds of alfa-, beta-cyclodextrin with phenylalanine (D-, L- and DL-Phe) and tryptophan (D-, L- and DL-Trp), J. Incl. Phenom. 54 (2006) 221232. https://doi.org/10.1007/s10847-005-7970-8.

[39] M.E. Cortes, R.D. Sinisterra, M.J. Avila-Campos, N. Tortamano, R.G. Rocha, The chlorhexidine: beta-cyclodextrin inclusion compound: Preparation, characterization and microbiological evaluation, J. Incl. Phenom. Macrocycl. Chem. 40 (2001) 297-302. https://doi.org/10.1023/A:1012788432106.

[40] M.I. Amaro, L. Tajber, O.I. Corrigan, A.M. Healy, Co-Spray dried carbohydrate microparticles: Crystallisation delay/inhibition and improved aerosolization characteristics through the incorporation of hydroxypropyl- $\beta$-cyclodextrin with amorphous raffinose or trehalose, Pharm. Res. 32 (2015) 180-195. https://doi.org/10.1007/s11095-014-1454-8. 
[41] M.M. Doile, K.A. Fortunato, I.C. Schmücker, S.K. Schucko, M.A.S. Silva, P.O. Rodrigues, Physicochemical properties and dissolution studies of dexamethasone acetate-beta-cyclodextrin inclusion complexes produced by different methods., AAPS PharmSciTech. 9 (2008) 314-21. https://doi.org/10.1208/s12249-0089042-z.

[42] M.I. Amaro, L. Tajber, O.I. Corrigan, A.M. Healy, Optimisation of spray drying process conditions for sugar nanoporous microparticles (NPMPs) intended for inhalation, Int. J. Pharm. 421 (2011) 99-109.

[43] É.Y. Suzuki, M.I. Amaro, G.S. de Almeida, L.M. Cabral, A.M. Healy, V.P. de Sousa, Development of a new formulation of roflumilast for pulmonary drug delivery to treat inflammatory lung conditions, Int. J. Pharm. 550 (2018) 89-99. https://doi.org/10.1016/j.ijpharm.2018.08.035.

[44] H. Cabral-Marques, R. Almeida, Optimisation of spray-drying process variables for dry powder inhalation (DPI) formulations of corticosteroid/cyclodextrin inclusion complexes, Eur. J. Pharm. Biopharm. 73 (2009) 121-129. https://doi.org/10.1016/j.ejpb.2009.05.002.

[45] F.J. Wang, C. Wang, Effects of fabrication conditions on the characteristics of etanidazole spray-dried microspheres, J. Microencapsul. 19 (2002) 495-510. https://doi.org/10.1080/02652040210140483.

[46] R. Vanbever, C. Bosquillon, C. Lombry, Influence of formulation excipients and physical characteristics of inhalation dry powders on their aerosolization performance, J Control Release. 70 (2001) 329-339. https://doi.org/10.1016/s0168-3659(00)00362-x.

[47] A.M. Healy, M.I. Amaro, K.J. Paluch, L. Tajber, Dry powders for oral inhalation free of lactose carrier particles, Adv. Drug Deliv. Rev. 75 (2014) 32-52. https://doi.org/10.1016/j.addr.2014.04.005.

[48] M.A.M. Momin, S. Sinha, I.G. Tucker, C. Doyle, S.C. Das, Dry powder formulation of kanamycin with enhanced aerosolization efficiency for drugresistant tuberculosis, Int. J. Pharm. 528 (2017) 107-117. https://doi.org/10.1016/j.ijpharm.2017.06.004.

[49] C. Bosquillon, V. Préat, R. Vanbever, Pulmonary delivery of growth hormone using dry powders and visualization of its local fate in rats, J. Control. Release. 96 (2004) 233-244. https://doi.org/10.1016/j.jconrel.2004.01.027. 
[50] L. Li, S. Sun, T. Parumasivam, J.A. Denman, T. Gengenbach, P. Tang, S. Mao, H. Chan, L-Leucine as an excipient against moisture on in vitro aerosolization performances of highly hygroscopic spray-dried powders, Eur. J. Pharm. Biopharm. 102 (2016) 132-141. https://doi.org/10.1016/j.ejpb.2016.02.010.

[51] S. Mangal, R. Xu, R. Guo, Q. (Tony) Zhou, H. Nie, A. Cavallaro, D. Zemlyanov, Physico-Chemical Properties, Aerosolization and Dissolution of Co-Spray Dried Azithromycin Particles with L-Leucine for Inhalation, Pharm. Res. 35 (2018). https://doi.org/10.1007/s11095-017-2334-9.

[52] K.A. Min, G.R. Rosania, C.-K. Kim, M.C. Shin, Functional and cytometric examination of different human lung epithelial cell types as drug transport barriers., Arch. Pharm. Res. 39 (2016) 359-69. https://doi.org/10.1007/s12272015-0704-6.

[53] International Organization for Standardization, ISO 10993 - Biological Evaluation of Medical Devices, 3rd ed., International Organization for Standardization, Switzerland, 2009.

[54] K.A. Foster, M.L. Avery, M. Yazdanian, K.L. Audus, Characterization of the Calu-3 cell line as a tool to screen pulmonary drug delivery, Int. J. Pharm. 208 (2000) 1-11. https://doi.org/10.1016/S0378-5173(00)00452-X.

[55] V. Vartiainen, L.M. Bimbo, J. Hirvonen, E.I. Kauppinen, J. Raula, Drug permeation and cellular interaction of amino acid-coated drug combination powders for pulmonary delivery, Int. J. Pharm. 504 (2016) 89-97. https://doi.org/10.1016/j.ijpharm.2016.03.052.

[56] W.-H. Lee, C.-Y. Loo, D. Traini, P.M. Young, Nano- and micro-based inhaled drug delivery systems for targeting alveolar macrophages, Expert Opin. Drug Deliv. 12 (2015) 1009-1026. https://doi.org/10.1517/17425247.2015.1039509.

[57] The World Health Organization, WHO consolidated guidelines on drug-resistant tuberculosis treatment, Geneva, 2019.

[58] C. Loira-Pastoriza, J. Todoroff, R. Vanbever, Delivery strategies for sustained drug release in the lungs, Adv. Drug Deliv. Rev. 75 (2014) 81-91. https://doi.org/10.1016/j.addr.2014.05.017.

[59] S. Katiyar, S. Bihari, S. Prakash, Low-dose inhaled versus standard dose oral form of anti-tubercular drugs: Concentrations in bronchial epithelial lining fluid, alveolar macrophage and serum, J. Postgrad. Med. 54 (2008) 245-246. https://doi.org/10.4103/0022-3859.41823. 
934 [60] FDA, TOBI ${ }^{\circledR}$ PODHALER ${ }^{\mathrm{TM}},(2015)$.

935

936 https://www.accessdata.fda.gov/drugsatfda_docs/label/2015/201688s006lbl.pdf

937 (accessed April 29, 2020).

938

[61] K. McKeage, Tobramycin Inhalation Powder: A Review of Its Use in the

939 Treatment of Chronic Pseudomonas aeruginosa Infection in Patients with Cystic

940 Fibrosis, Drugs. 73 (2013) 1815-1827. https://doi.org/10.1007/s40265-013-0141-

941 0 .

[62] R. Scherließ, C. Etschmann, DPI formulations for high dose applications -

942 Challenges and opportunities, Int. J. Pharm. 548 (2018) 49-53.

943 https://doi.org/https://doi.org/10.1016/j.ijpharm.2018.06.038.

944

945

946

947

948

949

950

951

952

953

954

955

956

957

958

959

960

961

962

963

964

965

966

967 
969

\begin{tabular}{|c|c|c|c|c|}
\hline $\begin{array}{l}\text { Cyclodextrin } \\
\text { condition }\end{array}$ & Solvent & $\begin{array}{l}\text { Molar proportion } \\
\text { CFZ:CD (mM) }\end{array}$ & $\begin{array}{c}\text { Temperature } \\
\left({ }^{\circ} \mathrm{C}\right)\end{array}$ & $\begin{array}{l}\text { Time } \\
(\mathrm{h})\end{array}$ \\
\hline$\beta C D \_a$ & Water & $1: 1 / 1: 2 / 1: 4 / 1: 6 / 1: 8 / 1: 10$ & 40 & 72 \\
\hline$\beta C D b$ & Ethanol:Water $(1: 1)$ & $1: 1 / 1: 2 / 1: 4 / 1: 6 / 1: 8 / 1: 10$ & 40 & 72 \\
\hline$\gamma \mathrm{CD} \_\mathrm{a}$ & Ethanol:Water $(1: 1)$ & $1: 1 / 1: 2 / 1: 4 / 1: 6 / 1: 8 / 1: 10$ & 40 & 72 \\
\hline 2-HP $\beta C D \_a$ & Ethanol:Water $(1: 1)$ & $1: 1 / 1: 2 / 1: 4 / 1: 6 / 1: 8 / 1: 10$ & 40 & 72 \\
\hline 2-HP $\beta C D \_b$ & Ethanol:Water (1:1) & $1: 1 / 1: 2 / 1: 4 / 1: 6 / 1: 8 / 1: 10$ & 40 & 72 \\
\hline 2-HP $\beta C D \_c$ & Ethanol:Water (7:3) & $1: 1 / 1: 5 / 1: 10$ & 50 & 72 \\
\hline 2-HP $\beta C D \_d$ & Ethanol:Water (4:6) & $1: 1 / 1: 5 / 1: 10$ & 40 & 72 \\
\hline 2-HP $\beta C D \_$e & Ethanol:Water (2:8) & $1: 1 / 1: 5 / 1: 10$ & 40 & 72 \\
\hline 2-HP $\beta C D \_f$ & Ethanol:Water (1:9) & $1: 1 / 1: 5 / 1: 10$ & 40 & 72 \\
\hline SBEßCD_a & Ethanol:Water $(1: 1)$ & $1: 1 / 1: 2 / 1: 4 / 1: 6 / 1: 8 / 1: 10$ & 30 & 144 \\
\hline $\mathrm{SBE} \beta \mathrm{CD} \_\mathrm{b}$ & Water & $1: 1 / 1: 2 / 1: 4 / 1: 6 / 1: 8 / 1: 10$ & 30 & 72 \\
\hline
\end{tabular}


994 Table 2. The characteristic peaks of CFZ, CDs, physical mixture and their complexes in 995 the XRPD diffractograms.

996

Main peaks $2 \theta$ (degrees)

\begin{tabular}{lcccccccc}
\hline $\begin{array}{l}\text { 1CFZ:7 } \beta C D \\
\text { Spray dried }\end{array}$ & --- & --- & --- & --- & 13.1 & --- & 18.8 & --- \\
\hline $\begin{array}{l}\text { 1CFZ:7 } \beta C D \\
\text { Freeze dried }\end{array}$ & --- & 7.7 & --- & --- & 12.3 & --- & 18.3 & --- \\
\hline $\begin{array}{l}\text { Physical } \\
\text { mixture }\end{array}$ & 4.4 & --- & 8.9 & 10.5 & 12.4 & 15.3 & 19.5 & 22.7 \\
\hline$\beta C D$ & 4.5 & --- & 8.9 & 10.8 & 12.5 & 15.4 & 19.6 & --- \\
\hline Clofazimine & --- & --- & 9.2 & --- & 13.4 & --- & 19.8 & 22.0 \\
\hline
\end{tabular}

997

998

999

1000

1001

1002

1003

1004

1005

1006

1007

1008

1009

1010

1011

1012

1013

1014

1015

1016

1017

1018

1019

1020

1021 
1022 Table 3. Clofazimine powder formulations and spray dryer settings.

1023

\begin{tabular}{|c|c|c|c|c|c|c|}
\hline \multirow[b]{2}{*}{ Formulation } & \multirow[b]{2}{*}{$\begin{array}{c}\text { Solid } \\
\text { constituents }\end{array}$} & \multirow[b]{2}{*}{$\begin{array}{c}\text { Liquid } \\
\text { constituents }\end{array}$} & \multicolumn{4}{|c|}{ Spray dryer settings } \\
\hline & & & $\begin{array}{c}\text { Inlet } \\
\text { temperature } \\
\left({ }^{\circ} \mathrm{C}\right)\end{array}$ & $\begin{array}{c}\text { Outlet } \\
\text { temperature } \\
\left({ }^{\circ} \mathrm{C}\right)\end{array}$ & $\begin{array}{l}\text { Pump } \\
\text { flow } \\
(\mathrm{L} / \mathrm{h})\end{array}$ & $\begin{array}{c}\text { Gas } \\
\text { flow } \\
(\mathrm{L} / \mathrm{min})\end{array}$ \\
\hline SP1 & $\begin{array}{c}\text { CFZ: } \beta C D \\
(1: 7)\end{array}$ & Ethanol:Water $(1: 1)$ & 95 & $45-48$ & 0.55 & 35 \\
\hline SP2 & $\begin{array}{c}\text { CFZ: } \beta C D \\
(1: 7)\end{array}$ & Ethanol:Water $(1: 1)$ & 65 & $41-43$ & 0.30 & 35 \\
\hline SP3 & $\begin{array}{c}\text { CFZ: } \beta C D \\
(1: 7) \\
\text { L-leucine } 10 \% \\
\end{array}$ & Ethanol:Water $(1: 1)$ & 65 & $41-43$ & 0.30 & 35 \\
\hline SP4 & $\begin{array}{c}\text { CFZ: } \beta C D \\
(1: 7) \\
\text { L-leucine } 15 \% \\
\end{array}$ & Ethanol:Water $(1: 1)$ & 65 & $37-42$ & 0.30 & 35 \\
\hline SP5 & $\begin{array}{c}\text { CFZ: } \beta C D \\
(1: 7) \\
\text { Isoleucine } 15 \% \\
\end{array}$ & Ethanol:Water $(1: 1)$ & 65 & $38-41$ & 0.30 & 35 \\
\hline SP6 & $\begin{array}{c}\text { CFZ: } \beta C D \\
(1: 7)\end{array}$ & Ethanol:Water (1:1) & 65 & $44-47$ & 0.35 & 35 \\
\hline SP7 & $\begin{array}{c}\text { CFZ: } \beta C D \\
(1: 7) \\
\text { L-leucine } 10 \%\end{array}$ & Ethanol:Water $(1: 1)$ & 65 & $44-47$ & 0.35 & 35 \\
\hline SP8 & $\begin{array}{c}\text { CFZ: } \beta C D \\
(1: 7) \\
\text { L-leucine } 15 \%\end{array}$ & Ethanol:Water $(1: 1)$ & 65 & $44-47$ & 0.35 & 35 \\
\hline SP9 & $\begin{array}{c}\text { CFZ: } \beta C D \\
(1: 7) \\
\text { L-leucine } 15 \% \\
\end{array}$ & $\begin{array}{c}\text { Ethanol:Water }(1: 1) \\
\text { Dichloromethane } \\
2 \% \\
\end{array}$ & 65 & $34-46$ & 0.35 & 35 \\
\hline
\end{tabular}

1024

1025

1026

1027

1028

1029

1030

1031

1032

1033

1034

1035

1036 
1037 Table 4. Bulk (b $\rho)$ and tapped density ( $\mathrm{t} \rho$ ), specific surface area (SSA) and aerodynamic

1038 characteristics of L-leucine free (SP6) and L-leucine spray dried formulations (SP7 -

1039 SP8).

1040

\begin{tabular}{|c|c|c|c|c|c|c|c|}
\hline & \multirow[b]{2}{*}{$\begin{array}{l}\text { Bulked density } \\
\qquad\left(\mathrm{g} / \mathrm{cm}^{3}\right)\end{array}$} & \multirow[b]{2}{*}{$\begin{array}{l}\text { Tapped density } \\
\qquad\left(\mathrm{g} / \mathrm{cm}^{3}\right)\end{array}$} & \multicolumn{5}{|c|}{ Aerodynamics characteristics } \\
\hline & & & $\begin{array}{l}\text { Specific } \\
\text { surface area } \\
\left(\mathrm{m}^{2} / \mathrm{g}\right)\end{array}$ & $\begin{array}{l}\text { Emitted dose } \\
(\%)\end{array}$ & $\begin{array}{c}\mathrm{FPF}<5 \mu \mathrm{m} \\
(\%)\end{array}$ & $\begin{array}{l}\text { MMAD } \\
(\mu \mathrm{m})\end{array}$ & GSD \\
\hline SP6 & $0.113 \pm 0.005^{\mathrm{a}}$ & $0.170 \pm 0.003^{\mathrm{c}}$ & $3.504 \pm 0.075^{\mathrm{e}, \mathrm{f}}$ & $95.19 \pm 1.83$ & $48.41 \pm 2.79$ & $3.38 \pm 0.19^{\mathrm{h}}$ & $1.65 \pm 0.12$ \\
\hline SP7 & $0.128 \pm 0.002^{\mathrm{b}}$ & $0.176 \pm 0.010^{\mathrm{d}}$ & $2.766 \pm 0.054^{\mathrm{e}, \mathrm{g}}$ & $95.02 \pm 1.39$ & $46.20 \pm 6.81$ & $3.06 \pm 0.09$ & $1.82 \pm 0.13$ \\
\hline SP8 & $0.185 \pm 0.004^{\mathrm{a}, \mathrm{b}}$ & $0.265 \pm 0.006^{\mathrm{c}, \mathrm{d}}$ & $6.104 \pm 0.285^{\mathrm{f,g}}$ & $94.13 \pm 1.52$ & $51.56 \pm 5.16$ & $2.98 \pm 0.08^{\mathrm{h}}$ & $1.80 \pm 0.11$ \\
\hline \multicolumn{8}{|c|}{ 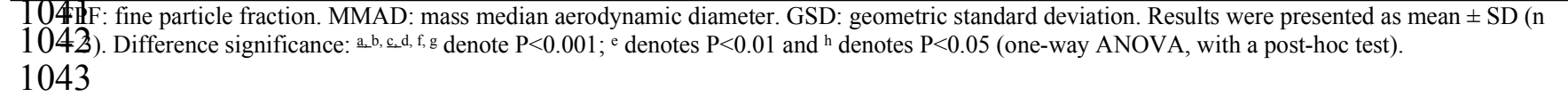 } \\
\hline \multicolumn{8}{|l|}{1044} \\
\hline \multicolumn{8}{|l|}{1045} \\
\hline \multicolumn{8}{|l|}{1046} \\
\hline \multicolumn{8}{|l|}{1047} \\
\hline \multicolumn{8}{|l|}{1048} \\
\hline \multicolumn{8}{|l|}{1049} \\
\hline \multicolumn{8}{|l|}{1050} \\
\hline \multicolumn{8}{|l|}{1051} \\
\hline \multicolumn{8}{|l|}{1052} \\
\hline \multicolumn{8}{|l|}{1053} \\
\hline \multicolumn{8}{|l|}{1054} \\
\hline \multicolumn{8}{|l|}{1055} \\
\hline \multicolumn{8}{|l|}{1056} \\
\hline \multicolumn{8}{|l|}{1057} \\
\hline \multicolumn{8}{|l|}{1058} \\
\hline \multicolumn{8}{|l|}{1059} \\
\hline \multicolumn{8}{|l|}{1060} \\
\hline \multicolumn{8}{|l|}{1061} \\
\hline \multicolumn{8}{|l|}{1062} \\
\hline \multicolumn{8}{|l|}{1063} \\
\hline \multicolumn{8}{|l|}{1064} \\
\hline \multicolumn{8}{|l|}{1065} \\
\hline \multicolumn{8}{|l|}{1066} \\
\hline 1067 & & & & & & & \\
\hline
\end{tabular}


Figure 1. Percentage of total mass of clofazimine recovered after complexation process.

Each condition is described in Table 1. Results are presented as mean $\pm \operatorname{SD}(n=3)$.

1072

1073 Figure 2. Clofazimine's phase solubility profile determined under different conditions

1074 (A) Condition $\beta C D$ _a in Table 1: excess amount of CFZ was added to aqueous

1075 solutions containing increasing concentrations of $\beta C D(1-10 \mathrm{mM})$ and were stirred at 40

$1076{ }^{\circ} \mathrm{C}$ for $72 \mathrm{~h}$, and subsequently filtered through a $0.45 \mu \mathrm{m}$ membrane. (B) Condition

1077 BCD_b in Table 1: excess amount of CFZ was added to ethanol:water (1:1) solutions

1078 containing increasing concentrations of $\beta \mathrm{CD}(1-10 \mathrm{mM})$ and were stirred at $40{ }^{\circ} \mathrm{C}$ for 72

$1079 \mathrm{~h}$, and subsequently filtered through a $0.45 \mu \mathrm{m}$ membrane. "CE" was the complexation

1080 efficacy. Results are presented as mean $\pm \operatorname{SD}(n=3)$.

1082 Figure 3. DSC curves of CFZ systems and $\beta C D$ : (A) CFZ raw material; (B) $\beta C D$ raw material; (C) physical mixture of CFZ and $\beta C D$ raw materials; (D) inclusion complex, freeze-dried; (E) inclusion complex, spray-dried.

Figure 4. XRPD diffractograms of CFZ from CSD (polymorph form I, DAKUI01) and

1087 CFZ raw material.

Figure 5. XRPD diffractograms of CFZ and $\beta C D$ systems: (A) CFZ raw material; (B) $\beta C D$ raw material; (C) spray-dried $\beta C D$; (D) physical mixture of $C F Z$ and $\beta C D$ raw materials; (E) inclusion complex, freeze-dried; (F) inclusion complex, spray-dried.

Figure 6. FTIR spectra of CFZ and $\beta C D$ systems: (A) CFZ raw material; (B) $\beta C D$ raw material; (C) physical mixture of $\mathrm{CFZ}$ and $\beta \mathrm{CD}$ raw materials; (D) inclusion complex, spray-dried. The dotted lines (---) and the circle indicates the main vibrational bands of CFZ (aromatic $\mathrm{C}-\mathrm{H}$ stretching and $\mathrm{C}=\mathrm{N}$ stretching).

1100 inclusion complex, freeze-dried. 
1102 Figure 8. Geometric mean diameter and polydispersity index (span) of raw material

1103 (CFZ and $\beta C D$ ) and spray dried formulations (SP). The SP formulation constituents and 1104 spray dryer settings are provided in Table 3 . Results are presented as mean \pm SD ( $n=$

1105 3). Difference significance: * $\mathrm{P}<0.05$ and $* * * \mathrm{P}<0.001$ (one-way ANOVA, with a post-

1106 hoc test).

1107

1108 Figure 9. Scanning electron micrographs of physical mixture of CFZ and $\beta C D$ and 1109 spray dried formulations. (A) physical mixture of CFZ and $\beta C D$ raw materials; (B) SP6;

1110 (C) SP7; (D) SP8 and (E) SP9.

1111

1112 Figure 10. Water vapour isotherms (sorption and desorption). (a) SP6 - CFZ:ßCD (1:7);

1113 (b) SP7 - CFZ:ßCD (1:7) + L-leucine 10\% and (c) SP8 - CFZ:ßCD (1:7) + L-leucine $1114 \quad 15 \%$

1116 Figure 11. XRPD profile after DVS analyses. (A) SP6 - CFZ:ßCD (1:7); (B) SP7 -

1117 CFZ:ßCD (1:7) + L-leucine 10\% and (C) SP8 - CFZ:ßCD (1:7) + L-leucine 15\%.

1119 Figure 12. In vitro aerosol deposition profile by use of NGI for spray dried formulations 1120 as calculated \% of recovered emitted dose vs. NGI stages. (A) SP6 - CFZ:BCD (1:7); 1121 (B) SP7 - CFZ:ßCD (1:7) + L-leucine 10\% and (C) SP8 - CFZ:ßCD (1:7) + L-leucine 1122 15\%. MA: mouthpiece adapter / IP: induction port. MOC: micro-orifice collector.

1123 Results are presented as mean $\pm \mathrm{SD}(\mathrm{n}=3)$. Difference significance: $* * * \mathrm{P}<0.001$ (two1124 way ANOVA, with a post-hoc test).

1126 Figure 13. Water solubility of clofazimine as free drug and formulations SP6 -

1127 CFZ:ßCD (1:7); SP7 - CFZ:ßCD (1:7) + L-leucine 10\% and SP8 - CFZ:ßCD (1:7) + L-

1128 leucine $15 \%$. The water $\mathrm{pH}=6.5$. n.d: not detected. Results are presented as mean $\pm \mathrm{SD}$

$1129(\mathrm{n}=3)$. Difference significance: $* * \mathrm{P}<0.01$ and $* * * \mathrm{P}<0.001$ (two-way ANOVA, with a 1130 post-hoc test).

1132 Figure 14. (A) Viability of Calu-3 grown as cell layer after 24h exposure to 3.125 -

$113325 \mu \mathrm{M}$ of equivalent clofazimine. CFZ: Clofazimine raw material. CFZ: $\beta C D(1: 7)$

1134 complex . PM: physical mixture of CFZ and $\beta C D$ raw materials. (B) Viability of Calu-3 1135 grown as cell layer after $24 \mathrm{~h}$ exposure to $25-200 \mu \mathrm{M} \beta \mathrm{CD}$. Both experiments were 
1136 measured by MTT test (mean $\pm \mathrm{SD}, \mathrm{n}=3$ ). The dotted lines mark $70 \%$ and $90 \%$

1137 viability. Difference significance: ** $\mathrm{P}<0.01$ and $* * * \mathrm{P}<0.001$ (two-way ANOVA, with

1138 a post-hoc test).

1139

1140 Supplementary material:

1141

1142 Figure S1. TEER values of Calu-3 culture during the permeability study. Control: no

1143 treatment; CFZ: Clofazimine raw material; SP8: CFZ: $\beta C D(1: 7)+$ L-leucine 15\%. The 1144 measurements were at the sampling time points. 


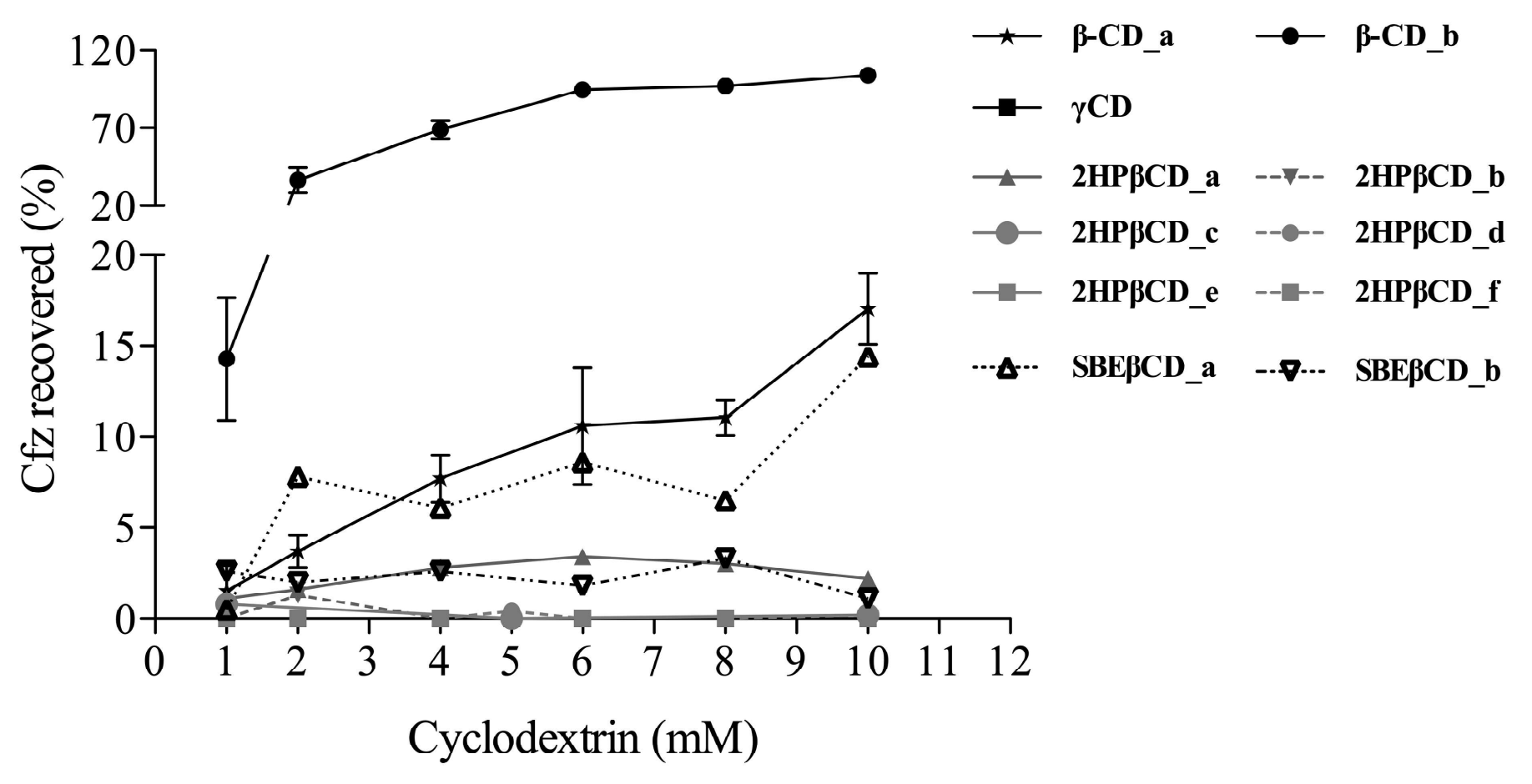



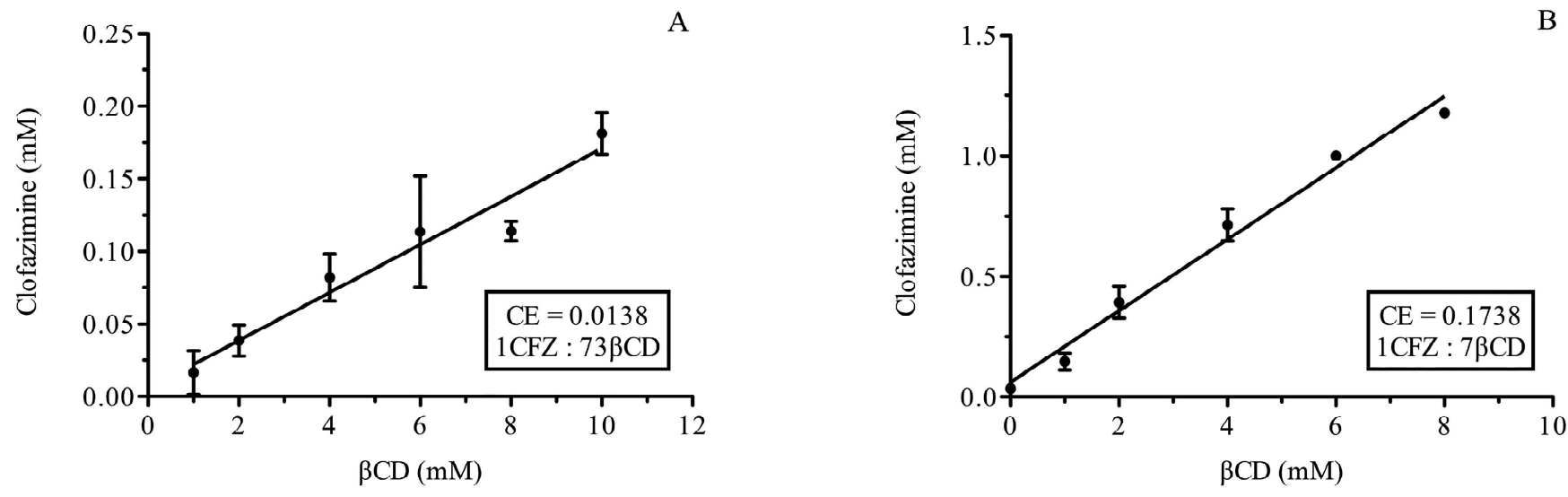


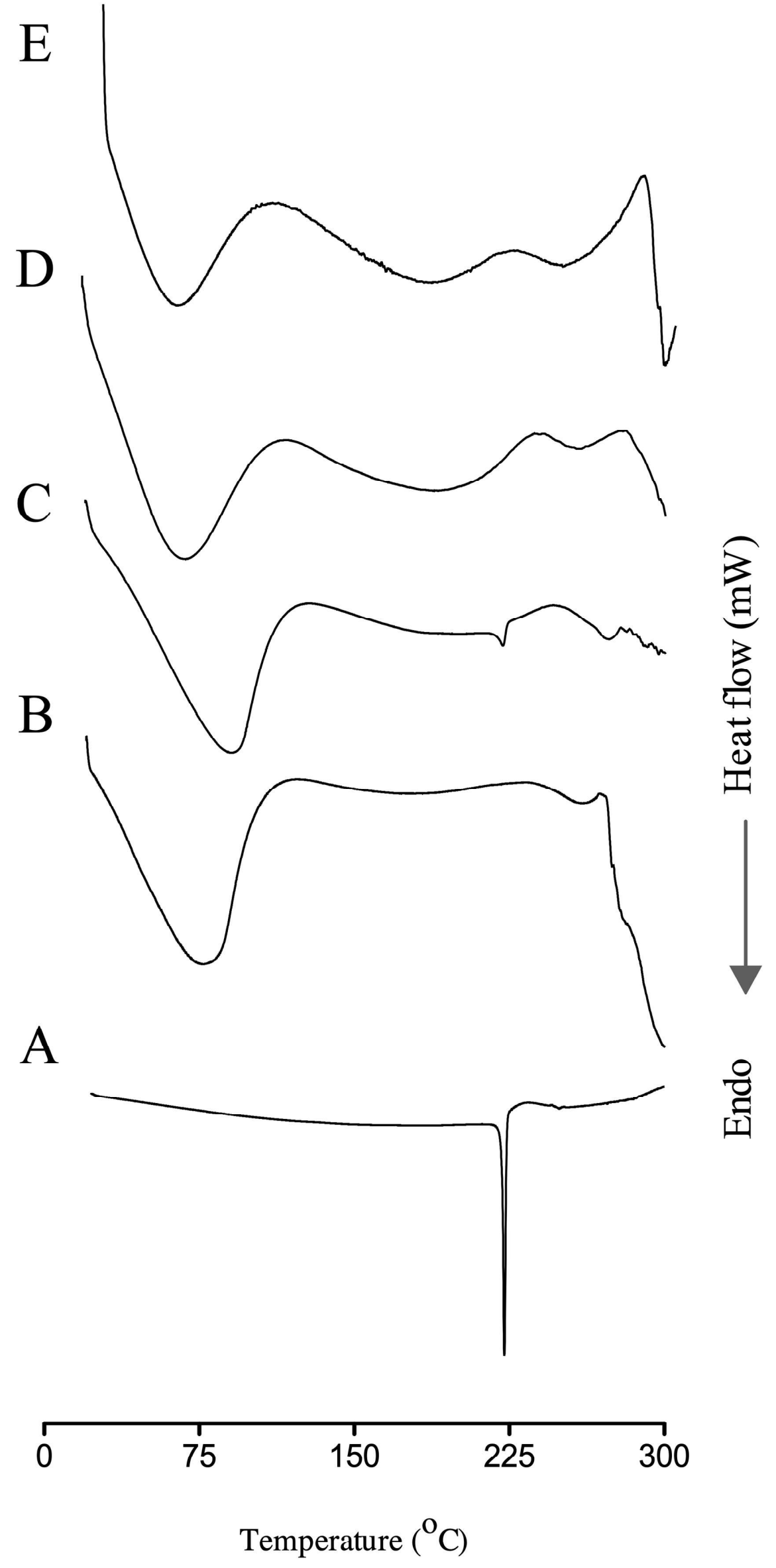




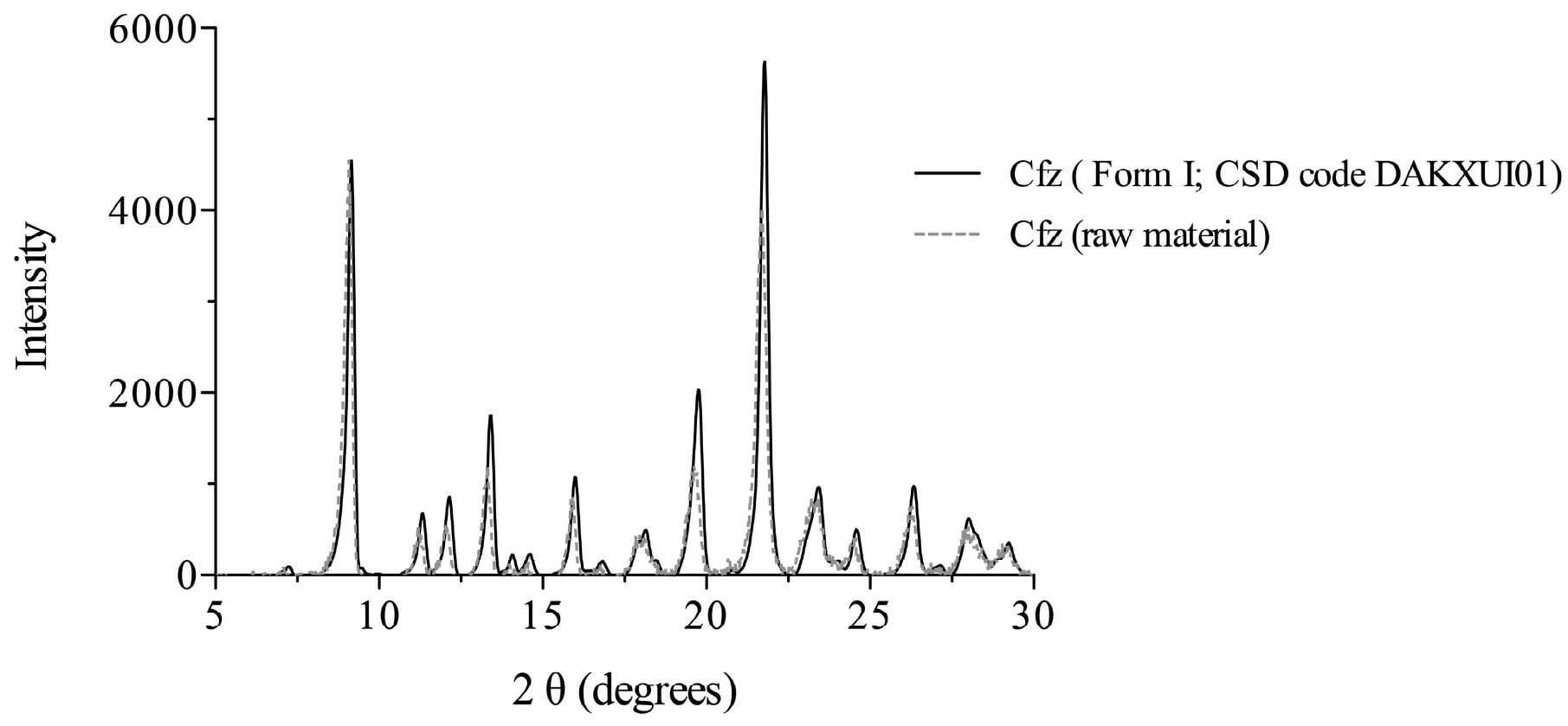


F

E

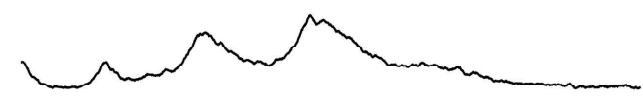

D

C

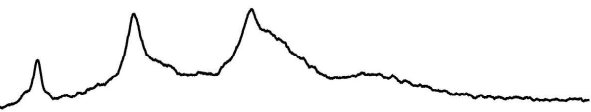

B

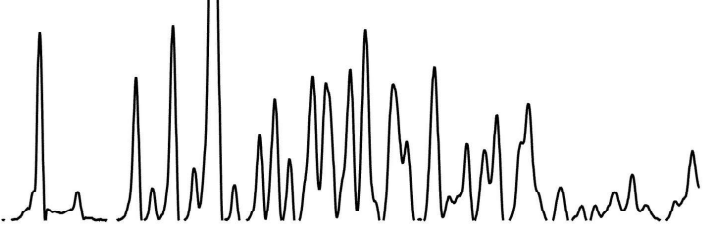

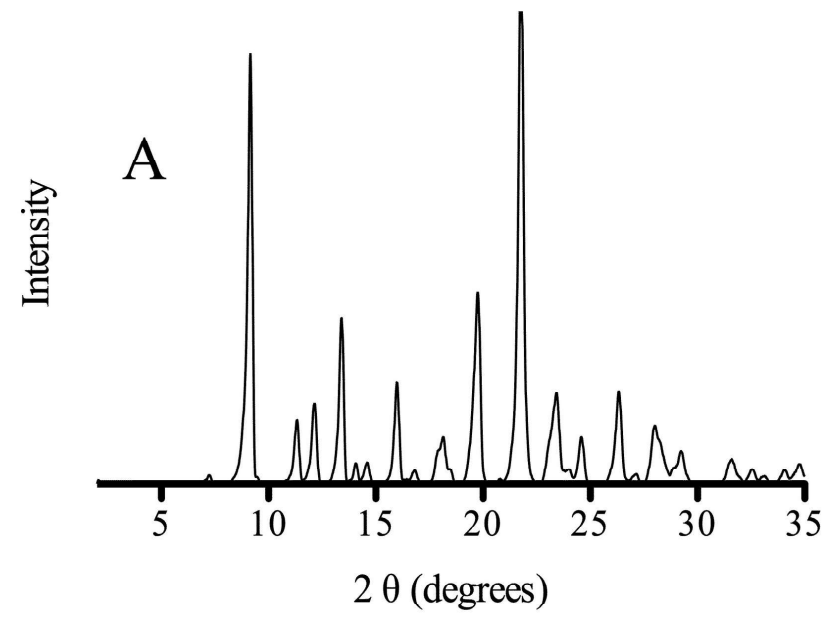




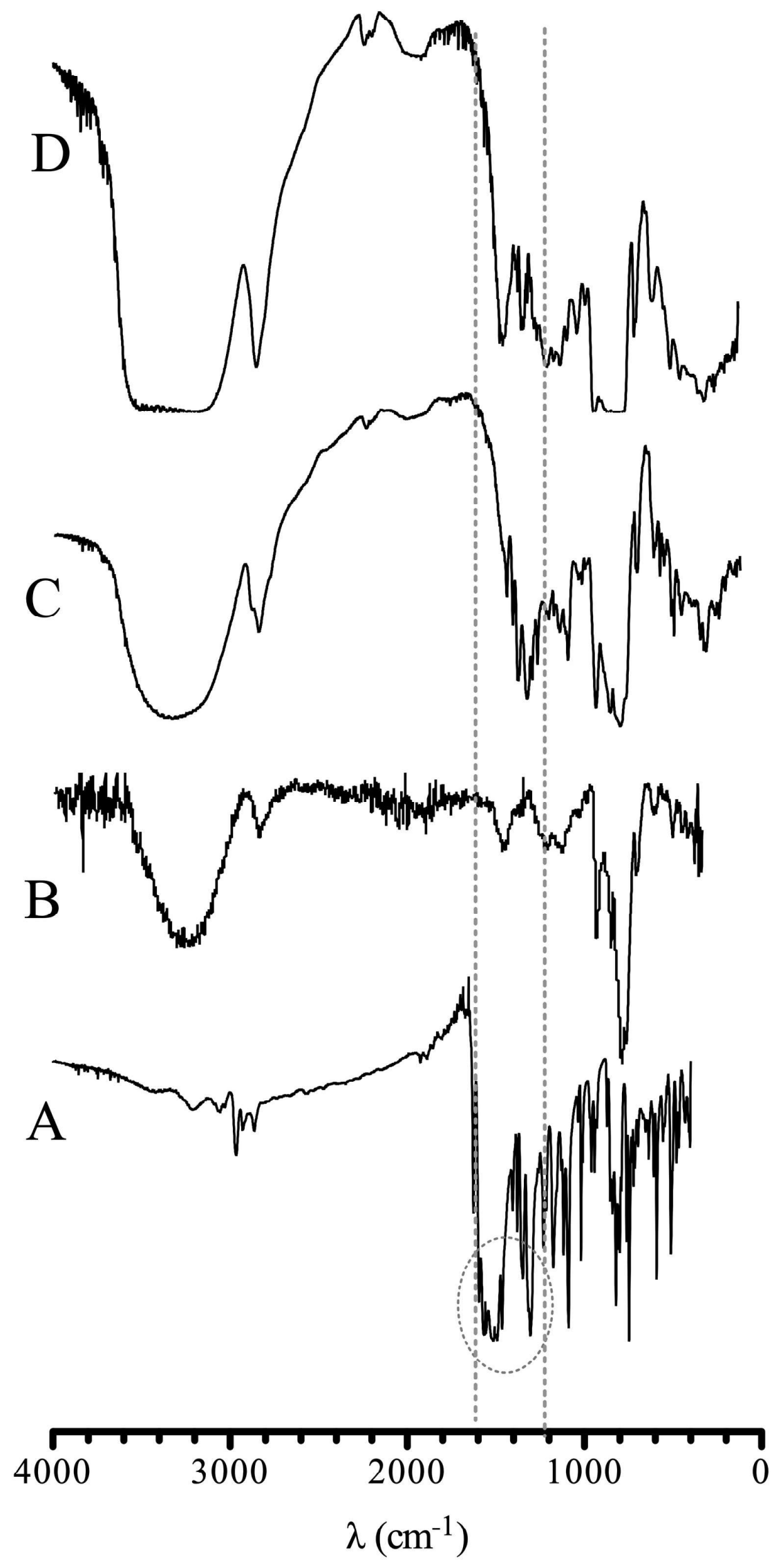



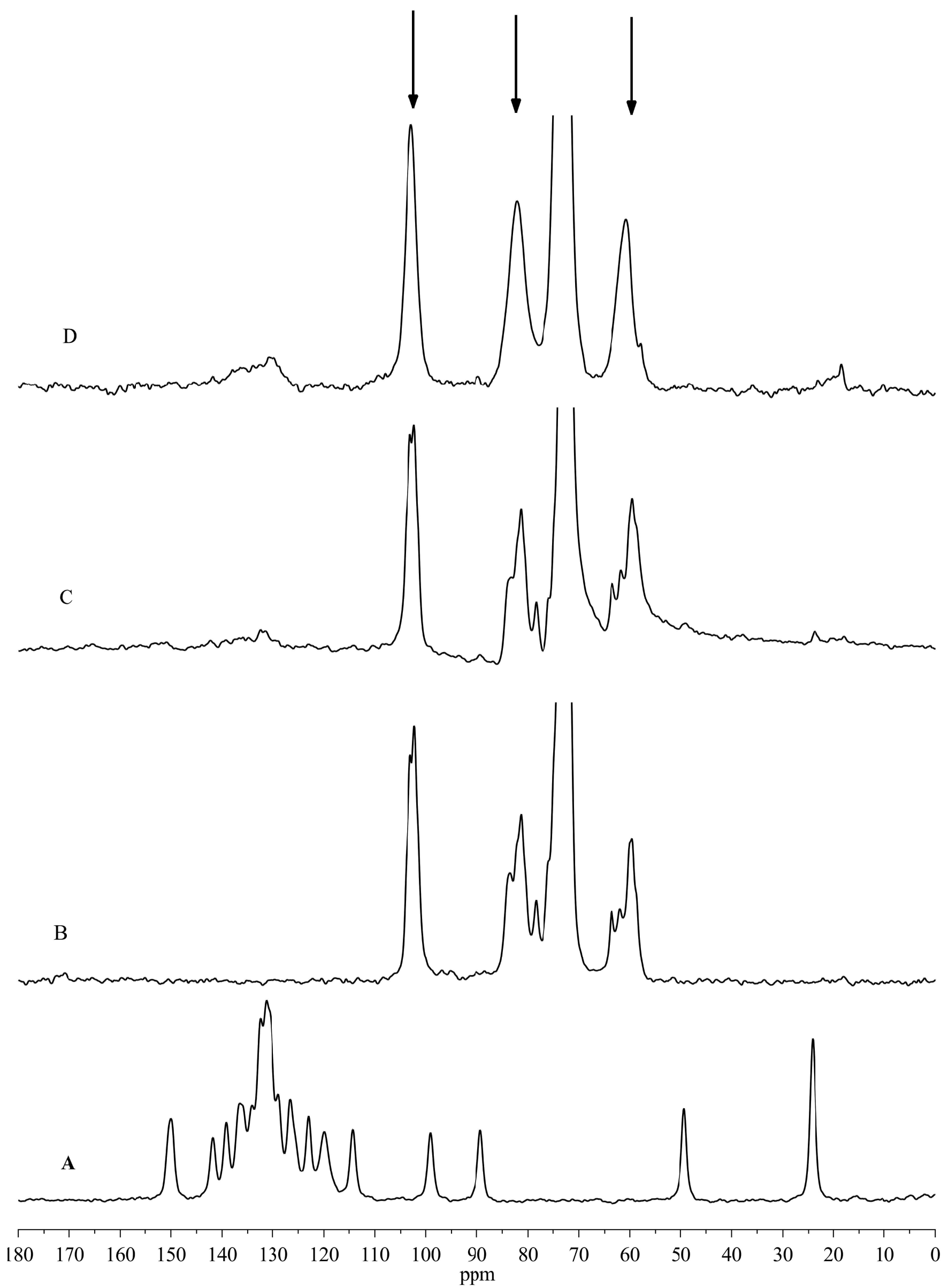


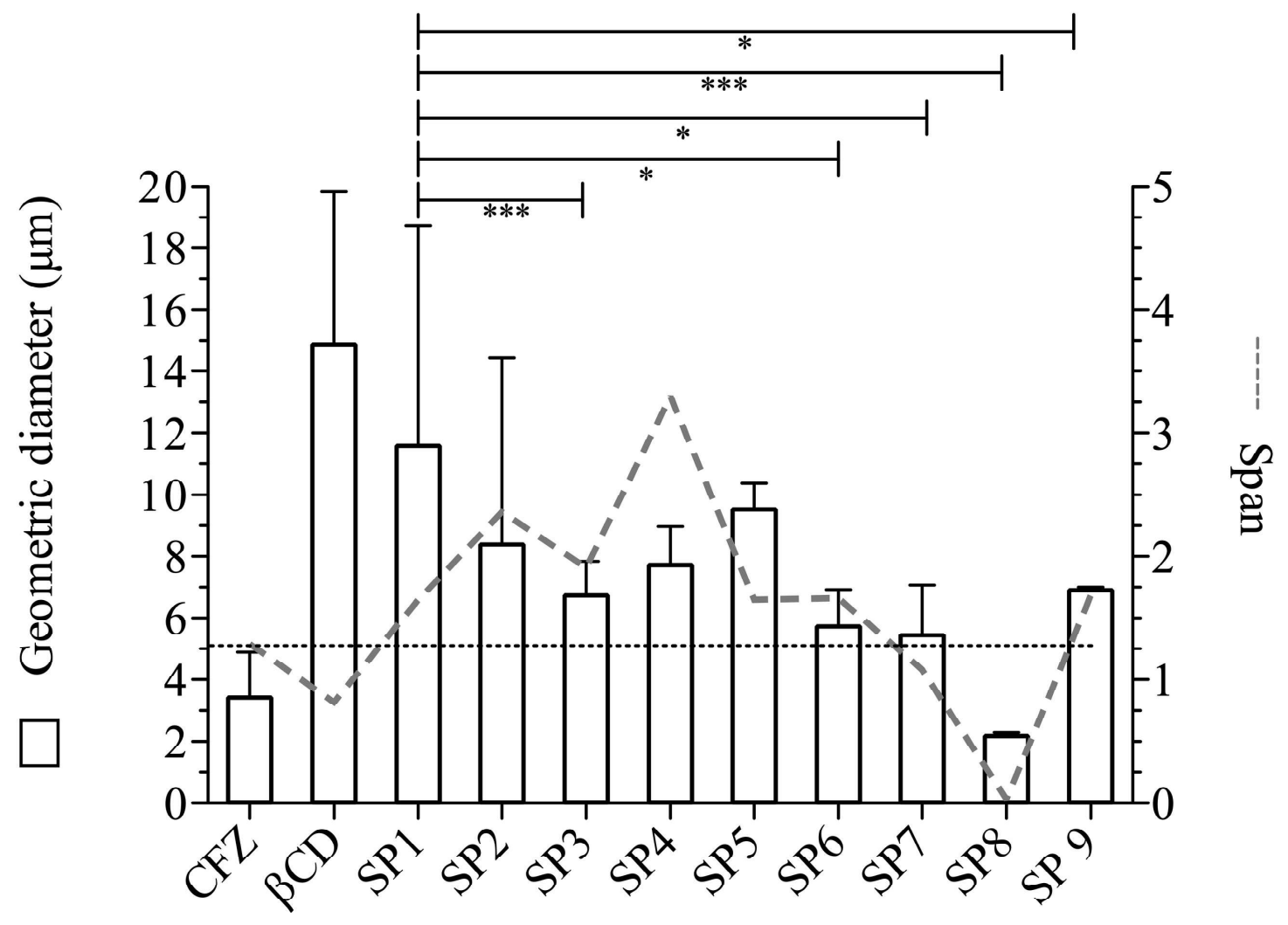

Formulation 

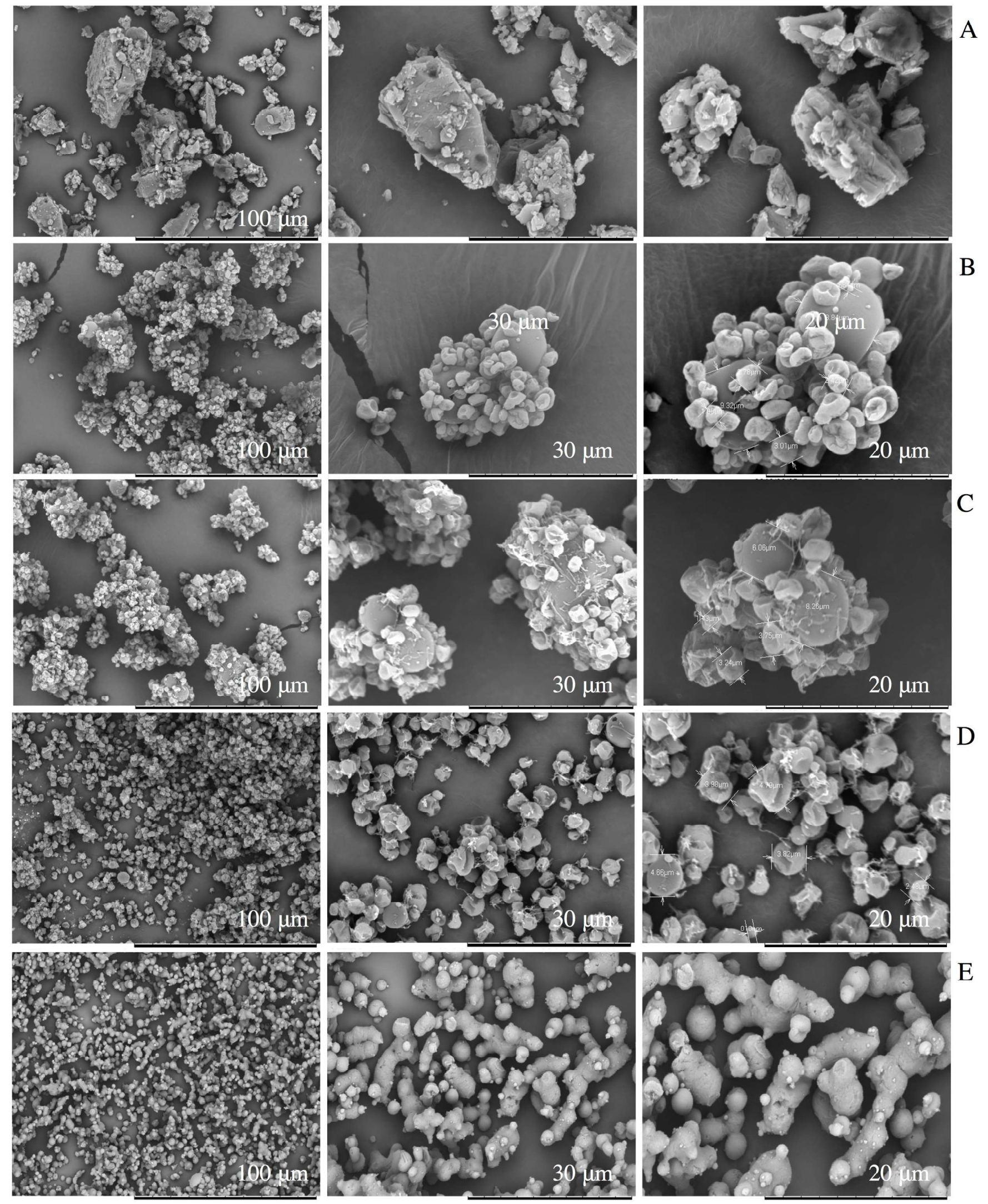


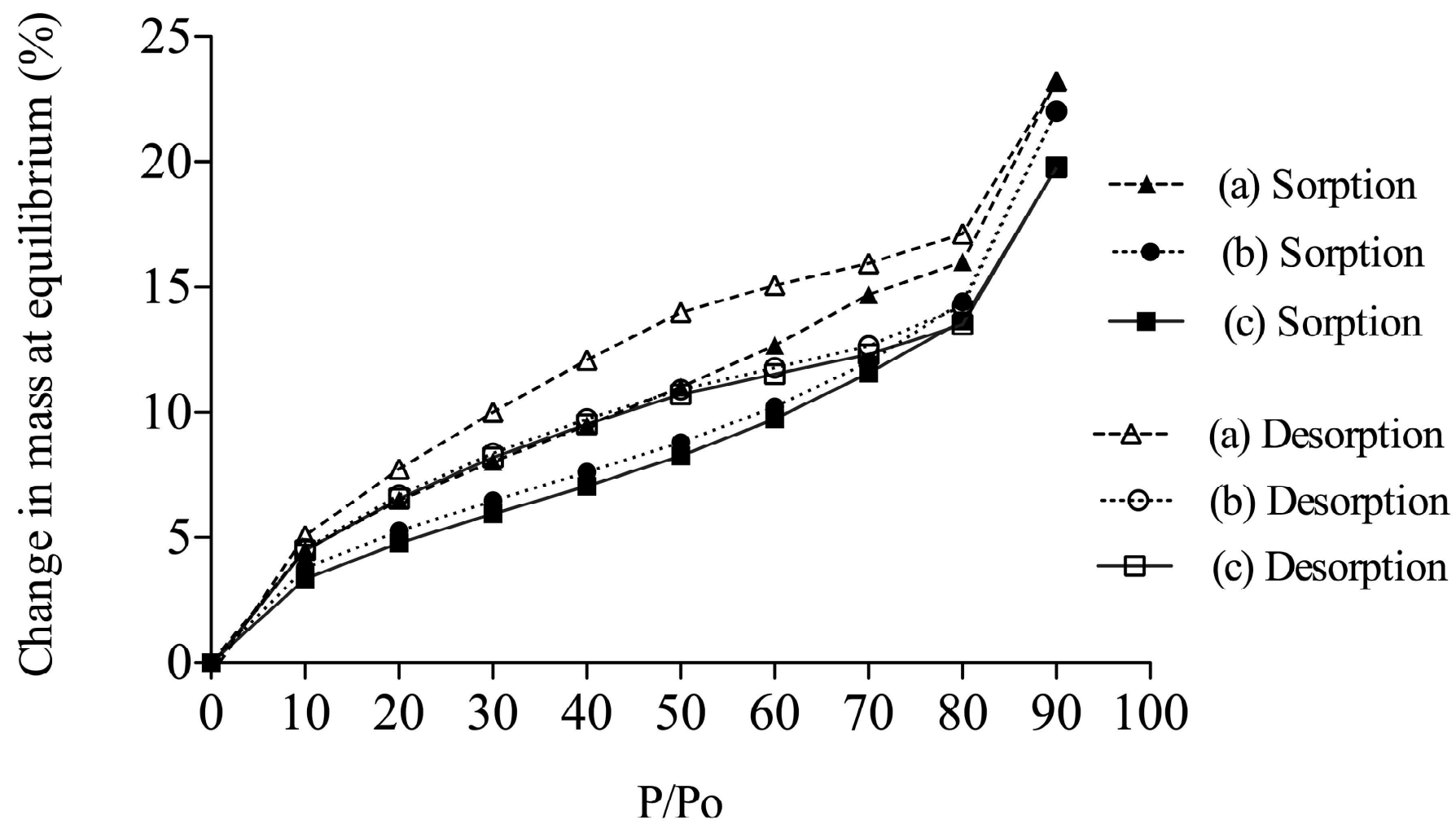




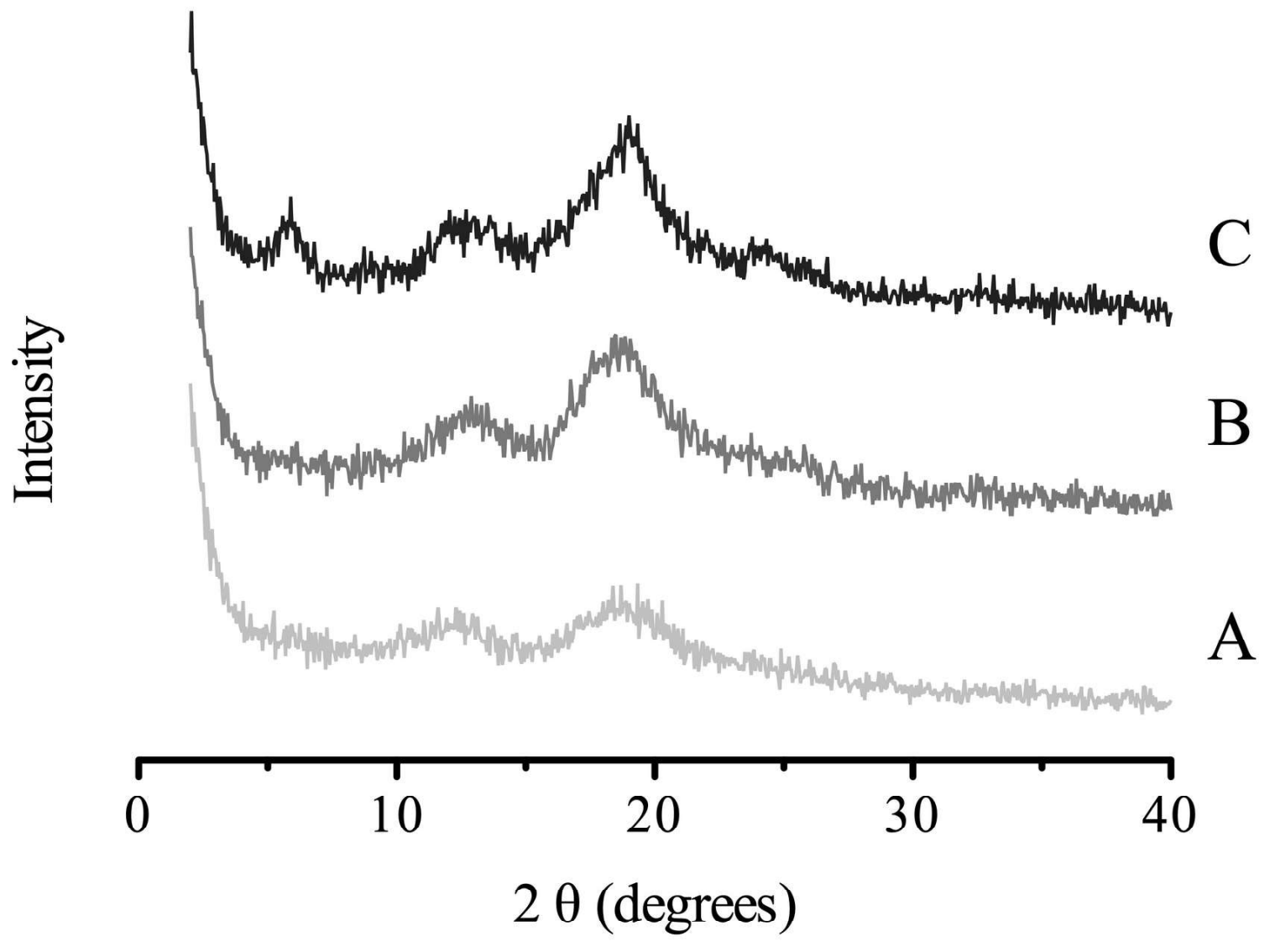




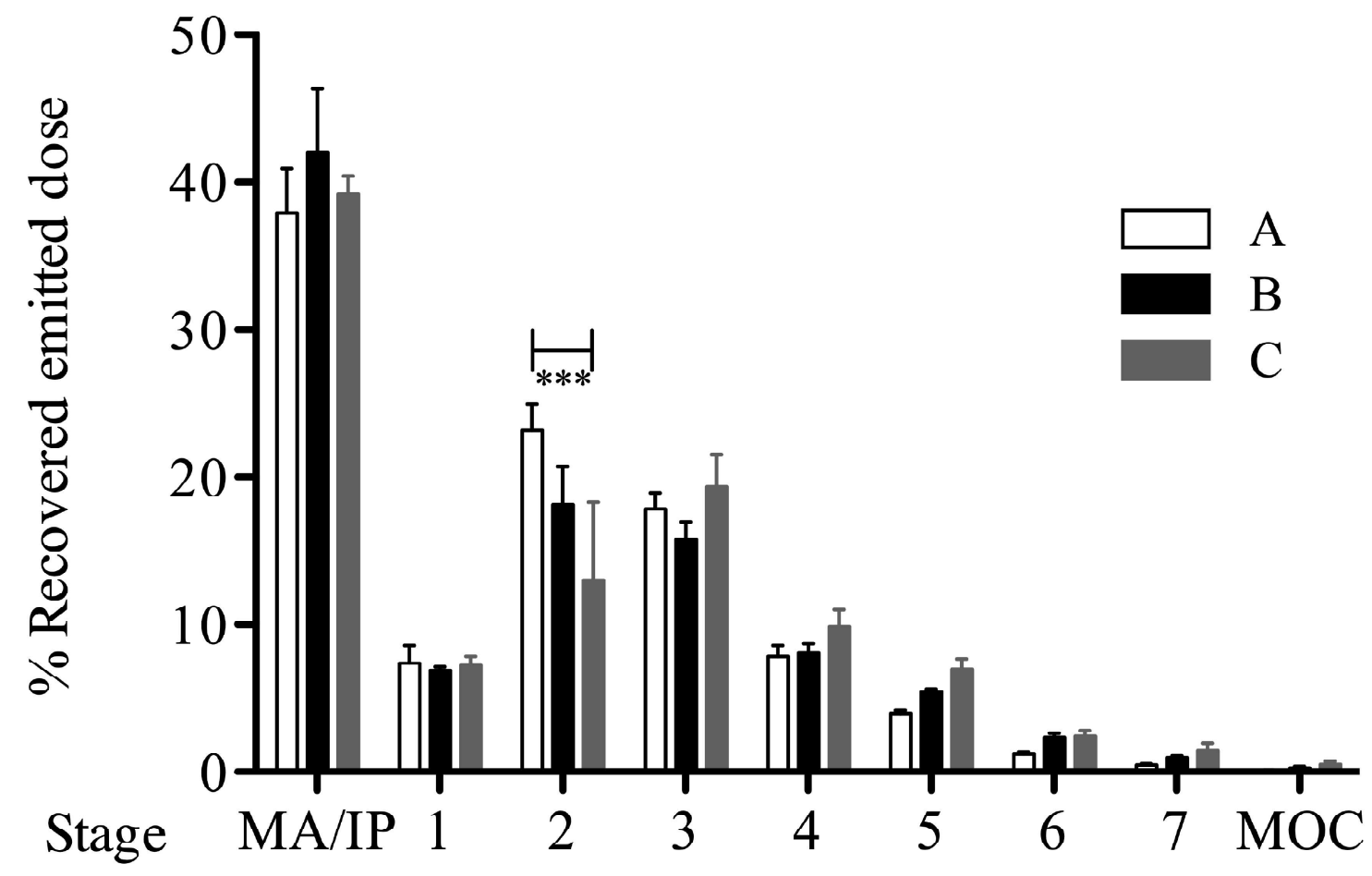

$\begin{array}{lllllllll}\text { Cut-point }(\mu \mathrm{m}) & 6.12 & 3.42 & 2.18 & 1.31 & 0.72 & 0.40 & 0.24 & 0.07\end{array}$ 


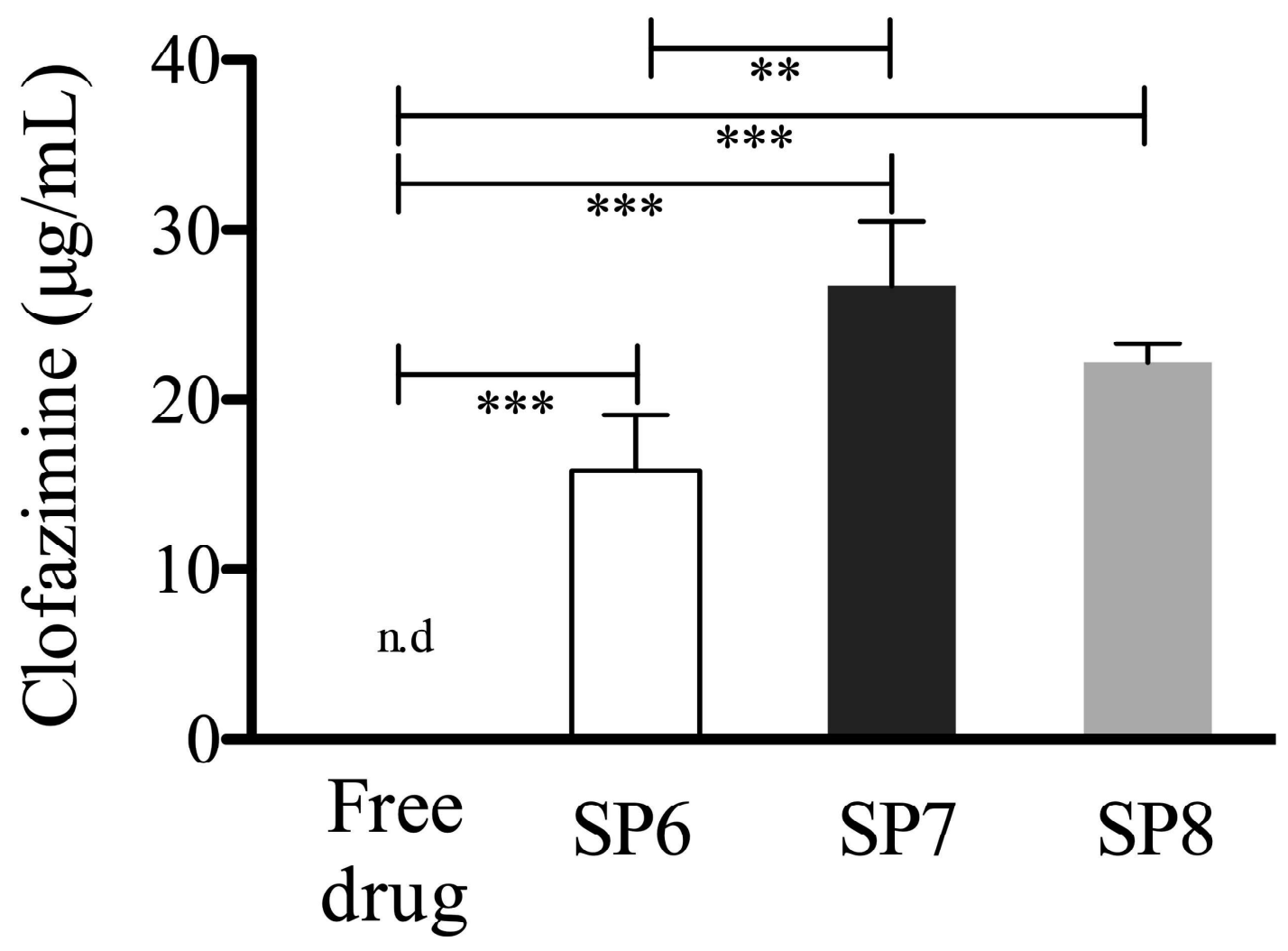



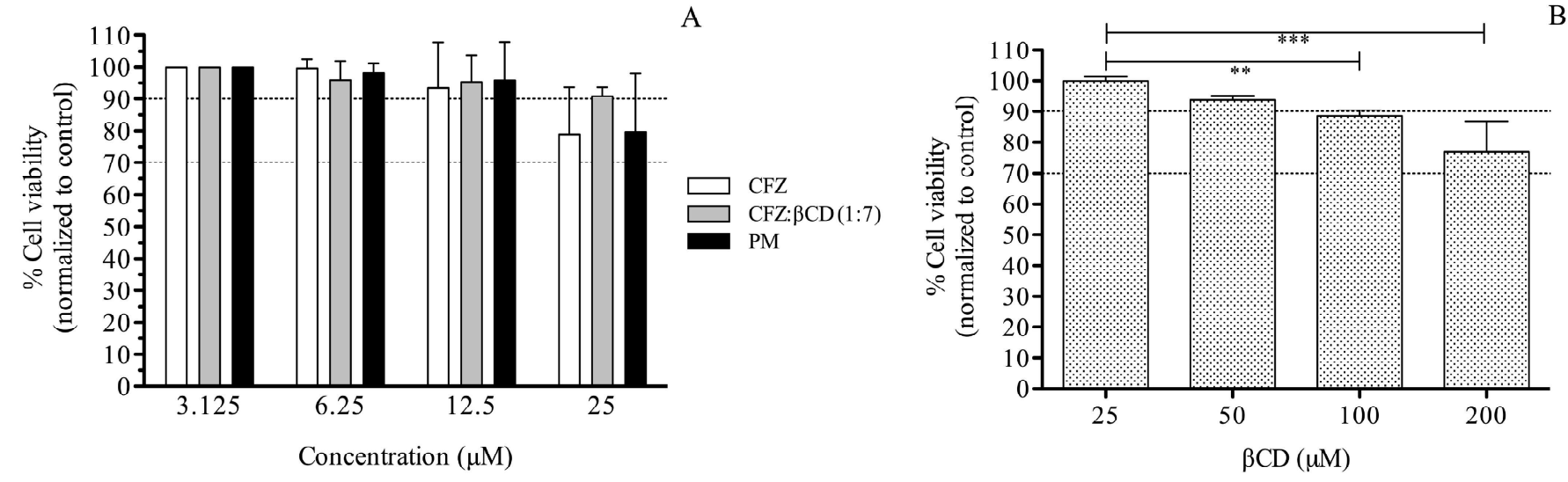


\section{Conflict of Interest}

Authors have no conflicts of interest to disclose. 


\section{Credit Author Statement:}

All authors contributed to the study conception and design. Material preparation, data collection and analysis were performed by Renata Ribeiro de Castro, Valério Todaro and Alice Simon. Bruno Sarmento, Anne Marie Healy and Lucio Mendes Cabral supervised the preparation and characterization of formulations. Luiz Claudio Rodrigues Pereira da Silva supervised the in vitro studies using Calu-3. The first draft of the manuscript was written by Renata Ribeiro de Castro and Flávia Almada do Carmo. The manuscript was revised and edited by Renata Ribeiro de Castro, Flávia Almada do Carmo, Valeria Pereira de Sousa, Carlos Rangel Rodrigues, Anne Marie Healy and Lucio Mendes Cabral. Valeria Pereira de Sousa, Carlos Rangel Rodrigues, Anne Marie Healy and Lucio Mendes Cabral were responsible for financial support. All authors approved the submitted and final version. 


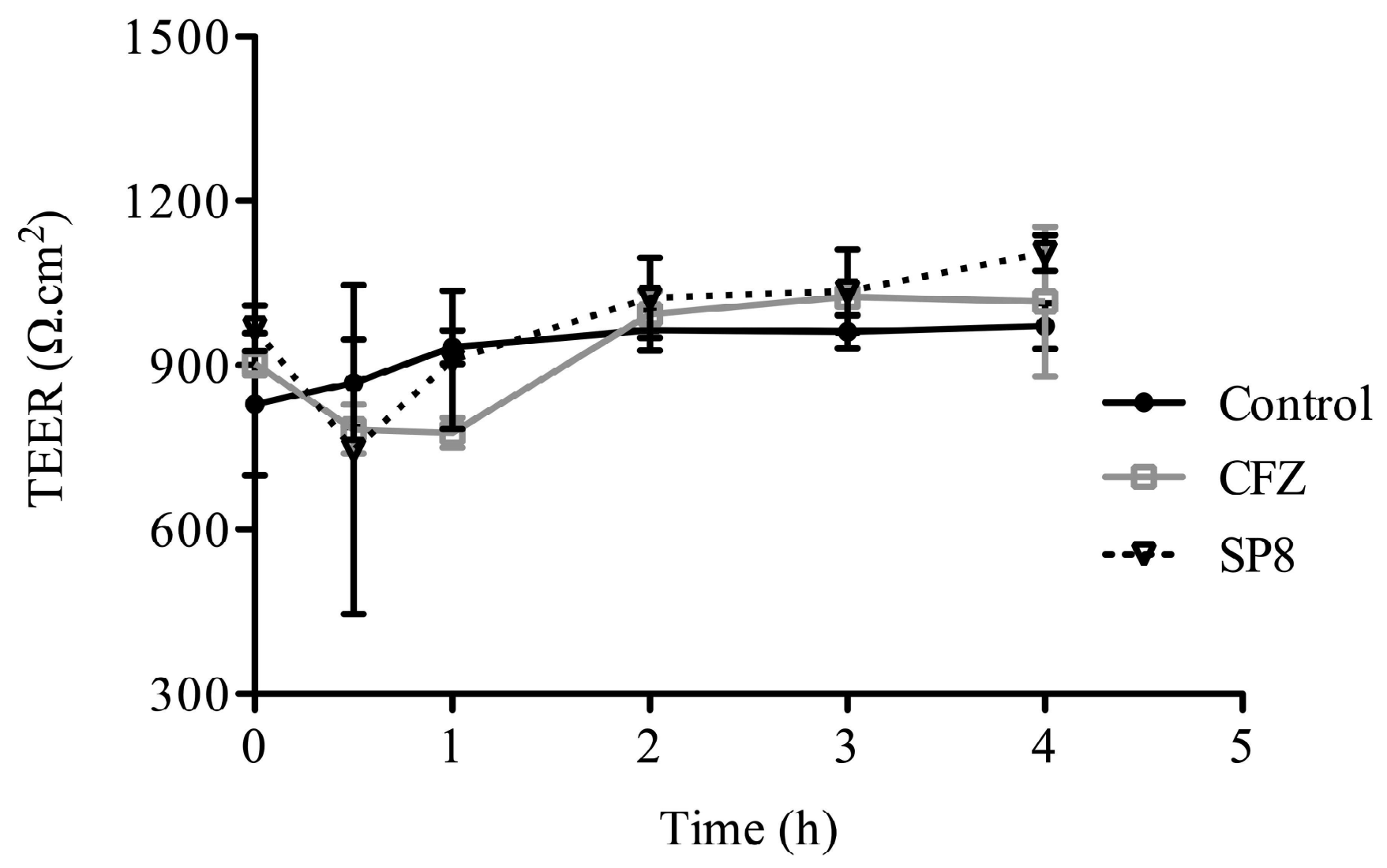

